Illinois State University

ISU ReD: Research and eData

Theses and Dissertations

2-23-2018

\title{
Learning To See The Forest For The Corn: Establishing Sense Of Place And Community In A Field-Based Ecology Course For Pre- Service Educators
}

Michelle Edgcomb Friday

Illinois State University, stemchef@gmail.com

Follow this and additional works at: https://ir.library.illinoisstate.edu/etd

Part of the Ecology and Evolutionary Biology Commons, Science and Mathematics Education Commons, and the Teacher Education and Professional Development Commons

\section{Recommended Citation}

Edgcomb Friday, Michelle, "Learning To See The Forest For The Corn: Establishing Sense Of Place And Community In A Field-Based Ecology Course For Pre-Service Educators" (2018). Theses and Dissertations. 825.

https://ir.library.illinoisstate.edu/etd/825

This Dissertation is brought to you for free and open access by ISU ReD: Research and eData. It has been accepted for inclusion in Theses and Dissertations by an authorized administrator of ISU ReD: Research and eData. For more information, please contact ISUReD@ilstu.edu. 


\title{
LEARNING TO SEE THE FOREST FOR THE CORN: ESTABLISHING SENSE OF PLACE AND COMMUNITY IN A FIELD-BASED ECOLOGY COURSE FOR PRE-SERVICE EDUCATORS
}

\author{
Michelle Edgcomb Friday
}

267 Pages

In this dissertation grounded theory techniques were used to characterize pre-service educators' experiences in a semester-long, field-based ecology course. Through participation in a citizen science project, participants formed a community of practice that extended their conceptions of themselves as ecology students and scientists. Extended field experiences in a variety of local ecosystems contributed to the development of a sense of place. Paired fieldwork with lecture aided their developing ecological literacy and their understanding of place-based pedagogy. All of these combined to support their growing understanding of their role in fieldbased ecology education. Lack of background in ecology and ecology pedagogy contributed to make these gains appear modest compared to established models of ecological literacy, but they were significant to the individual participants. Participants ended the semester with increased confidence in their abilities to learn in the field and to incorporate field-based techniques in $\mathrm{pK}-8$ education as well as their desire to do so.

KEYWORDS: Community of Practice; Ecological Literacy; Grounded Theory; Place-based Education; Pre-service Educator; Sense of Place 
LEARNING TO SEE THE FOREST FOR THE CORN: ESTABLISHING SENSE OF PLACE AND COMMUNITY IN A FIELD-BASED ECOLOGY COURSE FOR PRE-SERVICE EDUCATORS

MICHELLE EDGCOMB FRIDAY

A Dissertation Submitted in Partial Fulfillment of the Requirements for the Degree of

DOCTOR OF EDUCATION

School of Teaching and Learning

ILLINOIS STATE UNIVERSITY 
Copyright 2018 Michelle Edgcomb Friday 
LEARNING TO SEE THE FOREST FOR THE CORN: ESTABLISHING SENSE OF PLACE AND COMMUNITY IN A FIELD-BASED ECOLOGY COURSE FOR PRE-SERVICE EDUCATORS

MICHELLE EDGCOMB FRIDAY

COMMITTEE MEMBERS:

Tony Lorsbach, Co-chair

Allison Antink Meyer, Co-chair

Rebekka Darner Gougis 


\section{ACKNOWLEDGMENTS}

Of over 200 pages, this dedication is the hardest for me to write. So many people have contributed to this process that I am overwhelmed at the notion of succinctly and adequately thanking them all. So rather than serving as a summation of my thoughts, I hope for this to be part of an ongoing conversation.

I would not be finishing without the inspiration, encouragement, and support of my committee. This project grew out of long, wide-ranging conversations with Tony Lorsbach that broadened my ideas about science education, opened up new avenues of research, and were always entertaining. As I transitioned to the reams of data that came with qualitative approaches, Allison Antink Meyer was an untiring ally in my quest to make sense of it all. While I wrote (and wrote and wrote), Bekky Darner Gougis found the gaps in my explanations while never making me doubt my path. Tony, Allison, and Bekky, you have made this dissertation not only possible, but also enjoyable. I am grateful for your time, your knowledge, and your humor.

To the generous people who agreed to take part in my research, I can only say thank you. You made this work possible, and I got to know you better than I could have imagined. I appreciate your time and your openness. I also want to thank the people of New Woods who helped make our experiences so rich.

My time at Illinois State was enriched by the friends and mentors that I met in the program. Tami Dean was a friend from the start and the first person to celebrate when I took the sharp turn into qual. Cheri Toledo drew me further into the 21 st century classroom with every course. Lydia Kyei-Blankson was an indispensable resource as I branched into educational research. 
As I contemplated adding doctoral studies to my full-time job, I briefly asked myself if I'd given enough consideration to the size of the commitment, and then decided it was better not to think too much and to just jump. I want to acknowledge the people who helped make the landing possible. Sherri and Kelly inspired new interests in biology. Dean, Jan, Tim, Jana, and Vicki provided constant encouragement. Bob and Shari were always available for help and insight.

No dissertation would be complete without time spent lost in the weeds. I might still be there if not for Wendy, who patiently listened as I talked through ideas on our walks. Thank you for indulging me and laughing with me as I inevitably decided that the answer was pretty clear after all.

I have been lucky to have a rich and varied support network. My travel companions, Val and Poncho, reminded me not to put off the joys in life until I had time for them. They provided music, sharp wit, and, in Val's case, important suggestions for a patron saint for dissertations (appropriately St. Hildegard of Bingen was a naturalist). My friendship with Jen, Naomi, Jaime, Megan, John, and Ryan has grown and provided a lot of needed laughter during this time. They reminded me that delightfully random knowledge is the best knowledge.

For some people there will never be enough words. Liz, Sara, and Rusty, I can hardly remember a time when we weren't laughing, crying, or dreaming together. We've known each other for ... more than a year, and I look forward to so many more. Liz, from the first mind meld you've been my bestie. Sara, I could no more easily go a day without talking to you than I could go a day without a good rationalization. Rusty, I am actually very glad that we have so much in common. I could easily write another 200 pages, but I will say it all in the group text this week, anyway. 
My family has been my unending font of support. My parents, Mom and Wags, Dad and Melissa, always motivated by assuming that we would choose a challenge and that we would succeed. Mom and Wags always shared whatever excited me in the moment. Thank you for the long, sometimes very long, phone calls. Dad and Melissa laughed with me as my teaching began to incorporate Dad's beloved earth science. Thank you for trying to get me started young. My brothers and sisters, Scott, Steve, Kara, and Rachel, were sometimes friendly rivals, but were always my fiercest friends. My grandparents, each educational trailblazers in their own ways, encouraged by example and never failed to show their pride in our education. I was gifted with the best in-laws, especially Janet and Darrell who welcomed me into an entirely new family.

More than anyone, I rely on my husband, Friday. His faith in my work has always outpaced my own. He is there whether I need a laugh, a cry, or a goat. He is the best at deer spotting, he introduced me to the McWigglehoppers, and I love him more than I can say.

M. E. F. 


\section{CONTENTS}

$\begin{array}{lll}\text { Page } & \end{array}$

ACKNOWLEDGMENTS

CONTENTS iv

TABLES - ix

FIGURES

CHAPTER I: INTRODUCTION 1

Historical Background 1

$\begin{array}{ll}\text { Problem Statement } & 4\end{array}$

$\begin{array}{ll}\text { Purpose Statement } & 5\end{array}$

$\begin{array}{ll}\text { Research Questions } & 6\end{array}$

$\begin{array}{ll}\text { Significance of the Study } & 7\end{array}$

$\begin{array}{ll}\text { Definition of Terms } & 7\end{array}$

CHAPTER II: REVIEW OF LITERATURE 10

Pre-service Educators' Need for Ecological Literacy 11

$\begin{array}{ll}\text { Ecology in K-12 Education } & 14\end{array}$

$\begin{array}{ll}\text { Educators' Understanding of Ecology } & 15\end{array}$

$\begin{array}{ll}\text { Field-based Experiences for Ecology Understanding } & 18\end{array}$

$\begin{array}{ll}\text { Defining Field-based Experiences } & 18\end{array}$

$\begin{array}{ll}\text { Ecological Core Ideas } & 19\end{array}$

$\begin{array}{ll}\text { Practices of Science } & 24\end{array}$

$\begin{array}{ll}\text { Place in Education } & 26\end{array}$

$\begin{array}{ll}\text { Sense of Place } & 26\end{array}$ 
$\begin{array}{ll}\text { Place-based Pedagogy } & 28\end{array}$

Gap in Literature $\quad 32$

$\begin{array}{ll}\text { Theoretical Framework } & 33\end{array}$

CHAPTER III: METHODS

Research Trends in Ecology Education $\quad 36$

$\begin{array}{ll}\text { Case Study } & 37\end{array}$

$\begin{array}{ll}\text { Choice of Case Study } & 37\end{array}$

Choice of Grounded Theory $\quad 38$

$\begin{array}{ll}\text { Description of the Case } & 38\end{array}$

$\begin{array}{ll}\text { Field Sites } & 40\end{array}$

$\begin{array}{ll}\text { Guiding Research Questions } & 40\end{array}$

$\begin{array}{ll}\text { Data Sources } & 41\end{array}$

$\begin{array}{ll}\text { Participant Recruitment } & 42\end{array}$

$\begin{array}{ll}\text { Participants } & 42\end{array}$

Research Activities $\quad 43$

$\begin{array}{ll}\text { Data Analysis } & 44\end{array}$

Role of the Researcher $\quad 47$

$\begin{array}{ll}\text { Validity } & 48\end{array}$

CHAPTER IV: COMMUNITY OF PRACTICE IN FIELD-BASED ECOLOGY 50

$\begin{array}{ll}\text { Abstract } & 50\end{array}$

Ecological Literacy and Communities of Practice $\quad 50$

Students as Legitimate Peripheral Participants $\quad 51$

Field-based Ecology 300 as Legitimate Peripheral Participation 52 
$\begin{array}{ll}\text { Research Questions } & 54\end{array}$

$\begin{array}{ll}\text { Findings } & 55\end{array}$

Formation of a Community of Practice $\quad 56$

$\begin{array}{ll}\text { Domain } & 56\end{array}$

$\begin{array}{ll}\text { Community } & 59\end{array}$

$\begin{array}{ll}\text { Practice } & 61\end{array}$

Outcomes Associated with Participation in a Community of Practice 65

$\begin{array}{ll}\text { Citizen Science } & 65\end{array}$

$\begin{array}{ll}\text { Feeling Like a Scientist } & 73\end{array}$

$\begin{array}{ll}\text { Sharing Experiences } & 75\end{array}$

$\begin{array}{ll}\text { pK12 Community } & 78\end{array}$

$\begin{array}{ll}\text { Conclusions } & 83\end{array}$

CHAPTER V: DEVELOPING ECOLOGICAL LITERACY IN THE FIELD 86

$\begin{array}{ll}\text { Abstract } & 86\end{array}$

Defining Environmental Literacy and Ecological Literacy $\quad 86$

Frameworks Specific to Ecological Literacy $\quad 88$

Ecological Literacy in Field-based Ecology $300 \quad 89$

$\begin{array}{ll}\text { Research Questions } & 91\end{array}$

$\begin{array}{ll}\text { Findings } & 93\end{array}$

$\begin{array}{ll}\text { Prior Related Experiences } & 94\end{array}$

Emergent Ecological Concepts $\quad 96$

$\begin{array}{ll}\text { Human Impact } & 114\end{array}$

$\begin{array}{ll}\text { Habits of Mind } & 138\end{array}$ 
Abstract

Education for Ecological Literacy

Place-based Education and Sense of Place

CHAPTER VII: EXPERIENCING A FIELD-BASED ECOLOGY CLASS AS A PRE-

Abstract

Ecology in Education

Conceptions of Ecology Education in Field-based Ecology 300

Research Question

Findings

Field-based Pedagogy

Planning for the Future

Future Planning in Action

Developing a Model of Field-based Ecology Education for Pre-service Educators 
Ecological Literacy

Sense of Place

Class as a Pre-service Educator

Final Summary

REFERENCES

254 


\section{TABLES}

Table

Page

1. Alignment of Data Sources with Emergent Questions Regarding Communities of Practice

2. Field-based Ecology 300 Topics and Alignment

3. Alignment of Data Sources with Emergent Questions Regarding Developing Ecological Literacy

4. Alignment of Data Sources with Emergent Questions Regarding Sense of Place

5. Alignment of Data Sources with Emergent Questions Regarding Ecology Education

6. Lesson Plan Topics and Instructional Techniques Developed in Field-based Ecology 300 


\section{FIGURES}

Figure

Page

1. Organizational Scheme for the Theme, Community, with Major Categories and Subcategories

2. Organizational Scheme for the Theme, Developing Ecological Literacy, with Major Categories and Subcategories

3. Organizational Scheme for the Theme, Sense of Place, with Major Categories and Subcategories

4. Organizational Structure for the Theme, Experiencing Class as a Pre-service Educator, with Major Categories and Subcategories

5. Model of Field-based Ecology for Pre-service Educators in Field-based Ecology 300 


\section{CHAPTER I: INTRODUCTION}

\section{Historical Background}

In 1911, Anna Botsford Comstock wrote a nearly 1000-page book filled with ideas for developing content knowledge across the academic subject areas through nature study. This pedagogical approach focused on close observations of "any plant or creature which chances to interest the pupil" (Comstock, 1939, p. 5). As the studies were rooted in student interest, Comstock felt the entirety of the book was no more than what a student should be able to explore by middle school (Comstock, 1939; Pyle, 2001). Comstock's book was highly influential, and in the first decades of the 20th century a working knowledge of the local biological communities was educationally lauded, if not universally obtained (Pyle, 2001).

Nature study had conceptual roots in natural history, defined as the "close observation of organisms--their origins, their evolution, their behavior, and their relationships with other species" (DeBoer, 1991; Wilcove \& Eisner, 2000, para. 4), rather than ecology, which was not yet taught as a distinct biological science apart from zoology, botany, or natural history. Ecology education became common at the collegiate level in the 1950s and was ultimately "popularized" in K-12 education by the 1960s (Marcinkowski et al., 2013, p. 52).

As ecology rose in prominence, so did public concern over environmental issues (DeBoer, 1991; McBride, Brewer, Berkowitz, \& Borrie, 2013). Outdoor study was viewed as an important way to increase students' appreciation of nature and to increase students' desire to protect it (Ballantyne and Packer, 2002; 2009), rather than as a way to stimulate intrinsic interest. As such in the 1960s and 1970s, educational approaches were focused on students' abilities to identify problems and work to solve them, as well as to develop the desire to do so (Hungerford, 2010; McBride et al., 2013; McComas, 2002). While solving environmental problems by 
necessity required ecology understanding, the overall approach was probably better described as environmental science, a distinction that is not clear in the research literature.

On the surface, a problem-oriented environmental or ecological education would seem to be in line with the original goals of the nature study movement. However, there is some indication that the overwhelmingly negative focus of much education about the environment may have unintended consequences. Sobel (1996) noted that the study of large-scale environmental problems tended to remove the educational focus from what students can explore on their own to what they must learn about remotely. This may lead to students who can describe the challenges facing distant biomes, but not the organisms in their own backyards. Sobel's observation was supported by Lorsbach and Jinks (2013) and the writings of Louv (2005), who noted that students were generally more aware of problems on other continents than in settings they could see up close. Sobel (1996) described this as "premature abstraction" (p. 5) of science topics in education prior to middle school. He posited that students were regularly confronted with environmental problems that they could not study directly and asked to provide solutions that were removed from their direct experience of cause and effect. These intellectual challenges, rather than nurturing a love of nature that might lead to a vested interest in protecting local ecosystems, instead could lead to "ecophobia" (Sobel, 1996, p. 5), where nature became a source of fear or stress for students rather than wonder.

The minimization of the local environment as both a context and a setting for education about the environment potentially impacted more than students' affective responses to nature education. It also posed a problem in terms of what they were really taking away from their classes. Education on environmental topics in science classes was originally intended to be values "neutral," with a focus on preparing students to make their own decisions (DeBoer, 1991). 
However, considerable questions were raised about the degree to which environmentalism, rather than environmental or ecological education, was actually taught (Hungerford, 2010; Klemow, 1990; Mappin \& Johnson, 2005; McComas, 2002; 2003; Powers, 2004). Even if ecological education was the intended focus, the ability of students to differentiate between consensus and opinion could be hampered with an education removed from personal experience. In the 1980s, these concerns were interpreted in light of the book A Nation at Risk, and demand for deeper content understanding was the result (McBride et al., 2013).

While $A$ Nation at Risk was published over 30 years ago, the concern over what students should know and how they should display that knowledge continues. In 2012 the National Research Council (NRC) released A Framework for K-12 Science Education. The framework was not focused on rote knowledge or low-level skills, but was rather a far-reaching statement of how students should experience science. The purpose of the framework was "to help realize a vision for education in the sciences and engineering in which students, over multiple years of school, actively engage in scientific and engineering practices to apply crosscutting concepts to deepen their understanding of the core ideas in these fields" (NRC, 2012, p. 10). The integrative approach delineated practices, disciplinary-specific ideas, and discipline-spanning ideas as complementary aspects of science education with equal foundational footing. The "three major dimensions" (NRC, 2012, p. 2) of the framework were incorporated into the Next Generation Science Standards (NGSS), which were finalized in 2013 (Achieve, Inc., 2015). Each standard included a performance expectation written in terms of student action and addressing the framework, for example the third-grade level ecosystems performance expectation "construct an argument that some animals form groups that help members survive" (Achieve, Inc., 2015). While science standards written in terms of what students can do, rather than what they know, 
would seem in line with the spirit of an approach to ecology education that emphasizes time learning in nature, the NGSS may not result in pedagogical approaches that allow students to actively explore matters of personal interest on their own turf (Lorsbach \& Jinks, 2013).

A century after Comstock (1939) wrote her magnum opus on nature study, students spend an ever-increasing amount of time indoors isolated from their environment (Louv, 2005). Their environmental knowledge is often far removed from their personal experience (Louv, 2005; Lorsbach \& Jinks, 2013; Sobel, 1996) and what they do understand might actually discourage them from exploring their local ecosystems (Louv, 2005; Sobel, 1996). Furthermore, the distinction between ecology and environmentalism as a philosophy can be hopelessly blurred (Klemow, 1990; McComas, 2002; 2003).

\section{Problem Statement}

Education rooted in local natural history and other field-based experiences could provide the framework for students to truly engage with the study of ecology. Through this lens, students could actively explore ecosystems, developing an understanding of biotic and abiotic interactions and evolutionary relationships before engaging in experimental studies (Lorsbach \& Jinks, 2013). These experiences could lead to the development of "place attachment" and "place meaning," (Kudryavtsev, Stedman, \& Krasny, 2012, p. 231) vital components of a "sense of place" (p. 233). This approach is in line with the spirit of place-based pedagogy with "its aim to ground learning in local phenomena and students' lived experience" (Smith, 2002, p. 586). Likewise, it could increase the amount of time that children spend outdoors, something that has decreased internationally in recent years (Louv, 2005). However, for this approach to meet its potential, educators need to be prepared and willing to facilitate field-based learning. Current research indicates that time spent on ecological education at the K-12 level is limited (Cutter- 
Mackenzie \& Smith, 2003; Puk, 2003; Tal, 2008; Young \& LaFollette, 2009). Research on ecology education for pre-service educators is also lacking (Stevenson \& Evans, 2011), and ecology education is not consistently part of pre-service education programs (Weiland \& Morrison, 2013).

While research on field-based, undergraduate work has been published recently, there is still a gap in the literature specifically relating to field-based ecology courses for pre-service educators. This gap is situated within a debate about the nature of ecological understanding and the most appropriate framework for K-16 ecology education.

\section{Purpose Statement}

Field-based Ecology $300(\mathrm{FBE} 300)^{1}$ is a field-based science course at Oak Savanna University, a private university in the Midwest, designed for pre-service, pK-8 educators, which incorporates active study of locally accessible ecosystems. Lecture components focus on ecological concepts including biogeochemical cycling, succession, and impacts of invasive species. Field components begin with the characterization of a local area including plant identification, observation of invertebrates, and measurement of soil conditions. Prior to participating in FBE 300, all students take a prerequisite class with interdisciplinary, thematic content (e.g. Energy). In the 100-level, prerequisite class, students gain experience with hypothesis formation, experimental design, and descriptive statistical analysis. Aspects of lesson plan development, including choosing standards and writing objectives, are also included in the 100-level courses. The 100-level classes meet general education science requirements. As such, they serve as science content courses, although explicit instruction in inquiry-based pedagogy is

\footnotetext{
${ }^{1}$ In order to protect anonymity, pseudonyms have been used for proper names including participants, the name of the university, the name of the course, and field sites.
} 
included. Students in FBE 300 are not expected to share the same theme-specific content preparation from their 100-level courses, but they do have common experience working in collaborative groups to develop hypothetico-deductive research projects.

As a field-based course, FBE 300 includes extended time studying local outdoor areas. The course is designed for students working in pairs or small groups of two to four to characterize a location within an ecosystem, including identification of dominant plant life. These observations may be made within a quadrat and/or along a transect. Initial observations and measurements are used to generate questions of student interest that can be addressed locally during the semester through experimental or observational approaches. Students disseminate their findings through a written paper. Additionally, each student is expected to complete at least 10, 30-minute observation periods in outdoor settings. Class meets twice per week for three hours (27 total sessions) and once for a weekend field trip (5.5 hours total, approximately 4 hours in the field).

FBE 300 serves as the setting for this study on field-based ecology education. A better understanding of students' field experiences within the course and how those experiences relate to their developing conceptual understanding is necessary to improve ecology education for preservice educators and to help prepare students to teach field-based ecology. The purpose of this study is to develop a substantial, grounded theory concerning field-based ecology courses for pre-service educators (Corbin \& Strauss, 2015). The emphasis will be placed on how field experiences relate to the development ecological understanding and participants' sense of place.

\section{Research Questions}

This study was guided by three initial research questions:

1. How does pre-service educators' ecological literacy develop during a field-based course? 
2. To what extent do pre-service educators plan to incorporate field-based natural history and ecology education into their future practice?

3. Do pre-service educators develop a sense of place in temporary, collegiate environments?

\section{Significance of the Study}

This study is significant for those interested in pre-service ecology education and tangentially significant for those interested in pK-12 ecology education. Instructors of science and social studies methods and general education ecology courses could benefit from research on the role of field-based experiences on pre-service educators' developing ecological understandings.

\section{Definition of Terms}

Natural history was defined by Wilcove and Eisner (2000) as "the close observations of organisms - their origins, their evolution, their behavior, and their relationships with other species" (para. 4). This definition allows for considerable overlap with ecology although with natural history largely prioritizing biotic interactions. Distinct from ecology, the emphasis is on observation, rather than quantitative experimentation or hypothesis testing (Resetarits \& Bernardo, 1998). Although natural history is a "related discipline" to ecology (Stebbins, 2012, p.

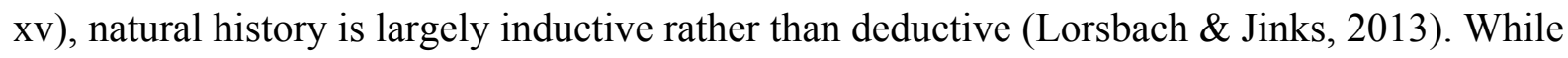
possibly reductive, for the purposes of clarity in this dissertation, natural history will be used to describe inductive, observational explorations of biological communities.

Nature study is a pedagogical approach to exploring aspects of natural history (Comstock, 1939). Like natural history, nature study depends on close observations of organisms and their interactions, but the motivating factor is student interest. Nature study also differs from natural history as it "often lacked the unifying theme of evolution" (Stebbins, 2012, p. 10) and 
could be too human-centered in focus (Lorsbach \& Jinks, 2013; Stebbins, 2012). For the purposes of this dissertation, nature study is considered a historical pedagogy. Natural history will be used preferentially in terms of current practice.

Environmental education is an umbrella term that encompasses learning "about the environment," "in the environment," and "for the environment" (Mappin \& Johnson, 2005, p. 3). Environmental education is a very diverse set of practices that include aspects of science, social sciences, the humanities, and critical theory (Sauve, 2005). For the purposes of this dissertation, all education about, in, or for the environment will be considered environmental education.

Ecology education is not equated with environmental education, but it is often used within the context of environmental education and therefore can be hard to pinpoint (McComas, 2002). To the extent that ecology education is meant to support ecological literacy, it can be defined in relation to models of ecological literacy. Many models of ecological literacy have been developed (McBride, Brewer, Berkowitz, \& Borrie, 2013). For the purposes of this dissertation, the model of Jordan, Singer, Vaughn, and Berkowitz (2009) will be used. This model includes three areas of focus: "possession of scientific habits of mind in ecology," "understanding of ecological connectivity and key concepts," and "appreciation of the links between human actions and the environment" (Jordan et al., 2009, p. 497).

Place-based education is meant to "ground learning in local phenomena and students' lived experience" (Smith, 2002, p. 586). In this way, potentially abstract concepts are explored in local social and physical contexts (Sobel, 1996). For the purpose of this dissertation, place-based education will center on field-based experiences, including natural history and ecology education that takes place primarily outdoors in local settings. 
Sense of place is described as a combination of a conceptual understanding of an area, "place meaning," and a strong connection to that area, "place attachment" (Kudryavtsev, Krasny, \& Stedman, 2012; Kudryavtsev, Stedman, \& Krasny, 2012, p. 231; Russ, Peters, Krasny, \& Stedman, 2015; Semken \& Butler Freeman, 2008; Stedman, 2002). For the purposes of this dissertation, sense of place will be defined by place meaning and place attachment either alone or in combination. 


\section{CHAPTER II: REVIEW OF LITERATURE}

A search of the literature on ecology education quickly reveals a wealth of competing terms. Ecology education, nature study, natural history, environmental education, education for sustainable development, outdoor education, and sustainability education all appear with dizzying frequency (Balgopal, Wallace, \& Dahlberg, 2012; Cutter-Mackenzie \& Smith, 2003; Erdogan, Usak, \& Bahar, 2013; McBride et al., 2013; McComas, 2003). Environmental education comes closest to being a unifying term, but even its meaning is debated. Mappin and Johnson (2005) describe three ways environmental curricula can vary in purpose (p. 2); the primary purpose may be "education about the environment," "education in the environment," or “education for the environment" (p. 3). Sauve (2005) describes 15 separate "currents" (p. 11) in

environmental education. The overall picture is of a very diverse set of practices and paradigms. While an understanding of ecology might seem vital to most purposes and currents, some have very little to do with ecology as a science (Sauve, 2005). Even when ecology is incorporated, it can be outmoded both in content and practice (Mappin \& Johnson, 2005).

If pinpointing a definition of ecology education is difficult, situating pre-service educators within that context is even more so. Much of the literature is international and focused on K-12 education. Stevenson and Evans (2011) conducted a 10-year review of environmental education research in Australia covering the period of 1990-2000 and noted "pre-service teacher education was conspicuous by its absence" (p. 36). D’Avanzo (2003) found that none of the ecology education articles published between 1997 and 2002 in the Journal of Research in Science Teaching focused on higher education. In a much-cited review of international literature, Rickinson et al. (2004) identified a need to determine how to prepare pre-service educators for field-based teaching and noted that field-based experiences for undergraduates were decreasing. 
Berkowitz, Ford, and Brewer (2005) called for research into ways "people learn to think ecologically" and "innovative programs and curricula" (p. 249). More recently Tal and Morag (2009) noted gaps on preparing teachers to incorporate field-based education. Researchers who do study field-based experiences for pre-service educators tend to focus on pedagogy, rather than content, courses (Blatt \& Patrick, 2014; Powers, 2004).

In this literature review, the competing frameworks of ecological education will be outlined and an argument will be made that pre-service teachers' science experiences should address ecology concepts and the practices of ecological science. The role of field-based ecology courses in developing these understandings will be developed. Consideration will also be made to the ripple effect field-based experiences for pre-service educators can have on place-based pedagogy at the K-12 level.

\section{Pre-service Educators' Need for Ecological Literacy}

After the publication of A Nation at Risk, much of the science curriculum discussion focused on science literacy (DeBoer, 1991; McBride et al., 2013). This conversation was mirrored in discussions of environmental literacy. While principles of ecology were meant to provide a foundation for environmental literacy, there was growing concern that very little science was involved and that environmental education was fueled by an environmentalist agenda more than anything (Hungerford, 2010; Klemow, 1990; Mappin \& Johnson, 2005; McComas, 2002, 2003; Powers, 2004). In response to these concerns, ecologists became involved in the efforts to define ecological literacy apart from environmental literacy (McBride et al., 2013).

In 1986, Paul Risser, the past-president of the Ecological Society of America, gave a speech in which he outlined a preliminary proposal for tenets of ecological literacy. Rather than a 
long list of concepts and terminology, he described four broad ideas, "multi-media transport of materials, clarification of the 'everything is connected to everything' simplicity, ecologicalcultural interactions, familiar ecological field observations" (p. 266). Risser meant to start a conversation, not end one, and while he connected ecology to both personal and social learning, those aspects were bound to expand.

In 1992, David Orr added a focus on sustainability and a critical dimension to ecological literacy (Cutter-Mackenzie \& Smith, 2003; McBride, 2013). Orr believed that ecological literacy was not simply connected to cultural concerns; it was at the heart of them. Orr (2005) noted "the disorder of ecosystems reflects a prior disorder of mind, making it a central concern to those institutions that purport to improve minds. In other words, the ecological crisis is in every way a crisis of education" (p. x). He called for education to return to a previous discussion of "the timeless question of how we are to live" (p. xi). This philosophical notion of ecological understanding would lead to a third conception of what made a person ecologically literate.

The third school of thought, ecoliteracy (or eco-literacy), was an extension of Orr's work (Cutter-Mackenzie \& Smith, 2003; McBride, 2013). While ecoliteracy maintained the focus on sustainable communities, the philosophical connection deepened. Cutter-Mackenzie and Smith (2003) defined ecoliteracy "to appropriately encapsulate (measure) both ecological literacy (complex knowledge) and environmental (eco) philosophy (belief) indicators" (p. 502, emphasis in original). Within ecoliteracy, there was an acknowledgement that an individual's understanding and philosophy were equally important. McBride et al (2013) described this as "the introduction of spiritual, holistic components" (p. 14).

Within ecological literacy and ecoliteracy additional frameworks continue to evolve. A notable addition was from Berkowitz, Ford, and Brewer (2005), who placed ecological literacy 
as a component of a broader environmental citizenship. They defined ecological literacy as "understanding the key ecological systems using sound ecological thinking, while also understanding the nature of ecological science and its interface with society" (p. 230). The authors elaborated with five ecological systems, "ecological address, ecological interaction web, key life-support ecosystems, the global ecosystem, evolution and genetic systems," and seven aspects of thought, "scientific, systems, transdisciplinary, spatial, temporal, quantitative, creative/empathic" (p. 234). Berkowitz et al.'s (2005) framework had the advantage of situating ecology in society while not losing sight of the field as a science. The framework's degree of specificity also discouraged the tendency to create a single class that met an ecological literacy requirement, but it could be argued that five systems and seven aspects of thought were a bit unwieldy. Another refinement came in 2009 when Jordan et al. noted that there was no "complete and broadly applicable framework of ecological literacy" (p. 496). The authors proposed a framework with three domains: "possession of scientific habits of mind in ecology," "understanding of ecological connectivity and key concepts," and "appreciation of the links between human actions and the environment" (p. 497). As with Berkowitz et al. (2005), each of Jorden et al.'s (2009) three domains were further elaborated to include eight specific components related to "ecological activity and key concepts" (p. 497).

As Risser (1986) had thirty years before, Jordan et al. (2009) called for further discussion on the topic of ecological literacy. They noted several outstanding definitional concerns, including: how to include sustainability education, how to address environmental issues without obscuring ecology's relationship to environmental science, the consideration of environmental values within ecology education, and the more philosophical and social aspects of ecological 
literacy. Even if a common framework was adopted, Jordan et al. (2009) noted that such a framework would not translate into a clear-cut plan for K-12 ecology education.

\section{Ecology in K-12 Education}

Berkowitz et al. (2005) and Jordan et al. (2009) presented involved frameworks for ecological literacy. This type of understanding cannot be obtained in one ecology course (Powers, 2010). Rather, the ecological literacy needs to develop over time. As such, looking at how ecology is taught at the K-12 level is necessary to understand the conceptual foundation preservice educators are likely to have as they enter college.

Young and LaFollette (2009) surveyed Illinois teachers on the incorporation of environmental topics in primary education. The authors divided the state into six geographical regions and randomly sampled schools within those areas. While over $90 \%$ of the respondents indicated that they taught environmental topics, $50 \%$ of the educators did so between two and five times per school year (p. 98). Based on the fact that almost $42 \%$ of the respondents indicated a lesson time of 20 minutes or less, the authors estimated that 22 to 100 minutes per year was not atypical for environmental education at the elementary level. Furthermore, only $2.8 \%$ of respondents indicated that their usual method of instruction included fieldwork, with an additional $2.8 \%$ incorporating field trips. The actual degree of outdoor work is hard to estimate as respondents were only allowed to identify their main method of instruction, but it does not imply a significant amount of field-based work at the elementary level in Illinois.

While Young and LaFollette's study was published before Illinois adopted the NGSS as the "New Illinois Learning Standards-Science" in 2014 (Illinois State Board of Education, 2015), the study is pertinent to issues of NGSS implementation. The NGSS include ecology or environmentally focused performance expectations at every grade level from kindergarten 
through high school (Achieve, Inc., 2015). Common concerns in Young and LaFollette's (2009) study regarding environmental education were lack of time in the schedule, access to resources, and district-level priorities. While the NGSS could lead to a shift in district-level priorities, time would remain a factor. These worries are supported by the report of decreased instructional time for science and social studies education, two likely places for environmental and ecology education, reported nationwide since the passing of No Child Left Behind (Blatt \& Patrick, 2014; Brewer et al., 2003; Common Core, 2012). Not limited to American K-12 education, educators report constraints on environmental education, especially field-based experiences, internationally (Cutter-Mackenzie \& Smith, 2003; Puk, 2003; Tal, 2008) and at the university level (Powers, 2004).

McComas (2003) investigated secondary ecology education in part by analyzing widely distributed textbooks and lab materials. He indicated that instruction is often textbook-driven and that about $10 \%$ of pages on average were devoted to environmental topics, including the main ecological topics taught. Additionally in almost half of the texts, ecology chapters were at the end of the book, which raised the risk that they were not covered at all. Based on these evaluations of K-12 ecology education, entering college students would not be expected to have a strong foundation of ecological literacy.

\section{Educators' Understanding of Ecology}

Research on ecology understanding of pre-service and in-service educators reveals that while some aspects are well understood, there is still considerable room for growth. In 2008 Zak and Munson published a study in which 56, pre-service students were asked to draw concept maps using 16 ecological terms. These terms were taken from sources including the National Science Education Standards (NSES) and the North American Association for Environmental 
Education (NAAEE), and the terms were considered indicative of concepts the participants would be expected to teach. While the participants showed understanding of how many topics tied together, almost half of the participants omitted the terms "biotic" and "abiotic" (p. 39) from their maps entirely. As many as a third of participants also included "generalized propositions" (p. 43) that indicated confusion about adaptation and extinction. This is in line with McComas' (2003) findings that only one of the major high school biology textbooks included information on the relationship between ecology and evolution.

Puk and Stibbards (2010) also noted problems with the conceptual understandings of preservice educators. When the researchers asked pre-service educators to define terms related to ecology and environmental science, they concluded that participants' answers were unclear and the definitions given were shallow. The study had problematic elements, including the fact that participants were expected to know how to write clear definitions. Likewise the authors noted that some terms participants were asked to define, such as "green" (p. 472), were vague. However, the authors highlighted an important point about the tendency for ecological discussions to include "simple ... words ... to describe very complex natural systems or human processes" (p. 472).

While the Zak and Munson (2008) and Puk and Stibbards (2010) studies relied at least partly on assessment of pre-service educators' understanding of terminology, Desjean-Perrotta (2013) took an approach that did not require participants to be familiar with technical vocabulary. In a study of both pre-service educators and fourth grade students, she asked participants to draw a picture of the environment. These pictures were then evaluated using a rubric with four criteria for included elements: "human, living, abiotic, human-built or designed" (p. 267). The researcher looked for the presence of the elements and the degree of interaction 
between them. Fourth-graders performed very similarly on the task to senior, pre-service educators without formal environmental education. A majority of both the fourth graders and the undergraduates drew pictures without any people at all. Neither set of participants demonstrated to a high degree "how living factors interact with other living and abiotic factors," but fourth graders, at $35 \%$, actually outscored pre-service educators, $13 \%$, in this regard (p. 263). While the fact that fourth graders showed higher performance in certain areas could be viewed optimistically for the next generation of pre-service educators, consistently higher performance was not measured, and fourth grade drawings were deemed more "naturalistic" overall (p. 263). The author went so far as to comment that without explicit knowledge of the artist, it was difficult to tell which group of students drew which pictures. All artistic merit aside, DesjeanPerrotta's (2013) study served to reinforce the work of Zak and Munson (2008) and Puk and Stibbards (2010) and to indicate that gaps in understanding are diagnosable even when vocabulary issues are largely eliminated from the research design.

Preliminary research indicates pre-service educators gaps in understanding may not be addressed before they graduate. Cutter-Mackenzie and Smith (2003) used a mixed-methods approach with 26, Australian elementary teachers to gauge their understanding of ecology as a field and the tenets of environmental education. The study included a quantitative survey and ethnographic interviews. The authors noted that the amount of college preparation in environmental education was age-dependent (younger teachers were far more likely to have specific training). Despite this, misunderstandings were noted across the board. Worse, they found "the majority of participants in this study neither obtained sufficient content knowledge of environmental education nor were particularly concerned about the fact" (p. 519). The authors 
noted that the lack of concern could come from a point-of-view that a teacher should facilitate, not provide facts; however, that did not make the lack of understanding less of an issue.

While these studies were mainly qualitative and not intended to be generalizable, the results were consistent with a review by McComas (2002) that noted "even some foundation knowledge in ecology is not well known" (p. 670). Common misconceptions were noted across a wide range of ages in Munson's 1994 review of literature and at the college level by D'Avanzo (2003). Misconceptions are problematic as they are notably hard to address (McComas, 2002; Munson, 1994). Likewise, educators are in unique positions to disseminate their misconceptions (although, as noted, time spent on ecology at the $\mathrm{K}-12$ level is limited). This calls for a deeper investigation of how field-based ecology courses can impact pre-service educators' ecological literacy and their intentions to teach ecology.

\section{Field-based Experiences for Ecology Understanding}

\section{Defining Field-based Experiences}

The research on the impacts of field-based experiences in ecology encompasses many outdoor contexts. Field experiences can take place in the form of field trips that are either isolated events (Ballantyne \& Packer, 2002; Morag \& Tal, 2012) or repeated over time (Ballantyne \& Packer, 2002; Dentzau, 2011; Kelley, 2009). Fieldwork can be confined to campus grounds, which at the K-12 level is frequently called schoolyard ecology (Feinsinger,

Grajal, \& Berkowitz, 1997; Hane, 2007; Tal \& Morag, 2009; Powers, 2004; Sukhontapatipak \& Srikosamatara, 2012) or can happen at residential camps (Ballantyne \& Packer, 2009).

Regardless of the nature of the field-based work, the time spent on such experiences is generally low at both the K-12 level (Puk, 2003; Young \& LaFollette, 2009) and in college courses 
(Powers, 2004). In a recent study by Blatt \& Patrick (2014), less than $15 \%$ of pre-service educators identified significant childhood, outdoor experiences through school.

Much of the research on the impact of field-based experiences is assessed as change in knowledge, attitude, or behavior. As this review focuses on gains related to the scientific study of ecology, the knowledge component includes both ecological core ideas and practices of science. Attitude and behavior aspects are considered along with the goals of place-based pedagogy. For the purposes of this dissertation, any environmental science or ecology education that focuses on scientific understanding and takes place outdoors will be considered a field-based experience, regardless of the length of the experience.

\section{Ecological Core Ideas}

There is an acknowledged need for field-based experiences for pre-service and in-service educators (Blatt \& Patrick, 2014; Metz, McMillan, Maxwell, \& Tetrault, 2010; Powers, 2004; Tal \& Morag, 2009). Educational researchers tend to focus on recommendations for pedagogy courses, such as science and social studies methods, professional development, and K-12 experiences. Less is said about the way science content courses might provide these experiences. Rather, assessment of field-based science courses tends to concentrate on future scientists (Schnurr, 2007; Sukhontapatipak \& Srikosamatara, 2012). This scarcity of research on fieldbased science courses for pre-service educators likely stems from the fact that introductory courses are not commonly field-based (Nugent et al., 2012). As such, information on field-based experiences is drawn from programs for science majors, pre-service educators, in-service educators, other interested adults, and K-12 students.

Post-secondary education. Hogan and Berkowitz (2000) evaluated year-long professional development programs that involved field-based summer workshops with periodic 
follow-up work throughout the following school year. Researchers evaluated the degree to which in-service educators incorporated schoolyard ecology with their students. The educators participating in the study reported gains in their content understanding. These self-reported gains were substantiated by reports from the professional development providers. The results from a professional development program are not directly applicable to undergraduate science education, but the sequence of on-campus field-based inquiries paired with lesson plan development could be incorporated for pre-service educators in both general education courses and methods courses.

More directly applicable was Nugent et al.'s (2012) quasi-experimental, comparative study of a field-based, geosciences course. The field course was conducted over a two-week period in Nebraska and Wyoming. A control group of students in the traditional class met three times a week for lecture and once for lab with limited half-day field trips (the exact number of field trips was unspecified). Students in the field-based course outscored those in the traditional courses, although the difference between groups was not statistically significant (significant gains in practices of science are discussed in a separate section). The authors expected similar content gains for both courses as similar content was included. However, assessment was limited to a 25-item, multiple-choice assessment. Any gains in content that were not anticipated by the researchers at the start of the study could remain unaccounted for by the instrument, leaving open the question of whether field courses improve content knowledge relative to non-field courses. A qualitative design that allowed for interpretation of written student work paired with interviews to assess student explanations could probe for differences left unaccounted for in a traditional pre/post quasi-experimental design. This could also help address differences between how students learned and how that learning was assessed. 
Schnurr (2007) may have encountered similar issues in assessing her sophomore-level ecology and evolution course. The course incorporated field-based experiments from the Teaching Issues and Experiments in Ecology (TIEE) project. A pre/posttest of content knowledge did not show significant gains for students, but the sample size (18) and the number of assessed questions (five) were very low. Both gains and misconceptions could easily be overlooked in this design. More qualitative assessment showed $72 \%$ of students provided better responses to the question "what is ecology" on the post-test (p. 11). The responses to this question indicated at least some increase in content understanding of ecology rather than an epistemic understanding. Encouragingly, 56\% of students reported that field-based experiences were most meaningful to their learning.

A more open approach to assessment was taken for a week-long, field-based course for adults interested in issues of land management (Slattery, 2000). A purposive sample of participants agreed to pre-post interviews where they had the opportunity to discuss ecology in an open-ended manner. Participants showed a marked decrease in common misconceptions related to conservation issues and "that some vegetation or animal types are more significant, more interesting than others" (Munson, 1994; Slattery, 2000, p. 89). These changes were directly tied to field observations, which have further implications for development of practices of science. The Slattery study evaluated a six-day residential program, which is a more immersive experience than would typically be expected for pre-service educators. However, the total amount of active learning time on-site was likely similar to what could be achieved in a semester-long class, and the same instructional time spaced over a longer timeframe could provide additional benefits. A semester-long course could increase time for reflection and allow for contemplation of seasonal changes not observable over a shorter timeframe. 
Time for adequate reflection on field-experiences follows the recommendations of Lederman, Lederman, and Antink (2013). Without time to explicitly consider the rationale behind a natural history study or an ecological study, participants in a field-based experience could take away the details for how to conduct a study, but not an appreciation of the benefits of the approach or how their process understanding relates to their content understanding.

Lederman et al. (2013; 2014), indicate that process skills are just one aspect of scientific inquiry (SI). A deeper understanding of SI "includes the traditional science processes, but also refers to the combining of these processes with scientific knowledge, scientific reasoning and critical thinking to develop scientific knowledge" (Lederman et al., 2013, p. 142). An immersive experience such as described by Slattery (2000) has the advantage of keeping participants focused and engaged on their work, but may not provide adequate downtime to process not only what they are doing, but why. Without that time for reflection, scientific process skills may not be incorporated into the broader context necessary for SI (Lederman et al. 2013; 2014).

K-12 education. Much of the study of content understanding in field-based courses has been focused on the K-12 level (Rickinson et al., 2004; Dillon et al., 2006). Content gains related to outdoor education have been reported across academic subjects and cultural contexts. Erdogan et al. (2012) reported knowledge gains in a review of Turkish literature. Dentzau (2011) also saw significant gains in the ecology understanding of students visiting a conservation center using both quantitative (true/false questions) and qualitative (student drawings) measures. Lisowski and Disinger (1991) reported quantitative concept gains for high school students after a weeklong period of fieldwork in the Caribbean. Furthermore, they saw evidence of retention of those gains through follow-up testing after four weeks. Morag and Tal (2012) noted that single field trips yield more cognitive gains than affective ones, although the field trips they evaluated 
varied somewhat substantially in implementation. While these content gains were encouraging, the researchers did not measure if field-based work increased cognitive gains compared to wellcrafted classroom approaches.

Ballantyne and Packer (2002) conducted a study of over 500 students from primary and secondary schools in Australia. In their study the researchers concluded that field trips might be best for affective gains, and cognitive work could be done in a pre-post manner in the classroom. While their study was large, interpretation of the results remained difficult. Their conclusions were largely based on student responses to broadly worded questions, for example, "what were some of the ideas and information you learned about during the excursion" (p. 234). Without follow-up, responses could indicate student prioritization of experiences as much as anything.

A less sizeable, but more directly comparative study was conducted with primary school students by Cronin-Jones (2000). The study involved 285 students in third and fourth grade. A quasi-experimental design was used in which the classes were assigned to one of three treatment groups: a control that was not studying ecology, a "traditional" approach, and a field-based approach (p. 204). Students were assessed with a fill-in-the-blank assessment after a three-week unit (only half of the students were given pre-tests). Content understanding increased for both the traditional and the field-based courses compared to the control, but the students in the field-based course performed significantly better than those in the traditional classroom.

Overall learning of core ideas appears to happen in the field. While the number of direct comparison studies is small (Dillon et al., 2006) and multiple-choice tests of content knowledge have inherent limitations (Nugent et al., 2012; Schnurr, 2007), there is reason to be optimistic that a well-developed, field-based course can match, even surpass, a traditional course for preservice education majors. 


\section{Practices of Science}

Core ideas are only a part of scientific understanding. When Risser (1986) defined ecological literacy, he noted (citing Yeagar) that "key concepts and principles" (p. 265) were only one aspect of concern. He further commented, "Nobody believes the first is the most important, yet it receives the most attention" (p. 265). Science as a process was one of those aspects that Risser saw as undervalued and "habits of mind" are explicitly a part of Jordan et al.'s (2009, p. 497) framework for ecological literacy. Korfiatis and Tunnicliffe (2012) went one step further when they stated "the outdoors is not just a setting which could add value to education; it is the starting point of ecological research: authenticity in ecology education has no meaning without field experiences" (p. 125). Practices of science relate to concepts of research design (experimental or observational), data collection and analysis, communication, and critical thinking. So how do field-based courses contribute to understanding the practices of science?

Post-secondary education. Nugent et al. (2012) explored several aspects of scientific practice in their study of field-based geosciences for pre-service educators. As part of what they termed "inquiry understanding and skills" (p. 513), the researchers assessed aspects of critical thinking, observation and inference, and cooperative learning. Quantitative analysis of all three aspects showed statistically higher gains compared to students in a traditional lecture and lab. Interestingly, these skills were measured through standardized assessments. If the ability to critically think and to distinguish between observations and inferences were honed in the field, they persisted in a classroom setting. This would imply not only gains, but transfer. Students in the same study also showed improvement in their understanding of geologic time. These findings are encouraging as ecology relies on similar differentiation between observation and inference. 
The ability to think in both "ecological" and "evolutionary" (p. 243) timescales is critical in Berkowitz et al.'s (2005) and Jordan et al's (2009) conception of ecological literacy.

Griffith (2007) studied the impact of a semester-long, field-based lab experience for biology majors studying plant ecology in a TIEE project that was evaluated for students over two consecutive years. The results showed "moderate improvements" (p. 8) on a multiple-choice assessment that included questions on both field-related topics (e.g. transects) and general skills (e.g. graphical analysis, literature searches, hypothesis formation). Increases in students' assessment of their confidence were also considered moderate. Griffith indicated the results were preliminary and they could be complicated by duplication of some topics in lecture. The increase in scores were interesting to note, however, because he indicated that over half of the students answered experimental design questions adequately during oral questioning and in written proposals although no formal analysis was done, which could be another indication that pre-post assessments might miss valuable gains.

Hane (2007) also evaluated a TIEE project. Biology students in an ecology course worked through field-based labs with varying levels of inquiry. The process culminated in an independent field-based project. Pre/posttests of experimental design were disaggregated based on whether students had previous undergraduate research experience. Those without research experience improved significantly in understanding, while those with the experience had higher pre-course scores and did not show significant gain. Like Griffith (2007), Hane (2007) also indicated lecture as a complicating factor. She also noted the instrument may have had a "ceiling effect" (p. 9) for the students with previous research. However, she indicated that field-based labs might be able to impart some of the benefit of undergraduate research. This is important for pre-service educators as few likely have the time or inclination required for a full research 
experience, but they could gain similar skills by engaging in a well-designed, field-based lab course.

Field-based components in theory could profoundly impact students' understandings of the practices of science. However, gains in this area may be obscured by the quantitative way they are assessed and the disconnect between how the skills are developed and how they are tested, despite some evidence of transfer in Nugent et al.'s (2012) study. Overall, a study that evaluates practices of science in multiple ways, both in the field and the classroom, could be useful.

\section{Place in Education}

\section{Sense of Place}

By their nature field-based courses require participants to study phenomena where they occur. While there is a broad range of actual time in the field for these types of classes (Ballantyne \& Packer, 2002; Dentzau, 2002; Kelley, 2009; Morag \& Tal, 2012), at least some course concepts must be personally observable for students. This approach can provide a focus for ecology classes on broadly applicable concepts that can be studied locally while still allowing room for choice on the concepts, ecosystems, and techniques emphasized during instruction. As such the field-based structure allows educators to highlight where ecology is being studied in addition to what ecology is being studied. This connects field-based instruction with instruction for sense of place.

Sense of place has been described widely in the literature across multiple disciplines, including environmental education and related fields of science (Kudryavtsev, Krasny, \& Stedman, 2012; Kudryavtsev, Stedman, \& Krasny, 2012, p. 231; Russ et al., 2015; Semken \& Butler Freeman, 2008; Warkentin, 2011). As a broadly studied phenomenon, sense of place does 
not have a single definition, but it is often described as a conceptual understanding of an area, "place meaning," and a personal connection to that area, "place attachment," (Kudryavtsev, Krasny, \& Stedman, 2012; Kudryavtsev, Stedman, \& Krasny, 2012, p. 231; Russ et al, 2015; Semken \& Butler Freeman, 2008; Stedman, 2002). Place meaning is highly personal and the ways people conceptualize a place, even a shared place, are nearly endless (Kudryavtsev, Krasny, \& Stedman, 2012; Kudryavtsev, Stedman, \& Krasny, 2012; Manzo, 2005; Russ et al, 2015; Semken \& Butler Freeman, 2008). Kuryavtsev, Stedman, \& Krasny (2012) gave ecological, cultural, and aesthetic place meanings as examples of importance in environmental education. Place attachment refers to the sense of connection people feel to places of personal importance. This can be a matter of "place identity," the sense of belonging to a particular place and of "place dependence," the tendency to think of a particular place as ideal for an intended purpose (Kudryavtsev, Stedman, \& Krasny, 2012, p. 231) or "place satisfaction," where the place is adequate for a purpose (Stedman, 2002, p. 564). For example, I am a Midwesterner (place identity); my city is the perfect place for me because of its amenities combined with a short commute (place dependence). While sense of place is often discussed as a positive, that is not a requirement. Manzo (2005) discussed place meanings that were positive, negative, or somewhat ambivalent. Regardless, place meaning helps to support place attachment (Stedman, 2002). Researchers are concerned with sense of place in ecology education because both "civic" attachment to place and ecological place meaning have been associated with environmentally conscious choices (Kudryavtsev, Stedman, \& Krasny, 2012, p. 235). Despite the potential for sense of place to foster environmentally minded attitudes and behaviors, the research on sense of place is unclear on whether there is a clear link (Kudryavtsev, Krasny, \& Stedman, 2012; 
Kudryavtsev, Stedman, \& Krasny, 2012; Russ et al, 2015; Semken \& Butler Freeman, 2008; Stedman, 2002).

For a field-based ecology class, ecological place meaning is of particular interest. Defined as "the extent to which ecosystem-related phenomena are viewed as valued or important characteristics of places" (Kudryavtsev, Krasny, \& Stedman, 2012, Kudryavtsev, Stedman, \& Krasny, 2012; Russ et al., 2015, p. 74), ecological place meaning expands on the notion of ecological literacy. For people to exhibit ecological place meaning, they need to not only understand ecological concepts, practices, and human connections (Jordan et al., 2009), but they need to see them as vital to a particular place. That is, they must see the importance of nature here, not just the importance of nature somewhere. In this way, sense of place connects to placebased pedagogies.

\section{Place-based Pedagogy}

Place-based pedagogy is a set of practices defined more by intent than by theory (Gruenewald, 2003). According to Smith (2002), "its aim is to ground learning in local phenomena and students' lived experience" (p. 586). Its roots in the United States trace back to nature study and Dewey's call to reconnect students' school lives with the rest of their experience (Gruenewald, 2003; Smith, 2002; Pyle, 2001). A focus on the connection between education and local concerns again became prominent in the 1970s when "the Foxfire project in Georgia spurred a national movement aimed at investigating and documenting regional cultures across the country" (Smith, 2002, p. 587). As a result, the aim of place-based education grew on multiple fronts and with a focus on interdisciplinarity. Sobel made the connection to environmental education in the 1990s (Zandvliet, 2014). 
The goals of place-based education are focused on what students can actively study (Smith \& Sobel, 2010). Sobel (1996) saw what he termed "premature abstraction" (p. 5) in environmental education in prior to middle school. He argued that young children learn better from what they can see and manipulate, but that curriculum for children tended to focus on far away places and problems. In the case of ecology, he noted a trend where students did not explore their local environment, but rather studied distant rainforests that they were still somehow expected to protect (Sobel's example). The result was for children to withdraw in frustration:

If we prematurely ask children to deal with problems beyond their understanding and control ... we cut them off from the possible sources of their strength. . . We can cure the malaise of ecophobia with ecophilia--supporting children's biological tendency to bond with the natural world. (p. 5-6)

The recommendation was not to remove large-scale environmental problems from curricula, but rather to start with local experiences in the early years and then move to larger, less directly actionable issues in middle school and high school when students were developmentally ready (Sobel, 1996). Even at the older grades, recommendations for place-based curricula favor local issues where students can directly interact and evaluate their efforts, or citizen-based science approaches where they can contribute local data to a much wider database (Smith \& Sobel, 2010).

Role of field-based experiences in place-based education. Smith (2002) noted, "Because place-based education is by its nature specific to particular locales, generic curricular models are inappropriate" (p.587). As such, a wealth of writing developed that describes placebased education in action (Crimmel, 2003; Smith, 2002; Smith \& Sobel, 2010; Sobel, 1996). 
These writings were meant to outline goals, implementation, and success without being procedural. Despite the lack of prescriptive curricula, as place-based efforts grew, commonalities developed and Smith (2002) found five "thematic patterns" in his review of placed-based education: cultural studies, nature studies, real-world problem solving, internships and entrepreneurial opportunities, and induction into community process (p. 587-591). As a scientific study of interconnections and relationships, ecology classes could be particularly well suited to connect across several of these themes, however, field-based experiences need to be designed to highlight the unique aspects of their locale. A sense of place does not automatically arise from inquiry-based approaches, although a specific focus on place has been demonstrated to increase place meaning (Kudryavtsev, Krasny, \& Stedman, 2012; Russ et al., 2015; Semken \& Butler Freeman, 2008) and sometimes place attachment (Semken \& Butler, 2008). While place-based educational experiences have demonstrated the ability to increase participants' sense of place, they are still uncommon at the post-secondary level (Semken \& Butler Freeman, 2008; Warkentin, 2011).

Mannion, Fenwich, and Lynch (2013) explored the impact of field-experiences designed to emphasize a sense of place through an extensive, 16-month professional development project in Scotland. In-service educators worked together to choose outdoor locations to explore before working collaboratively to plan, implement, and assess outdoor fieldwork lessons. Several insights arose from this work. Teachers with minimal experience teaching outdoors were more likely to focus on possible safety concerns and administrative barriers than more experienced instructors. This would appear to be of key importance when looking at similar opportunities in the United States where fear of liability can be a limiting factor (Louv, 2005). Collaboration helped to alleviate some of these fears. Over time, as the educators' experience with students in 
the field grew, they became better able to handle "contingencies" (p. 802). As one participant noted, "You've got to expect it so that you're not fazed by it when you're faced by it ..." (p. 802, emphasis in original). Perhaps the most important takeaway from this study was that the connection to place was intentional. As a participant noted, outdoor instruction could be "very mechanical and dull" without an emphasis on "the importance of the place itself" (p. 801). Kudryavtsev et al. (2012) also showed that a sense of place could be developed through experiences designed for faculty.

Part of the goal of place-based education is to develop a connection to nature that furthers study and action (Chawla, 2006; Louv, 2005; Sobel, 2013). Field-based courses have been shown to develop these affective benefits in addition to cognitive ones. This can be especially important for in-service and pre-service educators who may not have had positive formative experiences. For teachers to be willing to engage students in field-based ecology courses, they must be willing to go outside. Hug (2010) noted that pre-service educators frequently display signs of ecophobia. Whether what he encountered was ecophobia in Sobel's (1996) sense or a more social "ick" factor was unclear. However, his contention that pre-service educators often react with fear rather than interest in the outdoors was supported by Powers (2004). Field-based courses helped in both cases by providing positive reinforcement and through opportunities for instructors to show "curiosity rather than fear" (Powers, 2004, p. 6). Hogan and Berkowitz (2000) also noted in-service educators' increased willingness to teach outside following extended, field-based professional development in local ecosystems.

One of the criteria for place-based education is willingness to go off book. Skamp (2009) found educators with higher comfort in the field were more open to spontaneous learning from their students. Willingness to focus on emergent learning was a key finding of Mannion et al. 
(2013) as well. Powers (2004) noted that field-based work provided opportunities to move past standardized curriculum. This flexibility can lead to an atmosphere where educators and students engage as "co-learners," which further encourages spontaneous investigation (Knapp, 2005, p. 280; Krapfel, 1999; Mannion et al., 2013; Sayers, 2004).

On the whole, field-based approaches align well with place-based pedagogy as long as educators have the inclination and the preparation for fieldwork. This inclination may be developed by personal field-based experiences with deliberate attention developing a sense of place. Both Mannion et al. (2013) and Kudryavtsev et al. (2012), worked with in-service educators who may have a stronger place attachment than pre-service educators. Questions remain on whether pre-service educators view their place as transitory and how that translates to their development of a sense of place.

\section{Gap in Literature}

Field-based ecology education has the capacity to increase the understanding of ecology as a body of knowledge and a set of practices. As Risser (1986) said, "As we all know so well, the ultimate appreciation for ecology has to do with the field. The public cannot be literate about ecology until it is comfortable either in or about a specific spot in nature" (p. 267). There is a wide research base to support such endeavors, but gaps are notable in pre-service teacher education. Questions remain about pre-service educators' experience in field-based ecology courses and how those experiences inform their sense of place and their intent to use field-based methods with their students. Furthermore, gains in understanding are widely assessed quantitatively, which may underestimate the impact field-based courses have on ecological understanding. This vein of research is especially important as work with educators has the potential to impact generations of students. 


\section{Theoretical Framework}

Place-based education is more consistently applied as a pedagogical rather than theoretical framework (Gruenewald, 2003) and environmental education has been criticized for lack of a strong theoretical grounding (Dillon, 2003; Rickinson, 2006). However, field-based ecology education, an aspect of place-based education, draws upon situated cognition theory (Brody, 2005; Kudryavtsev et al., 2012; Morag \& Tal, 2012). Situated cognition theory is centered on the idea that "how a person learns a particular set of knowledge and skills, and the situation in which a person learns, become a fundamental part of what is learned" (Putnam \& Borko, 2000, p. 4). The situation in situated cognition theory includes both the social and physical settings in which learning takes place, as each contribute to the social development of knowledge (Brown, Collins, \& Duguid, 1989; Putnam \& Borko, 2000; Resnick, 1987).

Situated cognition is closely tied to the concept of communities of practice (Cobb, McClain, deSilva Lamberg, \& Dean, 2003; Wenger, 1998). Members of a community of practice collaborate towards a common goal while sharing a framework that includes common vocabulary, theory, and skill sets; they have a common situation (Cobb et al., 2003; Cook \& Buck, 2014; Wenger, 1998; 2011). In the community of practice literature, this is referred to as domain, community, and practice (Cook \& Buck, 2014; Wenger, 1998; 2011). A community of practice is united by a common purpose within the domain, involves active collaboration towards that purpose among a community, and shares a common set of approaches to achieve the purpose, which is the practice. Communities of practice serve as a framework for the education through "legitimate peripheral participation" (Lave \& Wenger, 1991, p. 37). New or less experienced members of the community of practice participate in limited ways initially, gradually becoming full participants over time (Brown et al., 1989; Wenger, 1998). In this way, 
education is seen as activity situated within a domain. Using community of practice as a framework, students are not passive, but rather make meaningful contributions along with other members of the community. Learning is a matter of moving towards full participation through greater activity.

Emphasizing community aspects of environmental education and education for sustainable development is growing in terms of prevalence and importance (Aguilar, 2016; Ardoin, Clark, \& Kelsey, 2013). This is seen in environmental education research that actively involves students in their local communities at the middle school level (Kelley, 2009; Roth \& Lee, 2004) as well as in programs for in-service educators focused on incorporating active student participation in communities through citizen science (Krasny \& Bonney, 2005). Likewise communities of practice are found as a framework for sustainability courses for pre-service educators (Cook \& Buck, 2014). Not all community involvement results in a formal community of practice. To qualify, student participants must be able to contribute ideas and techniques to work that they find personally meaningful; they cannot simply be going through the motions of someone else's project (Cook \& Buck, 2014; Wenger, 1998; 2011). Even so, community-based education emphasizes the social development of knowledge that is inherent in the situated cognition theory and the community of practice literature regardless of whether a true community of practice fully develops (Brown et al., 1989; Kelley, 2009; Lave \& Wenger, 1991; Putnam \& Borko, 2000; Resnick, 1987; Wenger, 1998; 2011).

Field-based ecology education, and more broadly place-based education, draw from situated cognition theory in their attention to the full context of learning (Brody, 2005; Kudryavtsev et al., 2012; Morag \& Tal, 2012). Field-based and place-based pedagogies do not simply occur in a location; rather the location is fundamental to the educational experience and 
the type of learning desired. This type of situated context, which Manzo (2005, p. 74-75) refers to as "experience-in-place," can be a vital part of forming place meaning. Likewise, both fieldbased and other forms of place-based education place an emphasis on the role of the learner within the community. Place-based education places the curricular emphasis not only on a local context, but also on how students can be an active part of that local context (Gruenewald, 2003; Smith, 2002; Smith \& Sobel, 2010; Sobel, 1996). In this way, place-based education encourages students to join communities of practice. 


\section{CHAPTER III: METHODS}

\section{Research Trends in Ecology Education}

The exact purview of ecology education is notoriously hard to define, but reviewers often classify it as part of the field of environmental education (Marcinkowski et al, 2013). First emphasized at the college-level in the 1950s and the pK-12 level in the 1960s, there has been a small but "steady level of interest in ecology education" in North America as indicated by the $10-16 \%$ of environmental education dissertations written specifically on ecology education from 1971 to 2000 (Marcinkowski et al., 2013, p. 53-54). In the early part of this timeframe, environmental education research was likely to be quantitative in design and North American in focus (Scott, 2009). However, approaches to research have expanded in recent decades with qualitative designs rising in prominence (Marcinkowski et al., 2013; Scott, 2009; Stevenson \& Evans, 2011). While this has been especially true for journal articles published outside of the United States (Stevenson \& Evans, 2011), the trend has been seen in U.S. dissertations as well (Marcinkowski et al., 2013).

Despite the overall trends in ecology education, studies with pre-service educators have been limited (Stevenson \& Evans, 2011). This paucity leaves room for research on the experiences of pre-service educators in ecology courses. This dissertation describes a qualitative case study of pre-service educators enrolled in a field-based ecology course. The purpose is to use the approach of Corbin and Strauss (2015) to develop grounded theory exploring how preservice educators develop ecological literacy through field-based learning and how they connect those experiences to their future educational practice. 


\section{Case Study}

\section{Choice of Case Study}

Merriam (2009) and Stake (1995) provide the clearest guidelines for when a case study is appropriate. They both argue that the choice of research topic determines whether something qualifies as a case study. Merriam (2009) notes that "a case study is an in-depth description and analysis of a bounded system" (p. 40) with Stake indicating that "the case is an integrated system" (p. 2). In this way, a case study is appropriate when the researcher can articulate how the parts of the study work together as a whole. In this study, the system is a field-based ecology course for pre-service educators. The system is bound by time and by participants. As such a case study design is appropriate.

Stake (1995) makes the distinction between "intrinsic case study" and "instrumental case study," where the former is not expected to help the researcher "learn about other cases or about some general problem" and the latter is used to "get insight into the [research] question by studying a particular case" (p. 3). This distinction hinges on whether the researcher is more interested in the case in isolation or as a way to draw more broadly applicable ideas. This case study is instrumental by design as the emphasis is on how the experiences of pre-service educators relate to the broader questions of field-based pedagogy in ecology. While Stake (1995) indicates that the border between an instrumental and an intrinsic case study is not rigid, the distinction is still worth noting. The instrumental nature of a case study relates to both the goal of the research and the appropriate method of data analysis. For this case, the goal is to perform an instrumental case study that serves to develop a grounded theory of pre-service educators' developing ecological literacy in a field-based course. 


\section{Choice of Grounded Theory}

Glaser and Strauss developed grounded theory collaboratively in the 1960s (Corbin \& Strauss, 2015). Glaser and Strauss were both sociologists, but the approach they developed was considered a general methodology applicable to other fields. The approach to data collection, analysis, and interpretation in grounded theory centered on "the need to build theory from concepts derived, developed, and integrated based on actual data" (Corbin \& Strauss, 2015, p. 6).

Defining features of grounded theory include the goal of theory development, the use of concepts from data to generate theory, and a continual, iterative approach to data collection and analysis (Corbin \& Strauss, 2015). Ultimately, Glaser and Strauss both continued to work on their approaches to grounded theory separately. This study incorporates the methods of Strauss refined with Corbin (2015).

\section{Description of the Case}

In order to protect anonymity, pseudonyms have been used for all proper names in this study, including those of the participants, the name of the university, the name of the course, and the field sites. The case in this study is Field-based Ecology 300 (FBE 300), a general education course designed for pre-service educators at Oak Savanna University, a Midwestern, private university. The case is bound in terms of time and participants. Nine students and two instructors, one of whom is the primary researcher and author, took part in the semester-long course. Eight students consented to be part of the study. The course was a team-taught, fieldbased course with an emphasis on place-based pedagogy. The course met for a total of 27 , threehour class sessions and one 5.5-hour, Saturday field trip. Approximately half of the instructional days included time in the field; on-campus fieldwork was conducted on three days, with an additional 11 days spent conducting off-campus fieldwork. 
Over the course of the semester, participants conducted two research projects. The first research project was based on the principles of citizen science and was conducted with the cooperation New Woods Nature Preserve (New Woods). The entire class collaborated on data collection and analysis for an on-going biodiversity survey of a wooded area undergoing active fire management at New Woods. Students conducted a plant survey of the woody overstory, woody understory, and groundlayer cover along a 100-m transect. Raw data along with relative density, relative dominance, and importance value (overstory) and relative frequency, relative cover, and importance value (groundlayer) for each species found were reported to New Woods' head naturalist. Data collection and analysis were conducted during 10 class sessions. These sessions were split evenly between data collection (field) and analysis (class). Students drew from their initial explorations during the first project, lecture material, and/or class discussions to develop testable questions that they addressed through small group research projects during the second half of the course. The second project was conducted over eight class days with more inclass time spent on planning, analysis, and writing (six days) than on data collection in the field (two days).

While the class focused on local ecology, discussions of pedagogy (with an emphasis on place-based pedagogy) were also included and incorporated into the assessments. Semester-long projects were designed to engage students in ecological education outside of the formal class setting and to help them make connections between ecology content and science pedagogy. Students made independent field observations throughout the semester. The field observations included details of 10, 30-minute observation periods. Students chronicled the details of their observations along with questions they developed as they observed. Personal reflection on field and classroom experiences and connections to their future practice were kept in the form of on- 
going participant journals. A "nature passport" assignment allowed students to receive credit for engaging with nature-focused art and media (e.g. books, films, fine art). To earn "stamps" in each category, students were required to summarize the experience and draw connections between the artwork and course concepts as well as how the experience might relate to their future practice. As a culminating project, students designed an individual lesson plan meant to incorporate both the scientific and pedagogical concepts emphasized in the course.

\section{Field Sites}

Located approximately 20 minutes from campus, New Woods served as the primary field site for the course. New Woods is a popular recreation site for hiking and running. Predominately forested, New Woods also has a restored grassland area. Six class periods were spent at New Woods, with one research group choosing to spend an additional day there for data collection on their second project. The Saturday field trip included sites that were not close enough to campus to visit within the three-hour class period. It included a restored wetland, Great Egret Wetlands, a state park, and a separate nature preserve within the boundaries of the state park, Glacial Dunes Preserve. Additional field trips included an animal park and a botanical garden for observations. One class period was spent on what was commonly referred to as the "erosion tour," a driving tour with stops in areas vulnerable to erosion and in places incorporating erosion abatement measures including a second restored wetland, Little Northern Wetlands.

\section{Guiding Research Questions}

Studies using grounded theory start with guiding questions or a broad topic of interest (Corbin \& Strauss, 2005). The guiding questions become more specific as data is collected and analyzed. For this study, three initial guiding questions were of interest. 
1. How does pre-service educators' ecological literacy develop during a field-based course?

2. To what extent do pre-service educators plan to incorporate field-based natural history and ecology education into their future practice?

3. Do pre-service educators develop a sense of place in temporary, collegiate environments?

These questions were refined based on on-going data analysis and review of literature. Research questions in their final versions are included in chapters IV-VII.

\section{Data Sources}

Multiple data sources were used to get a full picture of the case at the heart of this study (Corbin \& Strauss, 2015; Creswell, 2009; Merriam, 2009; Stake, 1995). Course assessments were developed to provide information on participants' developing ecological understanding as well as their perceptions of field-based ecology and their sense of place. Data sources for this dissertation included exams, participant field observations, journals, an initial survey, and researcher field notes. In-depth semi-structured interviews were conducted as a member check and to allow participants to expand their thoughts on the other data sources. Specific sources used to triangulate each research question are included in chapters IV-VII.

Analysis of the data sources followed the approach to formative assessment the instructors used in normal classroom practice. Students' responses to assessments guided further instruction and further assessment. Initial coding of classroom artifacts was used to form writing prompts for journals and midterm exam questions. Further coding of the midterms and the journals was used to craft individualized interview questions and final exam questions. This practice provided the basis for the "theoretical sampling" used in grounded theory (Corbin \& 
Strauss, 2015, p. 134) where new data sources are chosen to help expand developing theoretical directions.

\section{Participant Recruitment}

All students enrolled in FBE 300 were eligible for participation in the study. Because I was both the primary researcher on the project and an instructor of the course, a faculty member of Oak Savanna University who was not associated with the course visited class when the instructors were not present to obtain consent. She read the recruitment script and distributed a letter of informed consent during the fifth week of the course. The letter indicated that participation in the research aspect of the course was voluntary, although course assessments were required. She answered questions about the nature of the research project and collected letters of consent. Students who were absent on the day that she attended class were instructed to set up a short meeting with her at their convenience. The letters of consent were returned to me as primary researcher after final grades were assigned for the semester. Eight of the nine registered students agreed to participate in the study.

\section{Participants}

Eight participants took part in the research study. Six were female and two were male. All participants were upperclassmen by earned credit, with six seniors and two juniors, but not all seniors planned to graduate within the academic year. The participants all had majors in the department of teacher education and all had plans to teach upon graduation. Two participants were preparing for early childhood education, three for elementary education, one for middle school education, and two for special education. All participants were required to have a concentration in a field of study; two were concentrating in general science with the other six choosing a non-science field. Each of the participants previously completed a 100-level science 
course that incorporated active student inquiry as a pre-requisite for FBE 300. Of the eight participants, six had completed a course with one of the two instructors prior to FBE 300.

\section{Research Activities}

As a co-instructor of the course and the researcher involved in the study, I was present for each class session. Primary responsibility for lecture and other in-class activities was shared with the co-instructor, although we both contributed ideas and questions as appropriate during lecture and discussion regardless of who was the lead instructor on a given day. We facilitated fieldwork together throughout the semester.

I kept detailed field notes that I updated each class period. The field notes included a summary of the activities for each day including, but not limited to, lecture topics, fieldwork, and group projects as well as an approximation of the amount of time spent on each activity. Also included were attendance logs and a record of the day's weather. Notes on student participation, questions, and ideas were kept as well as my impressions of student engagement and concerns. The field notes served as both a source of data and as a place to memo about the developing research (Corbin \& Strauss, 2015). Entries varied in length, but were usually one to three, singlespaced, typed pages per class period.

Data in the form of coursework was collected throughout the semester. I periodically photocopied the observation notebooks and journals for coding and formative feedback purposes. I used these analytical sessions to develop writing prompts, a form of theoretical sampling (Corbin \& Strauss, 2015). I also photocopied exams for purposes of analysis. I kept either photocopies or electronic copies of lesson plan drafts and nature passports.

Semi-structured "instructor chats," or interviews, were conducted at the end of the semester with both instructors present. Initial questions were developed based on analysis of 
previous data sources, including observation notebooks, journals, nature passports, and lesson plans. Copies of the students' original work were available during the interviews for reference by the student and by the interviewers. The interviews were used as a member check of the research and to allow students to further elaborate on their ideas. Interviews ranged from 40 minutes to 65 minutes, with an average of 50 minutes. An analytical memo was written as close to the interview as possible. For six interviews, the analytical memo was written on the same day. For two interviews, the memo was written the following day. All interviews were audio recorded. A professional service was used for transcription.

\section{Data Analysis}

The recommendations of Corbin and Strauss (2015) for developing grounded theory were used for data analysis. Grounded theory was created through an iterative process where ideas were continually refined through successive rounds of data collection and data analysis.

Open coding stage. Concepts of interest were identified inductively from the original data sources, the process of open coding (Corbin \& Strauss, 2015). Open coding began with observation notebooks and journal entries that were collected on the third day of class. The data sources were organized by participant, type of data source, and number of the data source (e.g. participant journal 1). Early observations and journal entries were analyzed by microanalysis. During the microanalysis phase, codes were assigned on a line-by-line basis for each data source through open coding. Codes were chosen to describe a concept present in the data. While these were sometimes in vivo codes taken directly from the data, more often I named the concepts.

Analytical memos were written extensively at this point in the data analysis, with memos written for both individual participants on a single data source (e.g. developing ideas on one participant's first journal) and on the data source as a whole (e.g. developing ideas from the first 
journal entries) (Corbin \& Strauss, 2015). Multiple analytical techniques were used during open coding. The most frequently used techniques at this stage were asking questions about the data and making comparisons across data sources. Theoretical questions were used to make connections between different codes and between research participants and guiding questions were used to elicit further data through journal and interview prompts. Constant comparisons were made between data sources for a single participant and data sources between participants. These constant comparisons helped organize data that was similar and lead to the next stage of analysis, axial coding.

Axial coding stage. In order to develop each category, "concepts have to be woven or linked back together to tell the original main story of the research or observation but in conceptual terms" (Corbin \& Strauss, 2015, p. 157). This reintegration is referred to as axial coding. As analysis progressed past the initial coding stage, connections between codes became more apparent. At this point, axial coding began, where codes were linked together to form more developed conceptual relationships. During axial coding, microanalysis was not usually necessary, and codes were generally assigned to chunks of raw data from a few sentences to a paragraph long. Codes were linked together in a fashion where the most abstract concept was listed first followed by more specific details. In this way concepts were fleshed out in terms of their properties.

At this point, data was organized in an Excel spreadsheet. Each participant was given a sheet within the file. Data in the form of direct quotes was organized by participant, data source, location within the data source, date of data collection, and date of initial coding. Codes were then listed in order of decreasing abstraction (e.g. role of collaboration, shared sense making, conflicting descriptions). A Word document for each participant was used for analytical memos. 
Analytical memos were written for each coding session; they were organized using the same scheme as for the Excel spreadsheet.

Multiple analytical tools were used during axial coding. Asking questions and constant comparisons continued. Additionally a greater emphasis was placed on looking for outliers when considering general trends. Likewise, the significance of findings was weighted, with lesserdeveloped concepts incorporated into broader themes and categories. Axial coding was an iterative process that was not completely separate from open coding; open coding continued as needed if new concepts appeared in the data. The process continued until new data sources fit logically and consistently into the existing organizational system, what Corbin and Strauss (2015) referred to as saturation.

During axial coding, diagrams were used extensively to tie related concepts together (Corbin \& Strauss, 2015). Codes were written on sticky notes and moved around to explore various possible connections between them. This allowed for diagrams to be updated and rearranged easily. A record of the diagrams was kept in the form of digital photographs that were taken at the end of each session. As the organizational system matured, emerging concepts were color-coded based on category and ultimately theme. At this point electronic diagrams were made using Excel that kept the same color-coded themes. Methodological memos were written as needed to keep track of changes to the organizational scheme, addition of new codes, and overall ideas regarding the process of data analysis.

Theory formation. To develop substantial, grounded theory, the categories and themes of analysis are brought together through a "core category" (Corbin \& Strauss, p. 188). The core category describes a theme that appears in the data for each participant, that is broadly conceived, and that has the capability of tying all the other themes together. Throughout axial 
coding, diagrams were used to arrange codes into categories and sub-categories, which were in turn united in themes. Upon contemplation of the themes (a level of organization that Corbin and Strauss (2015) may term a category), a unifying core theme was identified. This theme was present in the data for all eight participants. All other themes in the study related directly to the core theme, and the core theme provided a motivation that helped explain participants' actions and reactions to course conditions throughout the length of the study.

Once the core theme was identified, diagramming was again used to visually connect each theme to the core theme and to each other. While diagrams of grounded theory may sometimes show a linear progression, they can be quite complex (Corbin \& Strauss, 2015). In this case study, the diagram showed multiple, non-linear pathways that participants could take through each theme identified in the study, but they all passed through the central, core theme.

\section{Role of the Researcher}

As one of the primary instructors in the course, I served a dual role in this study. This provided complication, but was not without precedent (Corcoran et al., 2004; Kelley, 2009; Tal \& Morag, 2009). As an active participant in the case, I knew the student participants, six before the start of the course and all by the end. This familiarity helped provide valuable insight, but ensuring that the students' voices were dominant in the discourse was crucial. To this end, I used journal prompts as a theoretical sampling technique to provide more information as research categories emerged. They were open-ended by design so as to elicit responses that could challenge my developing ideas. My co-instructor also provided an avenue to check my interpretations and assumptions as we worked together to provide feedback to students during the course. 
Culminating interviews with each participant were used as member checks at the end of the semester. Prior to each interview, I completed a review of all the data sources for the participant. This review was used to develop interview questions designed to give participant feedback on my developing interpretations. During the semi-structured interviews, participants were able to provide feedback, elaborate on their ideas, and provide perspective on their changing points-of-view from the beginning to the end of the course.

Serving as both the researcher and an instructor provided potential ethical conflicts. Data sources were embedded in the course; however, the member checks required some sacrifice from participants in terms of out-of-class time. To avoid potential coercion, informed consent was obtained from a faculty member not associated with the course, and I did not know which members of the class consented to participate in the study until after final grades were assigned. The Institutional Review Boards (IRBs) of both Illinois State University and Oak Savanna University approved the procedures for recruiting participants and obtaining consent.

\section{Validity}

Validity in qualitative studies comes from thoughtful evaluation of the data to ensure that both description and interpretation are correct (Creswell, 2009). "Rich, thick description" is used to provide as full of a picture of the case as possible (Creswell, 2009, p. 191; Merriam, 2009; Stake, 1995). To ensure accuracy of category development, more than one form of data is used to triangulate ideas (Creswell, 2009; Merriam, 2009; Stake, 1995). Stake (1995) refers to this as methodological triangulation (p. 114). In this study, journals, observation notebooks, exams, surveys, researcher field notes, and interviews were used to triangulate ideas. A table outlining which data sources were used for each research question is provided in chapters IV-VII. The points-of-view of multiple students were used to create each category. Extensive direct quotes 
from student artifacts and student interviews were used to support and illustrate the ideas presented in each chapter. As a check for interpretation, I looked for conflicting evidence or unusual cases. Any contradictions to the general themes in the research are presented along with the main findings as a way to outline the limits of interpretation.

While coding and theory development were performed by the researcher, as a qualitative research project this dissertation relied on the inclusion of multiple points-of-view and collaborative construction of ideas (Creswell, 2009; Merriam, 2009; Stake, 1995). As such, participant interviews were used to member check interpretations of student writings. Member checking did not replace researcher discretion in terms of determining what was pertinent to the case study, but rather provided further insight and a chance for participants to elaborate on their thoughts (Corbin \& Strauss, 2015; Stake, 1995). 


\title{
CHAPTER IV: COMMUNITY OF PRACTICE IN FIELD-BASED ECOLOGY
}

\begin{abstract}
This chapter explores the extent to which participants in a field-based ecology course for non-science majors developed as a community of practice and the student learning gains associated with the community of practice framework. The principles of grounded theory were used to analyze data collected during the semester-long ecology class and to determine the extent to which participants formed a formal community of practice. Participants formed a community of practice of ecology educators by participating in local scientific research in personally meaningful ways, developing their field skills, and expanding their identities as pre-service educators to include their ability to contribute to scientific research and for their future students to do likewise. This development was most closely tied to their work on a citizen science project at a local nature preserve. Through regular interaction with each other and with the nature preserve, students developed in the practice of local naturalists including expanding their hard skills of plant identification, data collection and analysis, and their soft skills of collaboration. Participation in a community of practice was important pathway students used to increase their ecological literacy and expand their views of themselves as ecology educators. The impact of community was used to develop a grounded theory of field-based ecology education that can be extended to other educational settings.
\end{abstract}

Keywords: community of practice, ecological literacy, citizen science

\section{Ecological Literacy and Communities of Practice}

Historically the definition of ecological literacy has been the matter of considerable debate (McBride et al., 2013). While no single definition has emerged, for this study the model developed by Jordan et al. (2009) was used for purposes of analysis. This framework included 
three main areas of ecological literacy including: "possession of scientific habits of mind in ecology," "understanding of ecological connectivity and key concepts," and "appreciation of the links between human actions and the environment" (p. 497). The model benefits from a strong focus on ecology as a science, but Jordan et al. (2009) acknowledged that it does not include philosophical or social aspects of ecological literacy, or the role of environmental attitudes in ecology education. One way to bring the social aspect of learning into the model is by using the concept of community of practice $(\mathrm{CoP})$ as a framework for developing ecological literacy, a usage that already is common in the literature on environmental education and education for sustainable development (Aguilar, 2016). In a CoP, learning is explicitly recognized as a social endeavor.

A CoP consists of a group of people united by a goal who share common vocabulary, theory, and skill set (Cobb et al, 2003; Cook \& Buck, 2014; Wenger, 1998; 2011). In the literature, these are defined as the community, domain, and practice, respectively (Cook \& Buck, 2014; Wenger, 1998; 2011). The domain is the common purpose of the CoP. It provides the context in which members of the CoP work and learn together and it sets members apart from people who are not part of the CoP. The community indicates the close association between members of a CoP. In order for people with the same domain to be part of a $\mathrm{CoP}$, they must be active collaborators. The practice is the skillset, theory, and tools common to the CoP. A CoP uses, develops, or adapts the practice to address the domain.

\section{Students as Legitimate Peripheral Participants}

CoPs are incorporated into environmental education in a variety of ways. One model is for students to join an existing $\mathrm{CoP}$ as legitimate peripheral participants. Legitimate peripheral participation is "a way of gaining access to sources for understanding through growing 
involvement" in the domain of interest (Lave \& Wenger, 1991, p. 37). In this way, learning is defined by the ability to become more active in a CoP. Cook and Buck (2014) used this approach at the college level with pre-service educators who developed inquiry-based projects with established researchers working on sustainability issues. Roth and Lee (2004) worked with middle school science students who joined research efforts at a local watershed. In both cases, students new to the domain of interest were able to collaborate with more experienced members of the community in a way that furthered the work of the CoP.

Students working on collaborative projects do not automatically qualify as a CoP. They need the opportunity to engage with a personally meaningful goal in a way that allows them to develop their own approaches to the work (Cook \& Buck, 2014; Wenger, 1998; 2011). Likewise, working as part of a $\mathrm{CoP}$ in an ecology course does not guarantee increased ecological literacy, as the outcomes of the collaboration may not be the same as the intended outcomes of the course with affective gains generally more common than cognitive gains (Aguilar, 2016).

\section{Field-based Ecology 300 as Legitimate Peripheral Participation}

In this case study, a CoP framework was used as an organizing structure for a field-based ecology course for pre-service educators (FBE 300). The course was centered on two projects, each of which lasted approximately half of the 14-week semester. The first project took a citizen science approach, in which the students in the class collected data for an on-going project in partnership with New Woods, a local nature preserve. Students contributed to a long-term biodiversity study in a wooded area undergoing active fire management. Students conducted a plant survey of the woody overstory, woody understory, and groundlayer cover along a 100-m transect. Raw data along with relative density, relative dominance, importance value (overstory) and relative frequency, relative cover, and importance value (groundlayer) for each species found 
were reported to New Woods. In this way, students acted as legitimate peripheral participants (Lave \& Wenger, 1991). The project required them to use the methods and vocabulary of New Woods naturalists to collect and analyze data that contributed to the nature preserve's understanding of the effectiveness of their fire maintenance program. Students worked as a single team to develop a collective final report during this time, which allowed for full class coordination of the project. In the field, data collection was managed in small groups of two to four with all data being shared with the class as a whole. The composition of these groups was flexible from class period to class period.

The second project moved the students past characterization of a single transect and towards hypothesis formation. Participants were allowed to form their own small groups with a minimum of two partners and a maximum of four. These groups used the knowledge that they gained from the first part of the semester to develop testable questions and hypotheses on ecological topics of local importance. Instructors helped students refine the questions with iterative feedback. A similar process was followed for developing methods to test the questions. Participants suggested methods for data collection and analysis and instructors provided feedback for improvement. Instructors also provided standard operating protocols when appropriate (e.g. on how to extract nitrates from soil). The final product was a formal lab report written by each group. While this second project was the more traditional in terms of science course structure, students were still provided access to the tools, methods, and test sites of the naturalists to a greater extent than with a traditional teaching lab for non-science majors. This included permission to collect samples from the nature preserve and access to instrumentation and equipment in the research lab of an ecologist who was not associated with the teaching of the 
course. Course instructors acted as facilitators for both projects, offering advice and guidance, helping to arrange access, but not dictating projects.

Additional course assignments, including observation notebooks, lesson plans, journals, and nature passports, were assessed individually for the purpose of course grades, but collaboration was encouraged. Peer-review was incorporated for lesson plans, and as questions about assignments arose, they were addressed and settled as part of class discussion. Course faculty worked to make their pedagogical choices transparent, and reflection on pedagogy was an explicit part of the observation notebooks, journals, and nature passports. Students in the course also had the opportunity to work with local fourth graders as part of a university-sponsored “college student for a day" program. This event was planned collaboratively between students in the course and the faculty members. In this way, a CoP framework was used throughout the course and not limited to the work done in partnership with New Woods.

\section{Research Questions}

While a CoP framework was used in FBE 300, formation of a CoP cannot be automatically assumed in mutual endeavors (Wenger, 1998; 2011). Likewise, students' identification of the outcomes of a course cannot be assumed to match the objectives intended by the instructors (Aguilar, 2016). From this, two research questions related to community of practice (abbreviated $\mathrm{C} 1$ and $\mathrm{C} 2$ ) emerged:

C1. Did student collaboration meet the criteria for participation in a community of practice?

C2. What outcomes did students recognize related to the CoP framework of the course? The emergent research questions stemmed from the first two guiding questions for this dissertation, “How does pre-service educators' ecological literacy develop during a field-based 
course" and "To what extent do pre-service educators plan to incorporate field-based natural history and ecology education into their future practice?"

\section{Findings}

While FBE 300 was designed using a CoP framework, formation of a CoP by the participants was not assumed from the beginning. Open coding was used on classroom artifacts including journal entries, exams, observation notebooks, and interviews to generate approximately 27 codes (see Table 1). Axial coding resulted in two major categories, Making it real and Building a community, each with related subcategories as part of the theme Community (See Figure 1). Within the CoP framework, Making it real related to Wenger's $(1998 ; 2011)$ concept of domain, or joint enterprise, and elements of practice, while Building a community encompassed aspects of both community and practice. Student artifacts showed recognition of both the structural elements of a CoP and aspects of ecological literacy supported by participation in a CoP. They connected these elements to their future practice through an emphasis on collaborative student learning.

Table 1

Alignment of Data Sources with Emergent Questions Regarding Communities of Practice

\begin{tabular}{lccccc}
\hline Question & Exams & $\begin{array}{c}\text { Observation } \\
\text { Notebooks }\end{array}$ & Journals & Interviews & $\begin{array}{c}\text { Researcher } \\
\text { Field Notes }\end{array}$ \\
\hline $\mathrm{C} 1$ & $\mathrm{X}$ & $\mathrm{X}$ & $\mathrm{X}$ & $\mathrm{X}$ & $\mathrm{X}$ \\
$\mathrm{C} 2$ & $\mathrm{X}$ & & $\mathrm{X}$ & $\mathrm{X}$ & \\
\hline
\end{tabular}




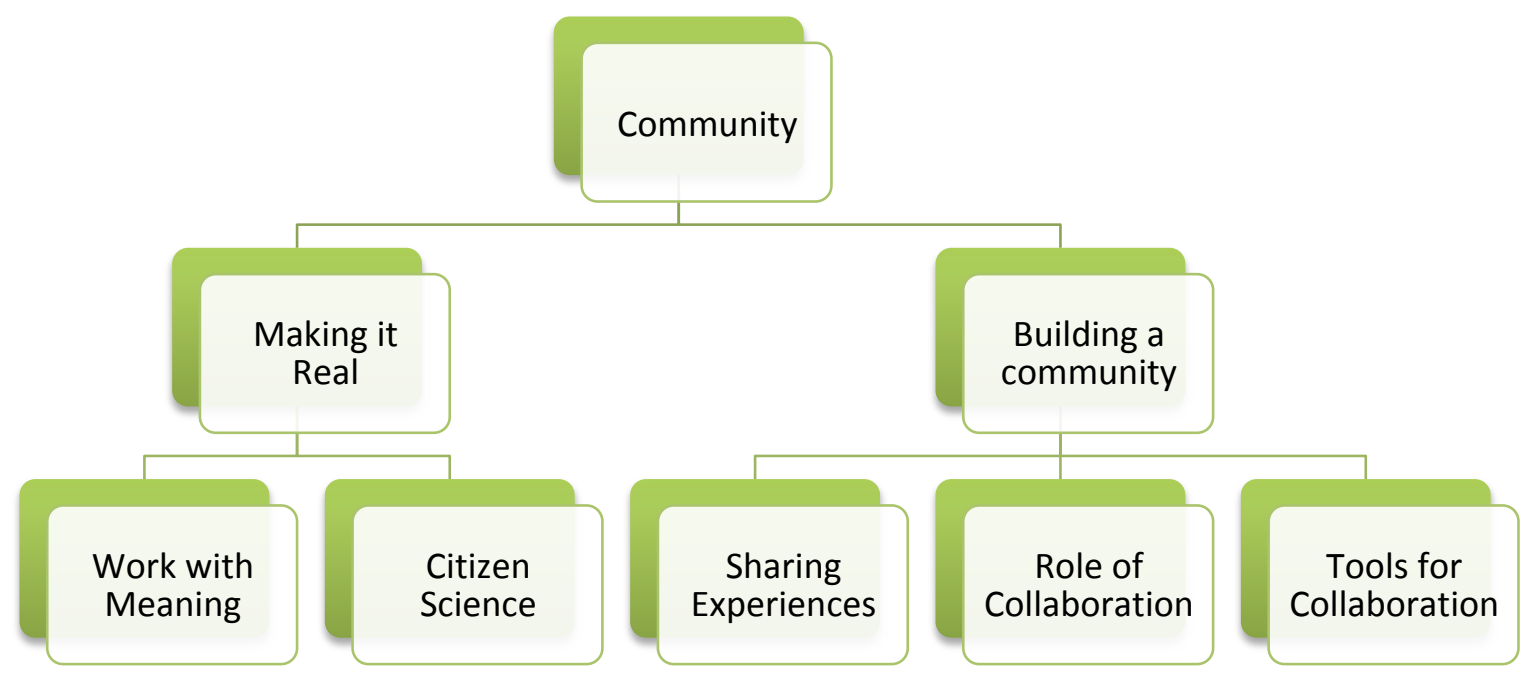

Figure 1. Organizational scheme for the theme, community, with major categories and subcategories.

\section{Formation of a Community of Practice}

\section{Domain}

An essential part of a CoP as described by Wenger $(1998 ; 2011)$ is the domain, or the joint enterprise. The domain provides the unifying structure of a CoP. It includes the shared purpose that brings a CoP together and the sense of identity that differentiates members from non-members. From the beginning of FBE 300, this sense of unity came from the students' identity as pre-service educators. Participants consistently referred to their future students and their future role as teachers. By viewing the course through the lens of pre-service educators, students made connections with the material that gave the work meaning beyond hoops to jump through or grades to earn. This was expressed by Chris in a journal as she explained how she approaches new content information, “. . . I'm starting to be able to relate the concepts covered to my own life and experiences, and think of ways to make the information relatable and accessible for four-year-olds." 
Participants began the course with a previously established domain. This did not change fundamentally during FBE 300; rather experiencing the class as pre-service educators was central to the course experience (see Chapter VII: Experience a Field-based Ecology Class as a Pre-service Educator). During the semester, the participants' domain expanded to include new facets of pre-service education. The expansion stemmed from the aspects of the course that the participants perceived as genuine (Making it real). Experiences were real if participants could articulate a direct benefit to those outside of the course or to themselves (Work with meaning).

Work with meaning. The first research project in FBE 300 was conceived as citizen science. The students collected data that was useful to the management of a local nature preserve. Both the goals of New Woods and the goals of citizen science more broadly were articulated in lecture and class discussion prior to the start of the project. A citizen science project was chosen for FBE 300 for several reasons. It was conceived as a way for students to gain important knowledge about the natural history of the local area, and also as a way for students to see how that knowledge might be used in conservation efforts. The intended effect of the citizen science approach was for students to see the worth of the data they were collecting, and see how they could contribute to scientific understanding outside of a classroom experiment. To a large extent, students recognized the goals of the project and were able to articulate their role in the process. Cameron provided this account in her interview:

I think it's ... it's different than any class I've taken in college ... so you know that makes it memorable in and of itself. And it's so hands on and so . . . in the field, but it's not . . pointless fieldwork. It all has a purpose ... In that, I think it's cool that we were able to contribute ... I think that's really neat that . . . it's not . . gonna sit in a room somewhere with . . 30,000 other lab reports for 10 years and then get shredded. You 
know ... it's actually being used... outside of [Oak Savanna University] which is really cool!

Many participants in the class expressed similar ideas. Alex noted that the knowledge that New Woods would use the data provided "motivation" for the work. Bobby saw the project as "something real." This sense of personal responsibility was not always comfortable early in the course, Sam expressed early worries regarding the project, "I am going to mess up their data for the park and it will be all my fault." Concern about the quality of the data and their ability to help the nature preserve were common early on. As students worked at New Woods over the semester, however, the expansion of their responsibilities was viewed as a positive development. Payton marveled at the level of participation he had as a newly trained researcher:

And to actually have the research we did there [New Woods] be studied by them is just kind of a neat thing to think about. You know, you wouldn't think they would want a bunch of college students who don't know much about ecosystems to go out there and run tests for them.

Not all of the participants commented on their role in conservation research; neither Cameron nor Taylor discussed this aspect of the experience in great detail. Overall, however, by expanding the students' domain to include their role as active contributors to scientific research, students found additional meaning in the course. This was true whether or not the students were inherently interested in fieldwork. Kit exemplified the response of someone excited by outdoor science experiences:

I feel like I was doing it, and I was so excited cause I was really excited and really wanted to do it and learn all this. But also to know that it was going to [New Woods] and they were going to ... use that information was very cool. Like I said in my passport, I 
think it's like important that students know that they can make a difference. And have input in things outside of just . . the classroom.

Cameron expressed the same ideas from the viewpoint of someone who otherwise did not find the experience personally enjoyable:

While I might not be thrilled about the idea of hiking a mile into the forest and then trekking out into the middle of the woods to look at the ground for two hours every Monday, I think it will all be worthwhile when I can look back and know that ... I was able to contribute to something much bigger than one small PVC pipe square in an effort to keep natural forests healthy and thriving... In all, while I might not have been too thrilled about field work in the beginning, I think it's going to give me a very authentic learning experience that I will definitely be able to take with me when I graduate.

\section{Community}

The community in a CoP is defined by a close collaboration (Cook \& Buck, 2014; Wenger, 2011). A shared domain of interest is not enough to form a true community, but rather members must work together. This aspect of community was emphasized in Wenger's (1998) earlier terminology, mutual engagement. For members of FBE 300 to function as a community, they needed to recognize and value a sense of cooperation and partnership. Evidence of community was found in journals and reinforced in the interviews (Building a community, Role of collaboration).

Role of collaboration. Participants acknowledged the collaborative nature of the course through journal entries that described their experiences and emphasized the combined effort necessary to successfully collect data at New Woods. These collaborations were seen both as an advantage and a responsibility. Bobby noted the benefit of working in a group early in the 
course, "My group helped me identify certain plants as a shrub, tree, grass and more. This helped when approaching data and collecting amounts of plant types." Sam had a similar experience when first learning how to do fieldwork, indicating that working with others had a positive impact on her experience, "I also think being out doing the field work has made a huge difference as well. I get to practice, but also work with other students who are learning as well and we get to build our skills together." Alex recognized her responsibilities within a community with flexible partnerships:

Regarding participation, I plan on doing my best to work well with my team mates, whoever I may be working with in our class, both at the forest preserve as well as when working on group projects in the classroom. If needed, I'm willing to meet with my group outside of class as well (to work on lab reports, etc.).

For Payton participation in a community was an experience that was both beneficial and served to expand the notion of how students can work together within science courses:

It is important to work with other people, because everyone one has strengths that they can bring to the table that you might not possess. For a long time I thought that there isn't much collaboration that goes on in a science course, I felt that science was a one man/woman show. I thought it involved a lot of individual work, however, [FBE 300] has showed me that this is not the case.

Cameron noted the way that working together moved students further than they could get on their own:

I think ... it was my uncle who taught me a proverb. . . He used to always say that "iron sharpens iron." I think it is Bible. And I mean just that right there; I mean if I'm stumped on something [Payton] might add a suggestion . . . [Sam] might add a suggestion. Even 
when we did the [citizen science project] as a group, it was the same way... if you're stumped on something, somebody can add something. I mean you can brainstorm together. ... Everybody's input is gonna be stronger than just one person's input. I guess that's debatable, but ... in our situation ... it was true, I thought.

Overall, participants in FBE 300 indicated that they worked together towards the goals of the course. This was seen as both an immediate personal benefit, as illustrated by Bobby, and as collective effort towards skill building, as noted by Sam and Cameron. In the case of Payton, the experience was used to challenge previous notions of science as a solitary pursuit. Taken together, the students showed a collective approach to meeting the goals of the course, an essential component of community.

\section{Practice}

The third defining aspect of a CoP is the shared language, theory, and skills that members use when collaborating to address the domain, the practice itself (Cook \& Buck, 2014; Wenger, 1998; 2011). The concepts and habits of mind developed during the semester are explored more fully in Chapter V: Developing Ecological Literacy in the Field. Here the skills most important to the CoP are considered. In FBE 300, an important part of the practice was the ability to identify local plants. This skill was a necessary part of the citizen science project and key to legitimate peripheral participation. Handling the data thus generated also required comfort with the use of technology to collaborate in flexible groupings. Outcomes of the citizen science project were not limited to hard skills; students recognized the essential nature of the soft skills required to work together effectively. While collaboration is essential to community, students identified the ability to collaborate as a skill that requires active development, part of the practice of the class. 
Plant identification skills. Over the course of the semester, all participants developed a common set of skills related to plant identification, including vocabulary related to plant morphology and facility with the use of field guides. Evidence of this shared practice came from multiple forms of assessment including observations, journals, and exams. Payton demonstrated the use of his new vocabulary while describing an unfamiliar plant during an observation, "Each of these branches had multiple compound leaves off of it. They were not opposite of each other so I assumed they were alternative." While the terminology was not quite correct in this early entry, Payton showed a willingness to use newly acquired vocabulary. Over the course of the semester, these skills developed for all participants. Bobby noted her increased familiarity with field guides on the midterm exam when answering a practical question that required identification of trees from leaves:

Most of the leaves had specific features that stood out. This helped in the process of elimination when finding the name. Also, look for leaves that looked similar that were in the correct area of the book when I knew it was alternate or opposite.

While the skills developed in plant identification were necessarily for the citizen science project and were included in the overall learning objectives for the course, their connection to the domain of pre-service education was most important in terms of lasting impact. Taylor connected the skills of plant identification directly with the domain of pre-service education:

We went to observe and try to identify trees. This was very easy at first because we would just happen to find the right page in the book but after a while it was more difficult to identify the trees. Although, once we began to learn how to use the book, with some guidance, it became much easier. I thought this was a really cool idea, because not only 
was I able to learn a lot, but I feel this could be a good activity to use in my class one day.

In this way, Taylor put the activities into a context with personal meaning and application, a key step if the practice of the course is to make a transition to the participants' future educational practice.

Tools for collaboration. Throughout the semester, the students needed to organize, share, and analyze large amounts of data. Google Drive was suggested as a platform that would allow all students to contribute to common documents. While chosen for practical reasons of access and affordability, the technology became an important tool that enabled the practice of the course. In a journal entry, Payton recognized the benefits of being able to work together and negotiate how to handle data. He extended the practice to the central domain of pre-service education:

Working on Google docs in class has been really helpful. We are working together to fill an Excel spreadsheet with the information we are collecting from the tree survey. It has been beneficial to work on Excel too to learn more about it. Also it helps us learn more about collaborating with classmates to gather and fill in information. Google docs is a very beneficial tool and resource to use within classrooms. In Google docs you can use documents, Excel, and PowerPoint. You can have a large group of people working on the same project at the same time on the same document.

While Payton did not make a distinction between platforms used (e.g. Excel was used as a generic term for spreadsheet), he recognized the power of a tool that allowed for synchronous editing. This early practice of the class carried over to later projects when students were working in smaller teams. During the second project, Kit noted the continued use of the technology for 
the same reasons, "Lastly, we made sure to create a lab report in a Google document so we could all start working on it together."

Not all participants were as comfortable with collective data analysis and writing as Payton. Bobby expressed early concerns about writing as part of a team in a journal reflection: When assignments are given I enjoy working with my classmates unless it is a written assignment. I believe it's hard to write a paper for a group assignment because everyone has different writing styles and it can only be written one person at a time.

Bobby did not elaborate later in the course on whether the use of Google Drive helped with her initial concerns. While the use of this technology facilitated synchronous writing, it was less likely to reduce issues inherent to clashing writing styles. Rather having a shared set of documents required students to work together to determine how to best deal with all stages of the writing process. This led to classroom negotiations about logical organization of data and stylistic choices. Students were required to deal with differing opinions and how to reconcile their collective approaches. As noted in the researcher field notes, sometimes these differences were negotiated more agreeably than others. Not all students had a laptop, and at times when participants could not reach a consensus the person typing made the final decision unilaterally. Sometimes students felt adrift by the non-linear approach to working on the report. Alex summarized this issue in her interview:

... I guess in one sense I liked how we worked on it [citizen science data] all together before doing . . our second one. But then at the same time . . I just felt . . a little confused when we would spend the time in class to work on the different parts of it. Cause a couple times I worked on . . different pieces of it, but it was helpful then when we had. . . that last lecture and talked about the data. 
In this case, Alex would have preferred a less flexible arrangement where she worked on one part of the report to completion. While ultimately Alex felt the project made sense, the process of gathering the data and moving from one part of the report to another was uncomfortable for her during the early stages of the project. While collaborative data analysis was an important practice within the course, not all participants developed the same level of comfort or saw the same value in this level of collaboration.

Participants in FBE 300 formed a CoP within the course. They shared a domain as preservice educators, which expanded to include a shared sense of responsibility for data collection at New Woods Nature Preserve. They worked as a community as they developed the practice of nascent naturalists and tied that to their practice as developing educators. Overall, FBE 300 met the first criteria for a $\mathrm{CoP}$ framework. The remaining question centers on what outcomes participants associated with that framework.

\section{Outcomes Associated with Participation in a Community of Practice}

\section{Citizen Science}

During FBE 300, participants gained an appreciation for their ability to contribute to the scientific community as non-scientists, a key aspect to an expansion of their domain within the course. Their work as legitimate peripheral participants on a conservation project was a key part of making it real in the context of citizen science. Over the course of the first half of the semester, participants were able to articulate the nature of citizen science, the types of research projects where citizen science could be useful, and personal benefits to participating in citizen science.

Benefits to scientists. Participants generally agreed on the nature of citizen science. They saw citizen science projects as a way for non-scientists to be involved in long-term research by 
collecting data or working in conservation. Sam summarized the nature of a citizen science project on the midterm:

Citizen science is when people from the community who are not scientists assist with the collection of data or conservation of a scientific related area or study. We are displaying this by helping [New Woods] collect data for their forest.

Alex elaborated on the definition with reference to their specific practice, in this case a common set of data collection techniques and analysis:

This data was going into [New Woods's] records to understand what was growing in the area. After receiving some training, for example in identification, to determine percentage of cover, and how to measure $D B H$, we were able to collect our data, and I feel that even someone without a "science background" would be able to do this as well. In her description of citizen science, Alex emphasized the ability of a novice to provide good information to New Woods while also demonstrating the knowledge of what she learned as part of the process. This is the very nature of legitimate peripheral participation. The dual benefit of citizen science, both to the citizen and the scientific community, was articulated even further by Kit, "The term citizen science refers to someone that is taking time to gain scientific knowledge and sharing it with the community to advance science." At this point, Kit moved beyond citizen science as an approach to data collection and really described a citizen scientist.

Projects amenable to citizen science. While participants saw their contributions as real and worthwhile for New Woods, they recognized that as novices they were likely to make mistakes. This caused consternation at first, as was exemplified by Sam's initial discomfort. Overtime, their ideas began to change. Chris explained citizen science as a way to get a big picture understanding of an area under study, rather than as focused hypothesis testing: 
The data collected is very general and is not expected to be $100 \%$ accurate. It is meant to help scientists get a basic idea for what is happening, changing, growing, dying, etc. in an area. Citizen science was appropriate for this project because the scientists aren't wanting something as specific as, for example, the effect of burning on the height of sugar maple seedlings within a 100 m radius of the origination of the fire. They want a broad scope of what's going on $100 \mathrm{~m}$ off of the trail with the ground cover and the trees. Chris explicitly acknowledged that the participants might misidentify some plants during the study. While this could be viewed as a casual approach to data collection, students had a more nuanced view of their roles in the project. Part of their shared definition of citizen science was that the type of projects involved usually required large amounts of data collected over time. In this way, the impact of small inaccuracies could be minimized. Bobby noted that the quality of the data improves over time as more data is collected, "Although data may seem insignificant it will be better and more accurate with more data taken. At [New Woods] we took a lot of data about the plants and trees in the area we observed." Sam echoed this idea:

The park has been collecting data overtime ([FBE 300] did the same thing last year). They are building their data collection hoping that any mistakes along the way will even out over time. They are using an appropriate method because it will allow them to have a lot of data to analyze and draw conclusions from.

Rather than dismissing concerns about accuracy, the FBE 300 students gave an honest assessment of their nascent skills. Through this assessment, they recognized both the limits of a citizen science approach and what made those limits acceptable from the point of view of the naturalists at New Woods. This may also have reflected their growing understanding of the importance of sample size in terms of drawing conclusions from data. 
Personal benefits of citizen science. Beyond the benefit to the scientists studying New Woods, the students in FBE 300 recognized personal benefits of participating in a CoP through citizen science. The personal benefits were two-fold. The first was the increase in knowledge and skills that came from legitimate peripheral participation (part of practice) and the second was an increased sense of access that came from being part of a group working toward a common goal (part of community). Taylor summarized the first benefit in her final:

For this specific project, by doing citizen science we were able to learn more in depth about ecosystems instead of just listening to lectures and observing them. This time we were able to learn hands on the material, and more, while helping them collect data.

To Taylor, both lecture and observation were limited means of learning, a "just" approach to the topic. Sam expressed similar thoughts, "It [citizen science] also allowed for us to learn more about something that we might normally not have known about or investigated deeper." When identifying specific skills, participants tended to focus on plant identification and tools for collaboration. However, when reflecting on the nature of the experience, they mentioned the depth of what they were learning. Fieldwork at New Woods added dimension to the learning experience.

The second benefit of participating in the CoP was the sense of access that being a part of the project provided. In his interview, Payton noted that access in terms of equipment and expertise:

And getting us there and us able to use their materials and their resources to go out and do a survey. And to actually have the research we did there be studied by them is just kind of a neat thing to think about. 
Ability to use the tools of naturalists enabled Payton to collect that data that lead to a meaningful collaboration with the park. This access also came in the form of working in parts of the preserve that otherwise would have been off limits, as Sam indicated on the midterm, “ . . by having citizen science occurring they are also allowing outsiders to learn more and experience the nature preserve in a way they normally wouldn't be able to." While Sam still discussed students in the class as "outsiders," she recognized that they got a behind-the-scenes view of the preserve, which contributed to their learning.

Collaboration as a skill. Outside of specific field skills or ecological content, students focused on their collaboration as a skill in and of itself. While this was a personal benefit of the citizen science, it extended beyond the initial project and to the rest of the course. While this course was not the only time these students were required to work in teams, FBE 300 was seen as a way to develop along the continuum of collaborative skill. When discussing collaboration, the participants noted the positive impact of the specific course structures that were designed to enhance the formation of a CoP, including flexible grouping, partnership with New Woods, and fieldwork itself.

Payton frequently reflected on the nature of collaboration in journal entries, exams, and the interview. Partly he linked these reflections to a course on collaboration he was taking concurrently. As he noted in a journal entry:

Not only have we collaborated with the community, but we have constantly been collaborating with our peers in class. We have done a few group projects within which we are using our collaboration skills. Every time we have gone out to the [New Woods Preserve] we have worked in groups, sometimes groups we are not used to, and we have to use collaboration skills to get what we need to done. There are times collaboration can 
be difficult and conflict can arise. All peers might not be on the same page or might and might have a difficult time agreeing. This is where those collaboration skills come into play. How can we find a happy medium and make agreements that everyone in the group adheres to.

Payton acknowledged that the ability to work together was something that needed to be developed and practiced and that fieldwork provided this opportunity. Cameron reinforced this opinion in his interview, citing his personal growth as a team member:

Ifelt like when we did it [citizen science project] as a group, I always like doing group things like that because it really helps me with my ability to work with other people. You know all sorts of different types of people, so I really liked that. I got a lot out of that. I felt like that project went pretty smooth.

While developing meaningful connections with other students was essential to forming a $\mathrm{CoP}$, for the approach to have meaning long-term, participants would need to apply the lessons to in their classrooms. In journal entries, Payton and Cameron extended collaboration beyond their immediate circumstances and to their upcoming work as educators. Payton saw the class as a model for working with local partners that would expand what he could offer future students: So as an entire class we have been able to collaborate and some of us haven't even realized it. Not only did we collaborate with the [New Woods Preserve], but also the [Local] Botanical Garden. All it took was a phone call and we were allowed free access to observe the gardens. It was beneficial to see this, because it gave me hope as a teacher that some field trips can be more affordable.

Here Payton showed that he was considering ways to move student learning beyond the classroom, but was also anticipating economic barriers to doing so. The explicit discussion of 
how community interactions were established within FBE 300 provided Payton with an idea of how to reduce some of those barriers. The connection between the framework of FBE 300 and Payton's pre-existing domain as a pre-service educator was something Payton identified as not typical in a science content courses:

I truly think [FBE 300] has been a real learning experience, I've strengthened my knowledge in areas of teaching that I didn't think possible in a science class. I've learned how to effectively collaborate within the community and how to work better with peers. Cameron acknowledged that collaboration was a skill that required practice in his interview. This emphasis on the learning process was also notable in his journal entries. One way that Cameron connected the skills developed in FBE 300 with his future as an educator was to note his role in helping his students develop the ability to work together:

One of the biggest obstacles of becoming a teacher is [to] make sure your students can work with each other. In my personal experiences, some of my acquaintances have made me a stronger individual. This group work that we engage in is something I must pass down to my students.

Like Payton Cameron saw the challenges of incorporating the community aspects of FBE 300, but still thought the results were worthwhile. Working with others made Cameron stronger, and that was a strength he wanted to share with his students. To Cameron this was part of a pattern of development that should span generations:

I believe younger ladies and men out there must realize that they must find a mentor to help guide them. At the same time younger students must mentor someone else at some point in their life. These two tasks have allowed me to mature and grow stronger every day. 
Cameron's emphasis on growth and strength was especially important as continuing to develop as collaborators required effort from the class. These efforts were not without a degree of struggle that could be frustrating for the participants. While collaborative skill was noted as a positive benefit, not all groups worked well at all times, something mentioned by Payton. Other participants also alluded to tensions that arose in their groups or that they noticed in others. In her interview, Kit reflected on how she felt her team for the independent research project came together most successfully:

... I liked that [second] lab. I like that we continued to like work with a group on it. I know some groups . . our group worked the best, I guess, to say. I know the other groups have had problems. So, that's kind of sad cause I didn't want that to happen, obviously. But I liked working in a group.

Kit's comments accurately reflected that progress towards community was not always smooth. While participants acknowledged the benefits of working together, their skills as true team members were developing along with their skills as field researchers. Neither pursuit was without struggle. Ultimately for Kit, the work required to collaborate was well worth the gains that came from having collaborators:

And I would've rather worked in a group for that than by myself because I feel like that's a lot to take on individually. And I may have gotten like burnt out or like frustrated with it if I had to do it by myself. So that big of a lab, I wouldn't . . make students, personally, do it themselves either. So I was happy that we could still work as a team. Or even like if you wanted to make more groups, ... at least have a partner so you're not by yourself in it all. 


\section{Feeling Like a Scientist}

An essential part of FBE 300 was participation in research projects, a directed project in partnership with New Woods Nature Preserve, and an independent project developed by small groups of students working together. All of the participants expressed benefits associated with the legitimate peripheral participation in the citizen science project at New Woods, for themselves and for the naturalists at the park. Citizen science was an important subcategory of Making it real. In this way data collection was not merely a task to endure, but something that provided active benefit. Participation in citizen science was not the only aspect of the CoP that helped students with Making it real. Another important aspect was Work with meaning, whether or not that meaning was associated with citizen science. In journal entries and the interview, Payton and Sam expressed the personal meaning derived from their independent research projects including increased access to the tools of the ecological domain. Their use of equipment in an ecology research lab to analyze soil samples increased their sense of themselves as scientists. Payton described the experience in a journal:

This week in class I felt like an actual scientist. It was a very cool feeling to go out and collect soil samples from the [New Woods Nature Preserve]. Being a teaching major, I've never had the ability to do a full on science research project.

Payton differentiated the independent project as something that was "full on." To Payton the fullness of the experience was related to both the tasks conducted (collecting soil samples) and the equipment that was used. In a second journal entry he elaborated, "I enjoyed being able to run tests using scientific equipment, and actually get some experience of what it is like to be an ecologist." This gain was related to the domain of the CoP. Payton felt less like a student, or an 
educator, and more like a scientist while conducting the independent project. This was an interpretation that was supported during his interview:

I loved the last ... lab report activity. Because it just kind of made me feel like a scientist for the first time in my life. I mean it was just kind of ... a neat experience that you don't necessarily get in another class, you know. I just always thought that was kind of cool and not that I've ever . . . dreamed about being a scientist, but it was just kind of cool to experience it for a few weeks of a semester. To see what it's like and get my hands dirty. Go out to the [New Woods Nature Preserve] and use the tools to get the dirt out. Ijust thought that was a really neat experience. And walking into the soil lab and putting the stuff in the oven and the shakers. I just thought that was a really cool, unique experience that you're not going to find in many other classes . . . as a teaching major. So, I thought that was neat.

Sam expressed sentiments very similar to Payton, who was one of her partners on the independent project. In a journal entry, she also noted the access to equipment that felt different, more professional, than what was commonly available in a teaching lab:

For my last reflection I wanted to reflect on how I felt like a real life scientist during the lab testing part of our lab report. It was really fun and interesting to use and work with all the high tech lab equipment. I never would have thought that working with soil could have led to the use of such interesting process and tools. I really thought that this was going to be a boring lab report, "how do we have fun with soil?" Well I have been proven wrong ... However although all these experiences were fun and exciting, the most exciting of them all was the day when we used the syringe and the special filter on 
the syringe to extract the liquid from the soil that had been shaken for an hour. It was so fun to act like such a professional scientist.

While other participants in the class expressed satisfaction in the independent project, the specific concept of feeling like a "real" scientist, rather than as a student in a science class, was specific to Sam and Payton. This was true even though the data they were collecting was not part of an on-going project. Sam and Payton's group had agreed to share their data with New Woods, as they collected soil from the preserve, but in their journals and interviews they focused on the equipment they were using, rather than the contribution to the preserve. By engaging in the practice of ecologists using the tools of ecologists, Sam and Payton participated in the domain of research in a way that felt very real to them even if the participation was limited in scope.

\section{Sharing Experiences}

From the beginning of FBE 300, students were already immersed in a CoP as pre-service educators. Membership in this CoP did not preclude membership in additional CoPs and, in fact, people frequently work within multiple, sometimes overlapping, CoPs at different levels of participation (Wenger, 1998). Students in FBE 300 had entire networks of other associations prior to the class, whether or not those associations met all the criteria for a CoP. To what extent students would connect their experiences in FBE 300 with their participation in their other networks was unclear at the beginning of the course. During the semester, multiple participants referenced ways that they shared aspects of FBE 300 with colleagues, friends, or family members. By demonstrating their developing ecological literacy to non-members and by inviting important non-members into their experiences, students were able to bolster their place in the developing CoP of FBE 300. 
One of the ways participants expanded their participation in FBE 300 was by sharing experiences with family members, a way of building a community. Inclusion of family members in the course took a variety of forms. Sam shared both positive and negative anticipation about the course with her mother as indicated in an early journal entry:

I called my mom and told her about how we were going to be helping collect data for this nature center. I told her how I was excited [but also nervous]. She said that it would be great experience and to stay positive.

By the end of the semester, Sam was planning trips to take with her family based on experiences within the course. She talked about this in her interview. "And those [field excursions] are things that ... I still think about and ... want to go back to. I want my parents to come and be like we're going to [Great Egret Wetlands]."

The urge to take friends and family members to new sites was shared by Kit, who invited her mother to join her at a long-standing bakery that the class visited at the end of one field day: I think the most meaningful part was just the fact that we got to explore so much. Like going to ... [Great Egret Wetlands] and then [New Woods], and then even though the bakery wasn't technically science related, that was cool because, I went back there with my mom! And I was like you have to see this bakery, it's so cool!

FBE 300 was not the first time Kit was inspired to revisit a field trip location. Kit said that she took her family to a local museum after visiting it in a different science course. However, Kit noted that FBE 300 provided her with new knowledge of the area that she would not have had without the class. And while the first place Kit took her mother may have been a bakery, Kit was equally drawn to revisit natural areas she'd visited: 
... I think just like seeing new places that I never got to see and I wouldn't have found in [town], if it wasn't for this class, was just really cool. And I, obviously, went back and enjoyed those even more, so that's I feel ... my favorite part about this class was that I got to get out of the classroom and just learn more things. And make more memories.

The work outside of the classroom contributed to Kit's overall enjoyment of the class, but also to what she felt she learned, what she remembered, and what she felt was worth sharing with others.

FBE 300 participants also shared their class experiences with friends and family members in ways more directly tied to course content. Payton noted in a journal entry that he identified plants while engaged in extracurricular activities:

I've also been able to inform my teammates about certain types of trees. I also have been able to give them some different facts based on what we've learned in class... It's also fun being able to explain that information to other people! All of the field experiences have really helped!

By identifying trees to others, Payton engaged in the practice of the course by simultaneously practicing and displaying a new skill set.

Alex and Kit were able to expand their practice by engaging with family members through their hobbies. Alex connected her mother's interest in gardening with her plant observations:

Probably before this class ... I've never looked so closely at nature. ... My mom is a big gardener ... for one of my observations I did it just like around my house, so I had her kind of come with me and point out certain things. 
Alex took the details she learned from her mother and used them in further observations when she was back on campus. Kit followed a similar process. As she learned to identify more plants, she began to ask her father questions about how they fit into a garden:

... I never was like what type of flower is this? Why do we put this in this area of the garden? Why does it need more sun than this plant? . . I never was super interested in what type of plant it was. I enjoyed it. I loved being outside. But, and I think [my dad] got that from his mom, too. So it's kind of just gone down the line, but this class, I have asked him more, actually, and looked in our backyard than I ever have. And he was like 'what is happening? Why do you have this sudden interest.' I'm like, well cause I want to know what this is ... So I mean he had a lot of influence in this class cause I would ask him questions about things all the time.

FBE 300 was designed for students to develop their practice through extended collaboration in fieldwork. The open-ended nature of the coursework and the encouragement to seek out other areas for observation allowed Alex, Sam, Kit, and Payton to find other people to help further their practice. Kit and Alex expanded their burgeoning skill sets by drawing on the knowledge of family as they shared their newfound abilities and interests. Similarly, Sam, Kit, and Payton were able to add further meaning to their fieldwork by inviting their friends and family to share in their enthusiasm about local natural places.

\section{pK12 Community}

Ultimately the most important way for participants to share their FBE 300 experiences would be with their future classrooms. Evaluating future use of a CoP framework was outside of the scope of this study, however students' thoughts on incorporating aspects of the structure in the future were elucidated in multiple sources including journals, the final exam, and interviews. 
Participants primarily discussed the community aspects of a CoP, part of the role of collaboration. They emphasized both the benefits of pK12 student collaboration, in terms of shared sense making, and potential avenues for engagement with local organizations and natural areas.

pK12 student collaborations. In general, the potential benefits that participants saw for their future students echoed the aspects of FBE 300 that they identified as valuable themselves. In terms of a CoP structure, this included allowing future pK12 students to work together to draw on each other's strengths, and also so that they could see other students struggle. In a journal entry, Payton tied collaboration specifically to science inquiry to describe an environment where student learning extends beyond superficial understanding of content:

It [collaborative inquiry] gives you multiple creative minds working together towards a common goal. Children in class will have different ideas that they can bounce off each other. Inquiry also requires some trial and error, students will learn from their errors and work together to reach a common goal. . . One other benefit of inquiry is when students work together they learn different ways to problem solve from other students that they wouldn't of thought initially... It also promotes students to problem solve on their own, which gives them a deeper understanding of the subject.

Kit directly addressed the frustration that can arise from the trial and error approach to science education. In her final exam, she explained how collaboration helps students see each other's frustration in a way that ultimately aids their learning:

When students see that they are not the only one struggling this is huge to the student learning. The student knows that they are not alone and it is okay to be frustrated. The student may realize that they can work with others to gain new knowledge. 
While increased content understanding was considered one result of collaboration, participants also focused on affective benefits. Sam, Cameron, and Payton extended successful collaboration beyond the surface goal of learning to work together into a deeper task of understanding how different students approach learning based on individual student needs or cultural background. For Sam and Payton the emphasis was on the idea that not all students have the same preferences or instructional needs. Sam saw collaboration as a way for students to develop the give-and-take necessary to see other people's differences as strengths:

When I was a kid I was pretty structured. I still am really structured. But there's value in experiencing the non-structure ... Maybe your partner that you're working with ... doesn't think the same way as you cause they're a different person. They have a different brain. So you have to realize how to see things from other points-of-view . . . As much as you want them to see your structure side, you have to be willing to see their nonstructured side. And so, then with a classroom like... science... you can use your structuredness [to] write an amazing method section.

Payton extended this line of thought to consider how collaboration works in the context of inclusive classrooms. He acknowledged that not all students have the same degree of comfort in social situations, but he felt that working towards a collaborative environment was still an important goal:

Because, there's gonna be some students who aren't gonna be as keen to socializing with students as others. But, as [Dr. S] said ... as the year goes you'll get a little bit more used to it. The kids will ... hopefully get a little bit more used to each other, and I want to kind of ... push a little bit more collaboration on, cause I think it'd be beneficial for all students to work together, and use their strength and weakness ... to ... do different 
activities. Like have certain students help the other students . . or vice versa . . it might be difficult, especially with special education, and I've thought about it a lot ... it's definitely something I want to be able to implement in my future classes.

While Payton looked to inclusivity, Cameron considered multicultural approaches. He saw building classroom community as a way for students to learn about and from students with different backgrounds:

What I just think is ... wise for young students, young men and women, ... to be aware of the culture that's all around the world, to just not be center-minded and to only care about yourself. .. I don't know how big of an issue it is now days, I mean I'm sure it's still a monstrous issue, but so you're not discriminating ... You don't have any hate in your heart, that type of thing. I've always been a big fan of culture. So when you get in a situation when you're working with somebody that you're not sure about, or they may have a different culture, background, ... it doesn't make you feel uncomfortable inside ... I think that's a good tool to have for in the future.

Sam, Payton, and Cameron all gave considerable thought to how students could work together and come to see others' differences as strengths. Community collaboration was considered key to these efforts much as it was in FBE 300. Importantly, participants saw the benefits of these approaches even as they continued to struggle with them personally. FBE 300 was a class that functioned because of a willingness to collaborate, but those collaborations required real effort. As participants continued to build their own skills, they anticipated the struggles and benefits for their students.

Local engagement. Even as participants focused on getting their students to work with each other, they considered how to extend working relationships to neighborhood organizations 
and natural areas. Chris, Bobby, and Kit all recognized an opportunity for students to become active members of their neighborhoods. Chris saw this in terms of potential service projects: .. . even ... if it's just. . . cleaning up the community. I think community involvement is huge. Getting people in the classroom from the community... and going out into the community . . organizing family days where maybe we go out and do something like this on a Saturday morning for two hours. You know that would be really neat.

While Chris' ideas for a project were in their early stages, she indicated at least three levels of potential interaction: inviting outside community members into the classroom, taking students out into the community, and involving family members. Bobby drew on her personal experiences to reach a similar idea, but with a focus on where students might like to visit:

I think, maybe, reaching out to other organizations in the community, and trying to figure out something there, just taking them on small field trips to a pond. Or, I used to take nature walks in elementary school with my class. So things like that.

Even modest plans such as Chris and Bobby expressed are not always realized. Kit acknowledged that community resources might not be incorporated into curricula, even when they are readily accessible:

In my social studies methods class, we were talking about . . . how to get our students involved in the community, and I think not in social studies, but in every subject . . that's important to do. Because, they really realize how they can make an impact ... or . . just explore things that they can't - in the classroom there's so many more . . resources [limitation] — and I know it's hard to do with . . financial . . stuff . . [M]y middle school, we had a prairie path that you could walk, and I feel like there were so many more things we could've ... done to utilize that, especially after being in this class that 
I've learned that we totally did not ... We were in the class all the time.... I go home and ... I walk that program all the time cause I just find it beautiful. But, no, we never used

it.

Chris, Bobby, and Kit all indicated an intention to connect their classrooms with their local neighborhoods. They saw steps that could help them accomplish this goal, even as Kit acknowledged that even a small step might not be taken without dedicated effort.

\section{Conclusions}

At the beginning of FBE 300 the extent to which students would form a CoP was an open question; not all collaborative settings qualify as a CoP (Cook \& Buck, 2014; Wenger, 1998; 2011). In this case study, the formation of a CoP was aided by the fact that students had a preexisting domain, their pre-service education focus. Within this primary domain, their understanding of the work of a pre-service educator broadened considerably throughout the course of the semester. These changes were tied most closely to their experiences with a citizen science project. Participants were able to see how their research efforts as non-scientist educators could contribute not only to personal understanding of ecological topics, but also to broader research goals of nature preserve naturalists. This expanded understanding of science education was supported by their close collaboration with each other and with the local conservation community. During the process, participants developed a practice that included hard skills in plant identification, biodiversity survey techniques, and the use of new technology. Most significantly, participants began to apply their experiences to their future students by consideration of ways that $\mathrm{pK}-12$ students could benefit from similar fieldwork in collaborative environments. 
In terms of ecological literacy, the CoP structure of FBE 300, and specifically the project at New Woods Nature Preserve, aligned with participant knowledge development during the course. Jordan et al. (2009) outlined a framework for ecological literacy that included: "possession of habits of mind in ecology, understanding of ecological connectivity and key concepts, and appreciation of links between human actions and the environment” (p. 497). Participant gains in all three of these areas were associated with their involvement in the ongoing research project at New Woods. Students describe increased skills in plant identification and data analysis, they drew conclusions on the effectiveness of the conservation efforts at New Woods, and they were able to observe firsthand how human action impacted the nature preserve in both positive and negative ways. They explored local biodiversity issues through efforts that they viewed as meaningful and impactful. As a result, students identified both scientific learning outcomes and affective outcomes of the course as a whole and of the citizen science project specifically. The dual nature of the outcomes described by the students contrasted with other studies of CoP frameworks in environmental education, where affective gains were identified more often than cognitive gains (Aguilar, 2016).

Participants' emphasis on both the hard skills and the soft skills, such as collaboration, that they developed within the course was significant. A CoP is an expressly social framework for learning (Aguilar, 2016; Cobb et al, 2003; Cook \& Buck, 2014; Lave \& Wenger, 1991; Roth \& Lee, 2004; Wenger, 1998; 2011). Participants expressly recognized the ways that they learned with and from each other. This was seen as a positive aspect of the course and a way to prevent the scope of the research projects from becoming overwhelming. This is another area where students made direct connections to their future practice. They saw collaboration as a way for pK12 students to develop also develop both hard and soft skills, including the ability to work 
through frustration. Overall, the CoP framework was useful for both ecological literacy development and as a way to introduce field-based pedagogical approaches. 


\title{
CHAPTER V: DEVELOPING ECOLOGICAL LITERACY IN THE FIELD
}

\begin{abstract}
This chapter explores the degree to which participants developed their ecological literacy within a field-based course. Jordan et al.'s (2009) definition of ecological literacy was used as a framework to evaluate participants' developing knowledge, skills, and dispositions. Participants' developing ecological literacy aligned well with the framework's overarching domains:

ecological connectivity and key concepts, scientific habits of mind in ecology, and links between human actions and the environment. Participants showed growth in their foundational ecological knowledge and fieldwork skills as well as their understanding of human impact on local landscapes. They showed an increased tendency to see fieldwork as a viable form of science education and to recommend similar experiences for their future students. Greatest growth was seen in areas where participants had extended field experiences that allowed them to explore course topics on multiple occasions and in different settings. Active reflection was essential for connecting across course experiences and to participants' future careers. The framework was less useful for granular analysis of participants' developing ecological literacy. While participants made gains across all three domains throughout the class, they primarily developed background knowledge and fundamental skills that were not well represented in the framework's emphasis on higher-order synthesis.
\end{abstract}

Keywords: ecological literacy, habits of mind, dispositions

\section{Defining Environmental Literacy and Ecological Literacy}

Environmental literacy is a common goal without a common definition. Environmental education reform efforts are rooted in the modern environmental movement of the late 1960s, when the growing concerns about environmental damage that lead to the formation of the 
Environmental Protection Agency also led to efforts to improve the environmental understanding of citizens (DeBoer, 1991; McBride et al., 2013). The call to create an environmentally informed populace resulted in three major paradigms, each drawing from different disciplinary foci: environmental literacy (environmental education), ecoliteracy (humanities), and ecological literacy (ecology) (McBride et al., 2013). All three approaches have the potential for significant degrees of overlap, but they emphasize different priorities and educational outcomes. The tensions between the three approaches are explored in more depth in Chapter Two: Review of Literature. In this chapter, the main goals of each approach and how they relate to Field-based Ecology 300 (FBE 300) at Oak Savanna University are briefly addressed.

To the North American Association for Environmental Education (NAAEE) (2011, p. 23) an environmentally literate person is "someone who, both individually and together with others, makes informed decisions concerning the environment; is willing to act on these decisions to improve the well-being of other individuals, societies, and the global environment; and participates in civic life." This definition includes both knowledge about environmental issues and actions to address them, which are the hallmarks of environmental literacy (McBride et al., 2013). Ecoliteracy expands on traditional definitions of environmental literacy by emphasizing sustainability issues, including a social critical aspect to environmental education, and prioritizing philosophical and spiritual approaches to ecological understanding (CutterMackenzie \& Smith, 2003; McBride et al., 2013; Orr, 2005). In contrast to both environmental literacy and ecoliteracy, ecological literacy is a bit more tightly framed. Ecological literacy stems from the effort of practicing ecologists to forefront scientific principles in environmental education and, to greater or lesser extent, to emphasize science as a way of developing knowledge and the interface of ecology and society (Berkowitz et al., 2005; Jordan et al., 2009; 
McBride et al., 2013; Risser, 1986; Powers, 2010). All three approaches are found in the current environmental education landscape, and while they differ in theoretical underpinnings and disciplinary emphasis, they share commonality in inclusion of ecological knowledge as an essential component (McBride et al., 2013).

\section{Frameworks Specific to Ecological Literacy}

Even within the single goal of ecological literacy, multiple frameworks exist. McBride et al.'s (2013) review identified eight separate frameworks specific to ecological literacy. These frameworks date to Risser's (1986) address to the Ecological Society of America in which he outlined a starting proposition that ecological literacy should include "multi-media transport of materials, clarification of the 'everything is connected to everything' simplicity," "ecologicalcultural interactions," and "familiar ecological field observations" (p. 266). Risser's initial suggestions lead to a conversation on ecological literacy that ranged from up to 20 specific concepts to more conceptual approaches that advocated as few as three overarching themes, with earlier frameworks tending to be concept-heavy (McBride et al., 2013). Differences still remain, but trends seem to favor using frameworks that have fewer overall themes that are supported by the more traditional lists of concepts.

In this case study, the framework primarily used to evaluate participants' developing ecological literacy is that of Jordan et al. (2009). The authors suggested three broad domains: "understanding ecological connectivity and key concepts," "possession of scientific habits of mind in ecology," and "appreciation of the links between human actions and the environment" (p. 497). Within the domain of ecological connectivity and key concepts are eight threads, one of which is supported by a separate list of approximately 15 "fundamental ideas" (p. 498), whereas the latter two domains are illustrated with smaller lists of important ideas. The framework is part 
of the on-going refinement of ecological literacy, and the authors acknowledge that there are still questions about how to implement the framework in the context of ecology courses.

\section{Ecological Literacy in Field-based Ecology 300}

As a general education course at Oak Savanna University, FBE 300 is open to students of all majors, while course design emphasizes the needs of pre-service educators. To this end, reflection on how course content and pedagogy align with pK-8 science instruction is embedded within the class. Prerequisite to FBE 300, students must successfully complete a 100-level, inquiry-based science class. Several courses fit the prerequisite, so students in FBE 300 are not expected to share the same background in terms of specific scientific concepts. Rather, they share a common pedagogical approach within their 100-level classes that includes open-inquiry lab work addressing student-generated questions, instruction in descriptive statistics and scientific writing, and discussion of inquiry-based science education in $\mathrm{pK}-8$ classrooms. Consequently students in FBE 300 are not expected to have prior college-level instruction in ecology nor experience with field-based science. In this study, seven of the eight participants met the prerequisite through a 100-level, inquiry-based science course designed for $\mathrm{pK}-8$ educators. One participant met the requirements through a combination of separate science and education courses.

The ecological content goals for FBE 300 are informed by the position of the course within a general education program, the field-based nature of the course, and the organizational framework. As a course for non-science majors, the working assumptions were that students would have limited or no previous ecology experience at any educational level and that they would not necessarily take a second ecology course on campus. These assumptions are consistent with survey results on the inclusion of ecology in pK-12 curricula (Cutter-Mackenzie \& Smith, 
2003; Puk, 2003; Tal, 2008; Young \& LaFollette, 2009), and the requirement for pre-service education majors at Oak Savanna University to take science classes across multiple disciplines. As a field-based course, priority was given to ecosystems that could be studied locally. The focus on students' direct experience is in line with the goals of place-based education (Smith, 2002; Smith \& Sobel, 2010) as well as the goals of the general education courses at Oak Savanna University, which emphasize science as a way of developing knowledge. A citizen science project was chosen as the focus of the fieldwork in the first half of the course (discussed in detail in Chapter IV: Community of Practice in Field-based Ecology). This project emphasized collaboration towards a common goal meaningful to both students in the class and science professionals. The citizen science approach is consistent with using a community of practice (CoP) as an organizational framework for the class (Aguilar, 2016; Cook \& Buck, 2014; Wenger, 1998; 2011). The resultant ecological literacy goals for FBE 300 were to:

1. develop foundational concepts in ecology

2. emphasize field-based techniques as a way of developing knowledge

3. increase familiarity with local ecosystems

Additionally the course had a goal specific to pre-service educators:

4. make connections between FBE 300 and $\mathrm{pK}-8$ science education These concepts best aligned with the "key ideas" indicated by Jordan et al. (2009) as well as the emphasis on local ecology supported by both Risser (1986) and Berkowitz et al. (2005). A course outline aligned with frameworks for ecological literacy is provided in Table 2. While all four of the course goals relate to ecological literacy, the first two, to develop foundational concepts in ecology and to emphasize field-based techniques as a way of developing knowledge, 
are the main focus of this chapter. Goal three is primarily addressed in Chapters 4 and 6, while goal four is addressed in throughout the dissertation.

\section{Research Questions}

As a non-majors' course FBE 300 was designed to provide students who had limited background preparation in ecology the opportunities to expand their ecological literacy (CutterMackenzie \& Smith, 2003; Puk, 2003; Tal, 2008; Young \& LaFollette, 2009). As a field-based course, the focus was on principles and ideas that could be studied in the local context

(Berkowitz et al., 2005; Risser, 1986; Smith, 2002; Smith \& Sobel, 2010). Related to the goals of the course, two research questions specific to ecological literacy (EL) were developed:

EL1: How does the students' developing ecological literacy compare to the goals of FBE $300 ?$

EL2: How does the students' developing ecological literacy compare to established frameworks of ecological literacy?

The emergent questions stemmed from the first guiding question of this dissertation "How does pre-service educators' ecological literacy develop during a field-based course?” 
Table 2

Field-based Ecology 300 Topics and Alignment

\begin{tabular}{|c|c|c|}
\hline Period & Topic & Alignment \\
\hline \multirow[t]{2}{*}{$1^{\mathrm{a}}$} & Introduction to field-based observations & $\begin{array}{l}\text { Local observation (Berkowitz et al., } \\
\text { 2005; Risser, 1986) }\end{array}$ \\
\hline & $\begin{array}{l}\text { Defining species, population, community, } \\
\text { ecosystem }\end{array}$ & Organisms, populations, species \\
\hline \multirow[t]{2}{*}{$2^{\mathrm{a}}$} & Citizen science & $\begin{array}{l}\text { CoP (Aguilar, 2016; Cook \& Buck, } \\
\text { 2014; Wenger, 1998; 2011) }\end{array}$ \\
\hline & Plant identification & Local observation; \\
\hline 3 & Biomes & $\begin{array}{l}\text { Organisms; Regional and global } \\
\text { processes }\end{array}$ \\
\hline $4^{\mathrm{b}}$ & Intro to New Woods & Local observation \\
\hline \multirow[t]{2}{*}{5} & Thermodynamics & Energy flow \\
\hline & Macromolecules & Biogeochemical cycling \\
\hline $6^{\mathrm{b}}$ & Data collection New Woods & CoP and local observation \\
\hline \multirow[t]{2}{*}{7} & Energy flow & Energy flow; Trophic levels \\
\hline & Biogeochemical cycles & Biogeochemical cycling \\
\hline $8^{\mathrm{b}}$ & Data collection New Woods & \\
\hline 9 & Glaciation & Regional and global processes \\
\hline $10^{\mathrm{b}}$ & $\begin{array}{l}\text { Observations Great Egret Wetlands and } \\
\text { Glacial Dunes Preserve }\end{array}$ & Local observation \\
\hline $11^{\mathrm{b}}$ & Data collection New Woods & CoP; local observation \\
\hline 12 & Ecosystem services & $\begin{array}{l}\text { Ecosystem services (Millennium } \\
\text { Ecosystem Assessment, 2005) }\end{array}$ \\
\hline $13^{\mathrm{b}}$ & Data collection New Woods & CoP; local observation \\
\hline 14 & Species interactions & Organisms; population interactions \\
\hline $15^{\mathrm{b}}$ & $\begin{array}{l}\text { Erosion control fieldtrip including } \\
\text { Little Northern Wetlands }\end{array}$ & $\begin{array}{l}\text { Local observations; Human-actions- } \\
\text { environmental linkages }\end{array}$ \\
\hline 16 & Midterm exam & \\
\hline \multirow[t]{2}{*}{$17^{\mathrm{a}}$} & Work with pK-8 students & $\begin{array}{l}\text { pK-8 education (Smith, 2002; Sobel, } \\
\text { 2004) }\end{array}$ \\
\hline & Lesson plan workshop & \\
\hline \multirow[t]{2}{*}{18} & Succession & Succession (Powers, 2010) \\
\hline & Science inquiry & $\begin{array}{l}\text { pK-8 education (Lederman, } \\
\text { Lederman, \& Antink, 2013) }\end{array}$ \\
\hline 19 & Independent projects & Scientific habits of mind \\
\hline $20^{\mathrm{b}}$ & Observations New Woods & Local observations \\
\hline $21^{b}$ & Independent data collection & Scientific habits of mind \\
\hline 22 & Independent projects & Scientific habits of mind \\
\hline 23 & Independent projects & Scientific habits of mind \\
\hline \multirow[t]{2}{*}{$24^{\mathrm{b}}$} & Soil formation & $\begin{array}{l}\text { Biogeochemical cycles; Regional and } \\
\text { global processes }\end{array}$ \\
\hline & Observations Botanical garden & pK-8 education; Local observations \\
\hline $25^{\mathrm{b}}$ & Observations Animal park & pK-8 education; Local observations \\
\hline \multirow[t]{2}{*}{26} & Community ecology & Population interactions; Biodiversity \\
\hline & Biodiversity & Biodiversity \\
\hline 27 & Presentations & \\
\hline 28 & In-class review & \\
\hline
\end{tabular}

Note. Topics are aligned with fundamental ideas from Jordan et al. (2009) except where otherwise noted. For the sake of conciseness, citations are provided only the first time an alignment topic is noted.

${ }^{a}$ Denotes on-campus, outdoor experiences. ${ }^{b}$ Denotes off-campus, outdoor experiences. 


\section{Findings}

FBE 300 was designed as an introductory course in field-based ecology for pre-service educators. The course was broadly aligned with the ecological framework developed by Jordan et al. (2009) with additional focus on local ecology in line with Risser (1986) and Berkowitz et al. (2005). Of the four course-specific learning goals, the first two, to develop foundational concepts in ecology and to emphasize field-based techniques as a way of developing knowledge, are the primary focus of this chapter with goals three and four included when appropriate. Progress towards these goals and adequate alignment with the chosen frameworks of ecological literacy could not be presumed. Open coding was used on classroom artifacts including journal entries, observation notebooks, exams, surveys, and interviews to generate approximately 77 codes (See Table 3). Axial coding resulted in three major categories, Concepts, Human Impact, and Habits of Mind, with corresponding subcategories, all part of the theme Developing Ecological Literacy (See Figure 2). Student artifacts indicated that students' displayed developing ecological literacy aligned with the learning goals of the course. Their literacy was also broadly aligned with the major domains used by Jordan et al. (2009); however, student understanding was in the nascent stages and it did not map well to the specific examples of scientific habits of mind in ecology and ecological connectivity and key concepts provided by the authors. For purposes of clarity, both research questions are considered together when discussing specific findings. 
Table 3

Alignment of Data Sources with Emergent Questions Regarding Developing Ecological Literacy

\begin{tabular}{lccccc}
\hline Question & Exams & $\begin{array}{c}\text { Observation } \\
\text { Notebooks }\end{array}$ & Journals & Interviews & Survey \\
\hline EL1 & $\mathrm{X}$ & $\mathrm{X}$ & $\mathrm{X}$ & $\mathrm{X}$ & $\mathrm{X}$ \\
EL2 & $\mathrm{X}$ & $\mathrm{X}$ & $\mathrm{X}$ & $\mathrm{X}$ & \\
\hline
\end{tabular}

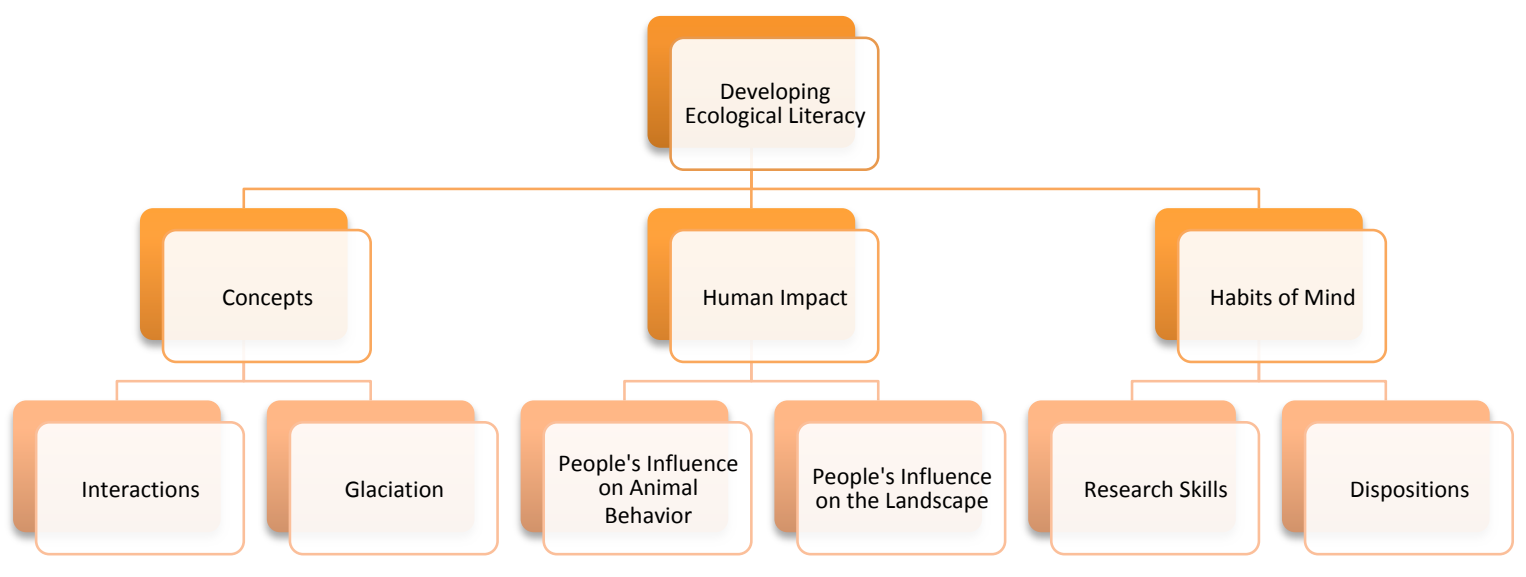

Figure 2. Organizational scheme for the theme, developing ecological literacy, with major categories and subcategories.

\section{Prior Related Experiences}

An underlying assumption when designing FBE 300 was that students participating would not have extensive preparation in ecology or environmental science. This assumption was supported by literature on inclusion of these topics in pK-12 curricula (Cutter-Mackenzie \& Smith, 2003; Puk, 2003; Tal, 2008; Young \& LaFollette, 2009). An open-ended survey was administered at the start of the semester to gauge participants' past experiences. The assumption 
was largely borne out in responses to the first statement, "Please describe your previous education in biology, earth science (geology), and/or environmental science." Of the eight participants, four mentioned a high school biology class explicitly with one also taking a dedicated environmental science class in high school. Two of the participants indicated they had taken biology at the college level. Generally students did not provide details beyond the types of courses taken, but Sam elaborated:

I took some of those classes in high school, but they were very general for the most part. I don't remember many specifics. I have taken [100-level inquiry course] and biology about three semesters ago. I learned a lot about cells, plants and human. While participants did not provide a lot of detail in terms of their courses, most did not have dedicated environmental education or earth science past the middle school level. The majority of courses as described were surveys of general biology.

Participants were also asked what kind of outdoor activities they remembered as part of their previous education. Two participants indicated they did not have or did not remember any such activities. Two participants indicated experience working with $\mathrm{pK}-8$ students outdoors as part of a college-level course in education or as part of their 100-level prerequisite science course. Five others listed a range of activities. Bobby remembered, "Looking at things in a pond under a microscope, collecting leaves, swim lessons, and getting in touch with my five senses outside." Kit experienced, "nature walks, several outdoor field trips, parks, recycling trips.” Alex noted, "I remember doing 'outdoor ed' when I was very young, elementary school, using compasses, learning about nature and wildlife, etc. In high school biology I also remember doing some outdoor activities." Sam had the most extensive list including, "erosion activity, air pressure, wind, plant/leaf searching, Newton's laws, butterflies, apple growth and development, 
stars/space gazing, kites, rockets, sun/UV rays, water, bio-fuel/alternative energy." Chris noted that there was an outdoor classroom at her high school, but not what was taught there. Overall, the participants in FBE 300 recalled more outdoor education than expected based on a study by Blatt and Patrick (2014) who found fewer than 15\% of the pre-service educators surveyed reported outdoor experiences in school. While $75 \%$ of the participants in FBE 300 indicated previous outdoor education, their descriptions were not indicative of extended experiences or field-oriented courses. Based on responses to the survey, the assumption that participants had limited experience with field-based ecology was supported.

\section{Emergent Ecological Concepts}

Based on student artifacts, two broad categories of ecological concepts developed, those related to Interactions within ecosystems and those related to Glaciation. Interactions were noted at the ecosystem, community, and population levels, whereas glaciation was considered in terms of landscape formation, subsequent changes, and evidence. These concepts reflected both the course schedule and alignment presented in Table 5.1, indicating that the enacted curriculum was in line with the intended curriculum. Student artifacts showed a range of understanding for each topic, but student statements were generally at the level of the fundamental ideas outlined by Jordan et al. (2009), rather than their eight, higher-order statements on ecological connectivity and key concepts.

Interactions. Students' use of the terminology to describe the environment varied at the beginning of the course, but tended to focus on common-language use. In his interview, Payton explained his understanding of ecosystems at the beginning of the semester, which was illustrative for many incoming students: 
I knew what an ecosystem covered. Very basic . . . material, but I didn't know ... how in depth it was, and what the different types of topics were, and that it involved species and all the different stuff. I was just thinking Earth ... stuff about the earth, and . . I didn't think about. . . everything else that goes into it like the living and non-living things.

In contrast, Cameron started the semester with more confidence in his background as noted in his interview, but still saw room for growth:

To be honest with you, I knew a lot about biomes. I knew a little bit about that, but . . . there was new information there I wasn't aware of. I think you strengthened my knowledge and relationships between species a little bit. I think just going out there in the field and learning ... how things work.

In order to develop a common vocabulary, the first class period included an observation period followed by a group discussion as a means to distinguish between an ecosystem, a community, and a population. By the midterm, some students were able to sketch the relationship clearly, e.g. a nested diagram by Kit showing a population within a community within an ecosystem or a three-panel sketch by Chris showing the same relationships, but confusion still remained, as in this quote from the midterm, where Bobby's used a mix of common and ecological definitions: As I continued working at [New Woods], I was able to explore the variety of plant and animal life in the woods. I saw bite marks in leaves, various animals, and trees standing or fallen over. Each of these observations was the contribution of the community, populations, biome, and ecosystem. All of these aspects keep the area present and successful. The species would [n't] be there if it weren't for the particular biome it's in and the community conserves the park so that there is a population of species. It's important that these aspects continue to [th]rive so that it stays intact. 
Also on the midterm, Taylor indicated that a community includes more than one population, which was also apparent in her sketch, but was less clear on how this related to plants identified in the field:

[Working at New Woods] also allowed me to learn the difference between a community and a population. [New Woods] had many small populations of plants, but overall the forest as a whole was a whole community of plants. It was a good learning environment because we were able to learn how to identify the plants and then decide if it were a population or a community.

Overall direct experiences helped to bolster vocabulary, although students differed in their fluency in usage. This pattern was apparent when discussing more complicated concepts that involved environmental, community, and population interactions as well.

Energy flow and biogeochemical cycles. Beyond providing definitions and using them in context, FBE 300 focused on foundational ecological concepts (See Table 5.1). Energy flow and biogeochemical cycles were presented in lectures within the class and revisited several ways throughout the course with two student groups choosing to focus on different aspects of nitrogen availability for their independent research projects. Direct information on participants' understanding of energy flow and biogeochemical cycles came from the midterm and the final. Each exam was divided into a series of topics with multiple short answer questions in each topic. Students needed to respond to ten questions with at least one question coming from each topic. Participants could choose from 17-18 possible questions. As such, participants' choices reflected what they felt best prepared to answer, but they could not avoid topics all together. 
All students were able to provide some details on energy flow and biogeochemical cycles. Bobby illustrated the difference between energy flow and a biogeochemical cycle on the midterm:

Energy flow is when the ecosystem works by one thing affecting the next. It is on going and does not go backwards [sketch of food chain]. A nutrients cycle in an ecosystem is a pattern the environment follows [sketch of arrows forming circle]. Certain things will happen multiple times and cause something that leads back to another effect. There is no beginning or end.

Sam's responses on the midterm were exemplary of the students who understood the material well as she discussed energy:

Energy flows refers to the idea that energy functions in an open system. Energy cannot be created or destroyed but it functions in a linear formation. ex: sun $\rightarrow$ producers $\rightarrow$ consumers $\rightarrow$ decomposers; producers $\rightarrow$ decomposers

Photosynthesis and cellular respiration contain the same chemical equation but opposite each other. For example, photosynthesis is the process of plants making energy and starts with $6 \mathrm{CO}_{2}+6 \mathrm{H}_{2} \mathrm{O}$ but then ends with $\mathrm{C}_{6} \mathrm{H}_{12} \mathrm{O}_{6}+6 \mathrm{O}_{2}$. However cellular respiration is the process by which humans create energy and we start with $\mathrm{C}_{6} \mathrm{H}_{12} \mathrm{O}_{6}+6$ $\mathrm{O}_{2}$ and end up with $6 \mathrm{CO}_{2}+6 \mathrm{H}_{2} \mathrm{O}$. Which is then released into the air for plants to use for photosynthesis. The two (photosynthesis and cellular respiration) are vital to each other.

Sam's responses were also an example of the way students move back and forth between scientific phrasing ("energy cannot be created or destroyed") and common usage ("process of 
plants making energy" and "process by which humans create energy") in a way that could indicate lingering misconceptions. In her discussion of the carbon cycle, Kit could articulate several ways carbon moves through the environment, but still had a lingering misconception of how plants get carbon:

The sketch drawn is a representation of a carbon cycle. The nutrient moves from the atmosphere into the soil which is then taken in by plants and either brought back into the atmosphere by cellular respiration or continues in the process being consumed by animals/humans. Atmospheric carbon can also be produced from fossil fuel emissions. Also it can be evaporated by water sources such as the ocean.

Payton's response indicated some of the challenges of the classroom approaches that considered energy flow and biogeochemical cycles together. While he understood how phosphorus could move through an ecosystem, he had difficulty reconciling the language of producer and consumer:

Cows are a producer of phosphorus they gain it from eating the vegetation, which has been fertilized by phosphorus through waste of consumers and producers of phosphorus. We as humans eat producers of phosphorus and we return it back to the earth within our waste. Fungi is also a decomposer of phosphorus, it breaks it down and returns it to the soil and vegetation.

Encouragingly, students made efforts to connect material across different experiences. Payton specifically mentioned fieldwork when discussing biogeochemical cycling on the midterm:

One in particular was the cycling of nutrient cycles. When [Cameron] and I tore apart the decaying log I was able to see nutrient cycling first hand. I saw the different fungi 
that were growing on the wood, helping it break down. I saw the hundreds of different insects that have claimed the log as their home all working and helping the decomposition process.

The connections made in this written assessment were an indication that Payton saw the lecture and field portions of the class as a cohesive whole, rather than two separate experiences.

Cameron also made explicit connections during his interview between biogeochemical cycles in FBE 300 to other classes and drawing new insights into previous coursework:

... for example, the ocean acidification ... I didn't know much about that. I think a lot of the terms that I've learned through [intro chemistry] and the early bio classes, ... it's made those concepts more concrete. . . But I think you locked up those cycles really well. I mean just knowing how they interact in chemistry labs and everything ... it just made more sense. The triple bond of the $N_{2}$, and a lot of things like that.

Participants were able to distinguish how the movement of nutrients in an ecosystem differed from the flow of energy. In sketches they could show abiotic and biotic transitions. They also related classroom lecture and discussions spontaneously to field experiences. These outcomes were in line with learning goals one and two for the course (EL1), likewise energy flow and biogeochemical cycling were two fundamental ideas identified by Jordan et al. (2009) (EL2). That said, student responses indicated that they were still in the early stages of developing their understanding and that in some cases misconceptions still persisted (e.g. plants' primary carbon source). Their ability to connect energy flow and biogeochemical cycles to broader topics also varied, as was seen in the case of ecosystem services.

Ecosystem services. Ecosystem services were addressed both as a lecture topic and in the field at New Woods and Great Egret Wetlands. For purposes of class, the model from the 
Millennium Ecosystem Assessment (2005) was used, which defined ecosystem services as "the benefits people obtain from ecosystems" and categorized them as "supporting," "regulating," "provisioning," and "cultural" (p. v-vi). As a class topic, ecosystem services were emphasized as way to provide context for the fieldwork and to increase the personal relevance of course content. Ecosystem services also aligned with Jordan et al. (2009)'s eighth key idea, “Ecological literacy allows people to understand connections between themselves and ecological processes, and can help them to make informed decisions about environmental issues" (p. 498).

Students showed a range of interpretation of the model. Alex exemplified someone who understood the model well and could apply it to field experiences on a response from the midterm exam:

Ecosystem services refers to the benefits that people can gain from an ecosystem. At [New Woods], both supporting and cultural ecosystem services take place. Supporting services include when nutrients, such as nitrogen, carbon, phosphorus, and water are cycling through the soil, through the plants/animals that live there. Also, the supporting service of primary production, via photosynthesis, is constantly occurring as the sun provides energy for the plants to produce food, which serve as food for other animals as well.

Regarding cultural services [New Woods] provides a setting in which recreational activities can take place as evident by the many walkers and hikers who make use of the available trails. Additionally, it provides the cultural service of education as it provides a setting through which we can learn more about the specific types of vegetation present there as we've been working on data collection for the park's records. 
This contrasted with Chris' response on the final exam, which indicated a common misunderstanding of the topic:

Ecosystem services are things that are done either intentionally or unintentionally to promote the health and wellbeing of the system. At [New Woods], we saw regulating with the controlled burns in the forest, and promoting with all of the native prairie grass growing throughout the park.

The misunderstanding could stem from the structure of the class. Fieldwork in the first half of the course centered on collecting data for New Woods Nature Preserve. Students knew that park naturalists used the data to help evaluate their conservation efforts within the preserve. A second source of confusion could be students' continued efforts to reconcile their understanding of the model with their primary understanding of the vocabulary used in the model. In this case reasoned conclusions of what, for example, a regulating service could be lead to incorrect conclusions. As Payton said on the midterm, "It also is a regulating service as well. There is a prairie preserve on the grounds that are nationally protected and regulated by the park district." Ultimately both sources of confusion probably contributed to student responses. Taylor directly connected the conservation work at New Woods with regulating the ecosystem, while understanding the cultural benefit to visitors at the park:

Ecosystem services are those things that keep the ecosystem populated and changing. At [New Woods] there are signs of regulating and cultural services. The first one being the reason we were there, for educational purposes. This would fall under cultural services, or how people enjoy the ecosystem. The second one being the regulating services, or how the ecosystem continues to change and its environment regulated. This would be done by 
controlled forest burns to get rid of the invasive species and keep the native ones. This helps to regulate how [New Woods] continues to grow and change.

In this case, Taylor's understanding of an ecosystem service as something done to an ecosystem to keep it healthy lead to an incorrect understanding of a regulating service while still allowing for a correct understanding of a cultural service.

Succession. As a field-based course, emphasis was placed on topics that could be explored first hand near campus. At a Midwestern university, that included exploration of restored ecosystems in areas previously used for agriculture. Succession was therefore an important avenue for discussion. Powers (2010) also included succession was one of five main concepts for ecological literacy in non-majors' undergraduate courses. Student generally were able to articulate the role of disturbance and provide examples for both primary and secondary succession, as Taylor noted on her final exam:

Primary succession is when there is a disturbance that comes through and doesn't leave any sense of life after, but it leaves behind other things. Primary succession is like when a volcano erupts. The volcano is the disturbance and it kills everything in the area, leaving no sense of life, but leaving volcanic ash behind. Secondary succession is when a disturbance comes through but there still is little signs of life, such as soil or seeds. This is similar to farming where the farmers plow through the area, destroying all the crops, but leaving seeds behind.

Kit provided a similar answer, citing the other major source of secondary disturbance related to coursework, in this case fire:

Primary succession is an area that has been destroyed or disturbed and no plant or animal life is sustainable because of the damaged soil. An example of this would be when 
lava forms \& hardens. Secondary succession is when an area is disturbed, however sustainable life may occur and an ecosystem may develop. A disturbance of secondary succession is wildfires. A plant that may be a pioneer species during this succession is fireweed.

While both of Taylor and Kit provided examples that were locally relevant, they did not make clear connections to fieldwork from the course. On the final, Bobby worked to connect the lecture material to experiences within the course:

However, if there is secondary succession that occurred, living things are able to reform the ecosystem. These disturbances could be a fire or farming. We can see that [Great Egret Wetlands] is a clear example of secondary succession after farming.

In the case of succession, students drew from examples from lecture and videos shown in class. Several students referred to fire as a source of disturbance in a way that related to their fieldwork, but Bobby was the only student who made a direct connection on the exam to a specific field site. Whether this was an artifact of how the material was presented or how the exam question was worded was unclear. On the final, students were asked to describe a "scenario" for primary and secondary succession, but a locally relevant scenario was not specified.

Community as dynamic. Succession was part of a recurring thread centered on changes in ecosystems with time and use. Course design was meant to emphasize that "nature" was not static, nor did it exist separately from human influence (Berkowitz et al., 2005; Jordan et al., 2009; Powers, 2010). Part of this thread highlighted changes in communities. Participants recognized communities as dynamic by describing differences in native versus invasive species, changes in biodiversity, and the role of controlled burns in local conservation efforts. 
Native and invasive species. Concepts related to native and invasive species were included in FBE 300 through lecture (community interactions), video, and fieldwork. Participants generally distinguished between native and invasive species based on how an organism was introduced an area, length of time the organism lived in an area, and impact of the organism on the community. Participants recognized that both plants and animals could serve as examples of native and invasive species. Overall, their explanations were fairly consistent and included local examples. On her final, Chris emphasized native and invasive plants:

An invasive species is one that either overpowers and prevents the growth of other plants by taking its nutrients, water supply, sunlight etc. These plants are often rapid growing. An example of an invasive species of plant is the ivy that often grows up tree trunks and other plants. This is of concern because the ivy climbs towards the sun no matter what, so it often prevents native plants from being able to photosynthesize causing them to die. Native plants are plants that grow in a specific region or regions, such as prairie grasses, and do not typically spread as rapidly or prevent other plants from being able to live.

Chris' response emphasized a specific problem, although the details of the plant itself were left hazy possibly because she was not describing an organism that we had seen locally. Sam provided a similar summary on the midterm for directly observable invasive animals: Invasive species: organisms that are not originally from (or native) to the environment they are currently living in. Asian carp are an invasive species to the [River]. It is concerning because it will (could) out compete the native organisms that are currently living there. They are becoming bigger and stronger than the native organisms of the [River]. There are not as many original (native) fish left in the river now. They are also 
dangerous because of how they jump due to the vibrations of boat motors. This is a threatening/harmful effect they created indirectly as well. They are so big and heavy they could knock a person on a boat out if they hit them.

While Chris and Sam centered on the harm that invasive species can cause in ecosystems, other participants also included the relative length of time an organism has been present in an area and how it arrived. As Bobby noted, "A native species is one that has built a life in particular area for a long time and is positively contributing to the ecosystem." Cameron discussed this in terms of native fish, "A native species is a particular organism which is known to come from a particular area. That organism has probably inhabited that area for hundreds maybe thousands of years. An example would be the flathead catfish in the [River]." Other participants noted how the organism came to be in an ecosystem. For example Kit said, "Native species are species that were born/originally developed in that area and make up the ecosystem." Alex provided a similar explanation, "A native species is one that [is] naturally occurring in a particular area, for example big bluestem prairie grass."

Participants' explanations were remarkably consistent on this topic both in what was included and what was absent. Explanations did not include reference to either adaptation or evolution. This was a missed opportunity in the course to explore the relationship between ecology and evolution more explicitly. Evolution and adaptation were discussed in context, but a dedicated experience on connecting evolution and ecology was not included. The relationship between evolution and ecology is a key idea in Jordan et al.'s (2009) framework, but it is an acknowledged limitation of textbooks and instruction (McComas, 2003). As such, a dedicated experience connecting evolution and ecology is recommended early in instruction and should be reinforced in subsequent fieldwork and class discussion. 
Controlled burns and biodiversity. Participants extended their understanding of native and invasive species by connecting their definitions and examples to discussions of their experiences in the field and to biodiversity. As they collected data for New Woods, participants learned about the use of controlled burns to reduce the impact of invasive species and to promote native biodiversity. Chris and Taylor noted the importance of controlled burns as a way of removing invasive plants on their midterm exams. Chris put this in the context of the most common field site, "At [New Woods], the area with our transect in it showed regulating by being burned off every year to prevent invasive species from overtaking the area." Taylor focused on Glacial Dunes Preserve, a more distant field site that was only visited once, "There are also many different plants here [Glacial Dunes Preserve] which are supported by creating a controlled burn to get rid of the invasive plants."

While both participants noted the importance of the control efforts to support native plant diversity, neither used the specific terminology. Discussions on the impact of invasive species and the use of controlled burns to promote diverse native plants were present throughout the semester. However, a formal lecture on biodiversity was only included as a culminating summary at the end of the semester. This was partly by design, as the instructors encouraged students to independently research information on community ecology as part of their work at New Woods. Early discussions of their fieldwork reflected this approach, as students used less technical language to discuss plant diversity at different field sites. As Chris noted in an early journal entry:

I've never given much thought to the ground cover in the woods, because I always just assumed that if it survives under the canopy and makes it into a full fledge plant, then it was meant to be there. However, after giving the concept [undergrowth] a considerable 
amount of thought, I can better understand and appreciate the idea of collecting data and understanding the changes taking place on the forest floor.

By the end of the semester, Alex provided this summary in a journal entry:

In class today we had a culminating lecture about communities, during which we discussed the findings from our data taken at [New Woods]. Three terms which we discussed were richness, the number of species in a sample, abundance, focusing on how much of each species was present (which can be measured in terms of density, basal area, biomass, frequency, and cover), and importance, suggesting the impact of both amount and size.

At [New Woods] importance values for both ground cover and the overstory were calculated. It is important to recognize that importance involves the addition of relative density (individuals of one type divided by individuals of all types) and relative dominance.

Both entries imply the students were thinking about their data in terms of what it meant for New Woods Preserve and their understanding of the ecosystem. Ultimately the technical terminology was useful, but not essential for students to see significance of controlled burns and the importance of studying the plants at New Woods to measure its effectiveness. This is significant as ecological literacy aims for an informed populace with the ability to make judgments on important issues (Jordan et al., 2009, key idea eight). Participants are unlikely to retain the formula for importance value, but they may remember that controlled burns help regulate invasive species. Ultimately the latter is more important in terms of understanding local conservation and restoration efforts in the future. 
Species interactions. The course emphasis on the dynamic nature of ecosystems and communities included time spent discussing basic species interactions. Major topics of discussion included competition, symbiotic relationships, and predator-prey relationships. While these were considered during one lecture section, as with other topics in the course, effort was made to introduce and reinforce ideas during the fieldwork.

On exams students were able to define both interspecific and intraspecific competition. Kit explained the difference on her midterm:

In a competition interaction between species in an ecosystem, there are two types (intraspecific and interspecific). Intraspecific competition is a interaction between two of the same species and they are both negatively impacted (-.-). An example would be two birds trying to fight for a worm, neither of them get the worm because it goes back deep into the soil. Interspecific competition is the interaction between two different species and both are negatively impacted (-,-).

Participants felt comfortable with the definitions of interspecific competition and intraspecific competition as was evidenced by the frequency with which they chose the topic on the midterm, but there was evidence that students were considering the topic beyond answering exam questions. As Payton noted during an observation on squirrels, "But even animals of the same species can have conflict, a battle for a home, a battle of dominance, and a battle for a mate. We learned in class that this was called intraspecific competition." This was not particularly surprising. Regardless of whether a student had studied competition previously, the term is used in much the same way to describe species interactions, as it is in common parlance. This common understanding of competition may have impacted retention of the distinction between interspecific interaction and intraspecific interaction between the midterm and the final exams. 
Both Payton and Cameron correctly identified interspecific and intraspecific competition on the midterm and reversed the designation (inter vs. intra) on the final.

Perhaps more interesting than being able to define competition were the examples that participants used to illustrate the concept. Participants used both locally observable examples (e.g. deer, squirrels) and more exotic choices (e.g. lions, alligators, hyenas). In some cases, students showed more surety of the exotic examples than they did of their local choices, as Sam did on the midterm:

Interspecific competition: a competition between different species for the same resource. Ex: Let's say hawks and crow both prey on mice. They are competing against each other for the mice.

This [intraspecific] is a competition that is between organisms of the same species. Ex: two lions are preying on an antelope. They are competing against each other for the antelope.

Sam seemed unsure of what crows and hawks eat, but was comfortable saying that lions eat antelope. This was just one instance, but it is in line with observations that students are often more familiar with distant ecosystems than they are with what can be studied in their own backyards (Louv, 2005; Lorsbach \& Jinks, 2013; Sobel, 1996).

Students were able to similarly define parasitism, commensalism, predation, and amensalism. As an artifact of test construction, students were never asked to define mutualism. Here again the examples were more illuminating than the definitions. As Alex wrote on an exam, "Amensalism is when one organism is harmed and the other is not. For example, when we walk off trail at [New Woods], we are harming the grasses/forbes/saplings, however, we are not 
impacted by this." Our work at New Woods was included in classroom discussion as a trade-off where being off-trail provided valuable information, but not without a cost. This apparently made an impression, as Kit and Sam also noted the issue on exams. This recognition was especially strong for Cameron, who noted a change in attitude from his childhood during his interview:

I love the outdoors. Love the ecosystems. And one thing you made me aware of is; you know when I was a little kid I would just rip bark off and destroy stuff, and to be honest with you I'm not going to lie to you about that, and now you've really gave me a more conscious thinking about that ... I don't necessarily just go uproot a tree that's newly grown, now. I don't know how you did it, but . . I think before I do things like that now. While the discussion of amensalism was not directly about human impact, in this case, simply making participants aware of the damage that they could cause was enough to cause reflection and possibly behavior change. This could be especially important to keep in mind for pre-service educators studying field-based ecology, as they may benefit from explicit discussion of the costs and benefits of letting pK-8 students freely explore ecosystems.

Glaciation. As ecology is inherently a multidisciplinary field, earth science concepts were also included in course design. Historical climate change, soil formation, and erosion, including evidence and impact on the local landscape, were considered in lecture, classroom discussion, and on multiple field trips. As discussion of soil and erosion centered largely on land use, they are considered as part of the category, Human Impact. Here glaciation as a fundamental concept is discussed.

As a course centered on Midwestern ecology, continental ice sheets were emphasized as a major contributor to the landscape. A lecture was dedicated to the glacial history of the region, 
including the evidence for glacial advance and retreat. Field trips to see glacial deposits and to consider their impact on plant and animal life were also included. Ultimately participants' gained an overall view of how glaciers contributed to the landscape, but their understanding of the details was mixed. Alex represented a high degree of overall understanding:

Evidence of glaciation includes loess and erratic rocks. Both represent material that has been carried from another geographic area. Loess is soil that has been carried by wind from another area, while erratics are rocks that have been picked up and deposited by glaciers into a new area. (They have a different chemical composition than the rocks of the area they are in).

As a result of glaciation, end moraines, ground moraines, and the cliffs for example... have formed. End moraines are long, low ridges compared to ground moraines which are rolling hills (and less common). The cliffs . . resulted from the breach of a morainal lake, formed by a melting glacier during the Wisconsonian glacial period.

Cameron expanded:

There are end moraines in [Midwest] that are areas where glaciers stopped advancing. The glaciers melt and leave traces of rocks and minerals, which are not native to that area. There is also loess which is debris blown which was left by a glacier. It usually deposits the remains in an area, which is not native to that debris.

Sam tied in specifics from a field trip, "With the [Glacial Dunes Preserve] the sand was brought there just like the [Great Egret Wetland] water with the help of glaciers." In general participants were able to describe glacial features of the Midwest, although they varied in their understanding of detail. Notably, they had a hard time explaining how glacial deposits could be responsible for 
both hill formation and for the flat areas of the landscape. They were also inconsistent in their identification of loess.

Perhaps more interesting than the specific details that participants could provide was their tendency to apply their understanding of glaciation to explain their observations from throughout the Midwest and surrounding regions. Several students wrote about observations from previous travels or from trips made during the semester that were unrelated to class. As they thought about where they had been, they indicated how glaciers might have contributed to their formation. This included the flint hills of Kansas, sandstone formations of southern Illinois, and features of the Appalachian Mountains. In these cases, the students were not correct in their explanations; however, it did show that they were using the course to try to make sense of their surroundings. This is a double-edged sword, as it can lead to misconceptions, but it was evidence that students were thinking about course topics in personally meaningful contexts and they were looking at natural areas as a place to learn more about concepts that are frequently confined to the classroom.

\section{Human Impact}

While defining the scope of ecology education, there is an open question to the extent that environmental problems should be included, or even fore-fronted. Earlier approaches to environmental education emphasized the identification and amelioration of environmental problems (Hungerford, 2010; McBride et al., 2013; McComas, 2002). More recent efforts at delineating ecology education have varied in the degree to which they include environment problems. Most frameworks for ecology education include aspects of human impact on the environment, but there is still a question of how to include environmental issues without blurring 
the lines between environmental science, ecology, and environmentalism (Jordan et al., 2009; McBride et al., 2013; Powers, 2010; Risser, 1986).

Within the context of FBE 300, certain local environmental problems were inevitably highlighted. Discussions in class and in the field focused on the issues most immediately relevant to the ecosystems actively being studied. Analysis of student artifacts resulted in the category of Human Impact in line with Jordan et al.'s (2009) category of "appreciation of the links between human activities and the environment" (p. 497). Human Impact was divided into two subcategories, People's Influence on the Landscape and People's Influence on Animal Behavior. While discussions of people's influence on landscape were built deliberately into the course, concepts related to people's influence on animal behavior arose more spontaneously as a result of student interest.

People's influence on the landscape. Participants' comments on how people influence the landscape tracked closely to concepts from lecture and to what they observed in the field. While students had a set of common experiences and could discuss them in similar ways, participants emphasized their experiences, and as a result specific human-environmental actions, to different degrees. While many of the impacts students noted were negative, the ability for people to have a positive, or at least mitigating, impact on the landscape was also noted. Overall, participants showed some interest in conservation and restoration efforts, cultivation, nutrient availability, and erosion.

Conservation and restoration. Students recognized people's efforts to restore and protect ecosystems related to a class field trip to Great Egret Wetlands and Glacial Dunes Preserve. Great Egret Wetlands is an approximately 10-year-old wetland restoration area that had been drained and used for farming prior to reclamation. In contrast, Glacial Dunes Preserve is a sand 
prairie that has been protected for over 40 years that contains some undisturbed areas. Both preserves were further from campus than could be accommodated during a regular class session, therefore a Saturday field trip was arranged. Five of the eight participants were able to attend. Participants described restoration and conservation efforts at the two field sites; however, the details of the efforts were not always clear. This was at least partially explained by the fact that the history of the sites was given orally in the field. For example, there was a perception that the formation of Great Egret Wetlands started with accidental flooding and only later became part of a restoration project, rather than deliberate removal of drainage pumps. As Sam noted: When we went on the trip to [Great Egret Wetlands] and [Glacial Dunes Preserve] we saw examples of how nature changed by itself and also with the help of humans. For example [Great Egret Wetlands] was farmland until the barriers broke and the river thus overflowing and rain caused it to create a wetland. The humans helped to maintain it as a wetland.

Taylor provided a similar account:

When we went to [Great Egret Wetlands] we were first told that it used to be a farm and then with all the rain and lack of irrigation it had become a wetland. This was caused by the farmers not creating good systems, and by nature out-thinking the farmers' systems. Now the more rain we get the more water is added to the wetland.

In contrast, the conservation efforts at Glacial Dunes Preserve were more recognizable to the participants. As Bobby explained:

One field site we have visited is [Glacial Dunes Preserve]. The park is hidden and has a small sign to prevent many visitors. This helps the park because its important 
characteristics such as cacti would be stepped on... However, there will be people that try to make a small path for the few visitors that find the park.

Sam also noted that, "Humans are preserving this unique land feature by not allowing many hikers and visitors in general to the area." Taylor went even further to explain, "The people who work there are able to regulate this by having visitors only walk on specified trails as to not create sand crusts/deposits [to] mix more together."

Overall the trip had a considerable affective impact on the participants, which contrasted with the work of Morag and Tal (2012), who indicated that single field trips might be better for purely cognitive gains; however, it was in line with work by Ballantyne \& Packer (2009) who indicated that learning experiences that elicit positive feelings also support larger affective outcomes. Bobby wrote a journal entry about the experience, paying attention to the variety of animals in the area:

My favorite place to go was the old farmland that now looks like a swamp. There were so many different birds and several frogs, butterflies, and dragonflies. The frogs hopped together in certain areas of the shallow water. The birds also were in unison except for the large crane.

The trip had a significant impact on Sam as well, although where Bobby saw a swamp, Sam saw a lake:

... it used to be a farmland. So ... there was ... stuff that was in the background, or like in the water, that still looked like it was . . cornstalks, almost. And so ... I would've never thought that ... farmland could've [been] taken over . . to this beautiful . . lake almost now. 
This affective response was important in changing participants' perceptions of the ecosystem diversity of the Midwest, which aligned with the third goal of the course and is explored more fully in Chapter VI: Sense of Place. While the affective response may or may not be permanent, participants' reflections on the event were encouraging, as reflection is considered high impact technique for fieldwork (Ballantyne \& Packer, 2009), and participants, including Sam, continued to discuss the Great Egret Wetlands and Glacial Dunes Preserve throughout the semester.

Cultivation. On a smaller scale, participants considered people's impact on plant life in curated settings including a botanical garden, a local park, and a vegetable garden. Alex had this observation at a park within close walking distance of campus:

In fact, it seemed that perhaps all flowers/plants in this area were dug up-as I only saw dirt and fallen leaves. I wonder if this is done (by the park district?) at the end of every summer before the temperature gets colder.

She returned to the experience in her interview:

And like seeing how it had changed from like September into November. I enjoyed that. . . I thought 'oh, [returning for a second observation] that'd be a good idea.' And ... there is one area where I think they had . . pulled up a bunch of the . . coneflowers and other ... because it was just completely bare. So I . . wondered how the park . . maintains that.

While this was a park that Alex was very familiar with, this was an aspect of park maintenance that she had not previously considered. Cameron also observed a carefully tended plot, but in his case he used the experience to draw comparisons to wild areas:

It looks as if the people in charge of the garden cut out any dead leaves because it has numerous amounts of dead stalks that have been systematically cut. I wonder how leaves 
that die affect the plant's overall health in untouched nature? In nature there is no gardener to choose which leaves should be cut.

Gardening was on Cameron's mind in several observations:

Does hunting affect the health of the tomato plants my aunt grows? I notice her plants thrive, but she does not use sprays or a fence. Does the fact that there is plenty of gunfire affect the animals that might eat on those plants?

In this case he combined the impact of humans on both the landscape and on animal behavior to connect course work with his everyday experiences. This type of work to build bridges between different areas of knowledge was a vital component to extend concepts beyond the limits of a semester-long course.

Participants had a similar experience when considering a trip to a botanical garden. They observed a familiar object, indoor plants, and started to think about the effort required to keep the plants alive on a larger scale. As Chris noted in her journal:

Today we went to the [botanical garden]. I thought it was very interesting to see tropical plants flourishing in mid-November when it was cold and rainy out. This is due, of course, to the greenhouse, but I couldn't help but think about the ability of these plants to adapt to the dramatic shift in seasons and weather. I think that a large part of that is due to the humidity-controlled environment, but that is something I would like to look into further.

Even as Chris acknowledged that the plants were in a climate-controlled environment, she still asked questions about adaptation. This may have stemmed from the knowledge that the plants still had different temperature and moisture tolerances that were not necessarily best supported in a single growing space. Bobby implicitly raised a similar issue: 
I was surprised to see the plants still living along with others in the same place. For example, there were orange trees and other cacti in the greenhouse. I noticed there were no bugs and they were completely covered so I wonder what people do to keep the plants alive especially in cold weather.

Whereas Taylor simply asked, "How do they control the temperature of the greenhouse so well? How do they keep every single plant alive?" Payton asked this question more directly before relating his observation back to gardening:

One of the biggest questions I have is, does the botanical garden climate have any effect on the development of the oranges on the tree? Why don't all the oranges grow at the same rate? Or at least closer in rate? This led me to think about tomato plants. In my experience of observing gardens, such as my grandparents' vegetable gardens, is that not all of the tomatoes are ripe at the same time. I wonder if there is a correlation since they are both fruits?

Ultimately students did not explicitly tie plant cultivation back to core concepts. As with other areas of their observations, the questions they asked mainly served to provide insight into how they were thinking and what connections they were making, rather than to jumpstart further exploration. However, dedicated time for observing did increase their awareness of the effort that goes into maintaining landscaped areas. Likewise, their questions about the botanical gardens indicate that similar fieldtrips could be used to start a deeper discussion about larger concepts, such as the benefits and tradeoffs of greenhouses versus seasonal gardening.

Nutrient availability. While observation in local areas was mainly responsible for participants' increased awareness of the effort to maintain parks and other public spaces, they learned about anthropogenic contributions to nutrient availability through a combination of 
lecture, discussions, and independent projects. Class development of biogeochemical cycles introduced changes to nutrient reservoirs and the concept of nutrient pollution. This was discussed for nitrogen, phosphorus, and carbon, but changes in the nitrogen cycle were emphasized in the field as much of the work was done in close proximity to agricultural areas. Ultimately one student group chose to focus an independent project on nitrogen availability in local ponds and lakes. While many students noted changes in nutrient availability on exams, Bobby's experience was exemplary of how those ideas expanded in the field.

Bobby chose to study nitrogen levels in local ponds and lakes. She picked study sites based on whether they were in-town or in rural areas. In multiple journal entries, she elaborated on the topic with reference to her project and her on-going data collection:

After looking at specific terms such as nutrient pollution and dead zones, we had a better understanding of the data we could collect and look at in a rural and urban community. Fertilizer is a main focus of our lab and its effect on the water. Certain chemicals like nitrogen can cause damaging effects to life in a body of water.

Early in the project, Bobby had a good idea of what she wanted to study and why it was a problem, although her terminology was still somewhat vague, especially in terms of the forms of nitrogen that were of concern. During data analysis, Bobby's writings became more detailed. After today our group was able to find more information on the nutrient pollution in the water. We expected the results for nitrate and ammonium to show many changes in the numbers. The only one we've tested was nitrate but we got an idea of how much the water has. Although, there wasn't a lot of data that stood out to us. [Park] was one of the few ponds that showed there was $2.5 \mathrm{mg} / L$ of nitrate in the shallow water. There was also 1.0 
$m g / L$ in the deep end. Other ponds showing similar numbers were [park] and [lake]. This shows that rural areas are revealing higher levels of nitrate in ponds.

In this journal, Bobby was approximately halfway through her water testing, and she was thinking about and trying to make sense of her data. Her writing indicates a level of investment in the project as she was thought about the data outside of class and tried to reconcile it with her expectations from her background research. As she progressed to the end of the semester, her writing became more specific, with nitrate and ammonium replacing the use of "chemicals" in a more general sense:

Nitrogen levels may increase based on nutrient pollution in a water-based ecosystem. Fertilizer is an example of something that may cause this to occur ... An ecosystem in the water may be destroyed based on many people using material with nitrogen. Fertilizer is a good example because it can be used for farming, gardening, or golf courses. Eventually it will run off into water by rainfall carrying its nutrients in the water.

When the levels of nitrate and ammonium increase, organisms living in the water will die off. When the dead zone is present in the water fish and plants are unable to survive and the water life becomes impossible for any new species.

Through her independent project, Bobby was able to make eutrophication and dead zones, concepts that students frequently find confusing, and make them more concrete and personally relevant. Her writings became gradually more technical as her vocabulary expanded through regular use and experience, rather than through memorization. This is an important aspect of how field and lab work expanded students' experiences in personally meaningful ways, a topic 
explored more fully in Chapter IV: Community of Practice in Field-based Ecology. Likewise, it shows the connection of ecological concepts to the type of decisions that participants will likely face in the future, such as when and how to fertilize, an important outcome for many frameworks of ecological literacy (Berkowitz et al., 2005; Jordan et al., 2009; McBride et al., 2013). While Bobby did not take the next step of actually addressing how she might make decisions based on her understanding of nutrient pollution, participants started to bridge that gap in terms of erosion.

Erosion. Formal discussion of erosion within FBE 300 took place on a driving tour of the local area. Several stops were made so that the participants could view erosion-prone regions, efforts made to mitigate the effects of erosion, and to discuss how changes in land management contributed to the rate of erosion. This trip seemed to be particularly powerful in shaping participants' ideas about the topic, and it featured prominently in student writings. Payton included this in a journal entry:

[Michelle] then explained how erosion and run off from the hilltop have made the water extremely shallow. This was interesting to me because looking at the river with the naked eye you can't really tell.

What was also shocking was the amount of erosion that was occurring. It is scary to see how close it was to affecting the [building].

Alex was also surprised by the degree of visible erosion and its potential impact on the area: In addition we drove through the cemetery off of [Avenue]. I was shocked to see how some gravestones were right at the edges-before potentially falling over the side of the ravine? If erosion continues to occur . . . We saw new soil was being added in certain places to help prevent this problem. 
More than perhaps any other topic, participants in FBE 300 saw the impact of people on the landscape in terms of erosion. This was likely because of the dramatic visual examples in the area and the apparent immediacy of the problem. A visibly eroded hillside within feet of a prominent building and gravestones perched perilously close to a ravine made an impact.

A certain amount of shock factor may have made a first impression, but erosion was a problem for participants that, once it was seen, could not be unseen. They identified evidence of erosion throughout the area in their journals and observations. As Chris noted in an observation and a journal entry:

Creek bed carved into hill and valley where two hill slopes meet. Erosion from water left roots of trees and plants exposed. Soil on top of roots is darker than underneath.

It was very interesting because there was a large area of erosion where you could see the exposed tree roots, and layers of soil and rock that had fallen away. The erosion area was on the ... dry creek bed where you could see all of the trees that had already fallen in the creek, presumably from the erosion.

Bobby's description in her observation journal was almost poetic:

Hill cuts off and mud shown

Roots out of the ground and back in

Trees leaning inward toward ravine

Fallen trees lay across ravine like bridge

Sunlight towards top of the hill

Very shaded with some light peeking through

Alex also continued to noted erosion in both observations and journals: 
Area where you can see the soil and no leaves are covering — can see long roots (evidence of erosion?)

In addition, I noticed how hilly the land was on either side of the trail, as well as what looked like the area where a former creek ran through-or where water collects when it rains. I recognized areas on the hills and along the edges of the creek where it looked like erosion had occurred — because I could see bare dirt.

In this way, erosion was much like glaciation. Once students were aware of it, they began to identify evidence of it all around them. Impacts of erosion differed from glaciation, however, in that they were actively occurring and easily recognizable, therefore not subject to as much misidentification. If the easy visibility lead to increased awareness of erosion, so did the participants' firm grasp on why it was a problem. Unlike issues that were distant or abstract, erosion was something that had tangible impacts. Cameron contemplated the constant effort required to address increased river sediment in a journal entry:

As I watched the barges move very slowly down the river, I wondered how much manpower does it take to maintain the channel in the river. I also wondered if the barges would move faster if the river was not subjected to so much sediment runoff.

Simply understanding erosion as an environmental problem does not imply an underlying ecological understanding. While not all participants could describe the causes of erosion as well as they could the effects, overall they worked to understand it in terms of changes to the landscape that affected soil structure. Chris described this on her final, connecting material from both FBE 300 and another course she was taking concurrently: 
Erosion can become an issue when land owners clear out woody areas for fields and development, because the soil that was held together by all of those deep roots is compromised, and the aggregates are broken apart, making water retention less possible. Payton expressed similar ideas on his final:

Erosion is a major problem in [here]. We saw it first hand on our tour ... When people cut down trees and completely destroy a landscape it takes away root structure. Roots hold the soil together and are one of the reasons soil keeps its nutrients. When people keep changing the landscape they take away the natural elements that were helping keep the soil together and keeping it fresh and healthy.

And Alex included some specific suggestions for better soil retention in a journal entry: We then discussed how oaks have more extensive root structure than maples, which have the ability to hold onto the soil, and prevent erosion. We suggested that for management, [New Woods] should plant more oak seeds, which Michelle mentioned that these efforts are being done.

Notably participants discussed erosion with reference to wooded areas. This made sense in terms of their work at New Woods, especially when recognizing that oak trees were more desirable for erosion control than maple trees. Chris also extended the issue to agriculture. Overall, however, they missed the connection to removal of native grasses with extensive root structures. This was important in terms of their understanding of historical changes in land use of the Midwest, but also as an indication of how participants viewed the areas they were studying. Generally, participants viewed wooded ecosystems, no matter how highly disturbed, as intact natural areas and viewed disturbance in terms of construction and agriculture. And while 
participants understood grasslands to be part of the native plant systems of the region, their almost complete removal kept that understanding more academic and less immediately relatable.

In addition to erosion being memorable, it was one area where participants felt they could have a direct impact on an environmental problem. Making the connection between problems, causes, and potential solutions is particularly important for pre-service educators as their feeling about environmental issues can influence the structure of their future courses. Sobel (1996) argued that when environmental problems are viewed as both insurmountable and as the only focus of environmental education, they can potentially turn students away from ecology all together. In the case of erosion, participants saw a major problem, but they did not see the issue as hopeless. As Chris noted in a journal entry:

Taking this class with [soil class], I have been given the opportunity to take a much closer look at soil, its purpose in nature, and the important roles it plays in ecosystems.

I would be interested to see erosion prevention happening, because while it is obvious that while erosion is a huge problem, it doesn't seem like a quick fix, but one that's very important and necessary.

In this case, Chris noted that significant work needed to be done, but acknowledge the possibility of erosion prevention. Alex, in particular, took note of individual actions that people can take to make a difference. In a journal she wrote:

Some small practical ways that home owners living in this area could do to help prevent erosion would be to place rain barrels around their gutters (to collect rainwater, instead of it running off) or to plant rain gardens, which can take up rain water, slowing runoff, as well as "clean" it as plants take up nitrogen and phosphorus that are present in it. 
She came back to these actions in her interview, and expanded them to efforts she could make with her future classes:

I really didn't know much about [the area] before, but . . visiting . . was neat, I think. Keep that [driving tour] for future classes, ... and talking about erosion. ... Just 'cause I didn't know that it was as much of an issue before and I know we talked about . . little ways that we can help . . . with rain gardens and so I think that made me think . . "oh, I can do that on my own." Or . . that could be . . something that could be done at an elementary school.

In this case Alex focused on concrete ideas and small actions, which is in-line with Sobel's (2004) recommendations for place-based elementary education and serves as an argument in favor of field-based education.

As participants described the impact of human-environmental issues on the landscape, their writings paralleled lecture, classroom discussions, and fieldwork fairly closely. This was true for both negative environmental impacts, such as nutrient pollution and erosion, and positive impacts, including ecosystem restoration and conservation projects. Their developing ecological understanding aligned with the first two goals of the class, as they built foundational concepts in a way that linked both classroom and field experiences. The understanding also aligned with fundamental ideas as identified by Jordan et al. (2009) including biogeochemical cycling, regional and global processes, and biodiversity. Additionally, the field-based nature of the course contributed to expansion of course content to include ideas that were not explicitly a part of the course design. The second sub-category related to human impact on the environment, People's Influence on Animal Behavior, largely arose from such spontaneous learning opportunities. 
People's influence on animal behavior. One of the major semester-long projects for FBE 300 required students to spend time in outdoor observation. Participants were required to keep a notebook of at least ten, 30-minute observation periods of which one needed to be an animal in its natural habitat, one needed to be a plant study, and one needed to be in a nature park (e.g. a zoo or botanical garden). Opportunities for the last observation were embedded within the course through field trips to both a native animal park and a botanical garden. The intent of the project was for students to develop core course concepts through a natural history approach. As such, ideas related to people's influence on animal behavior were not unanticipated, but the specific nature of those ideas was largely student-driven and at times fortuitous.

Wild animals in captivity. Close to the end of the semester, FBE 300 took a trip to a native animal park. Participants had the opportunity observe both familiar animals and those they may not realize were native to the area including several that were extirpated. For some participants this was their first tip to the animal park, but others had attended for social or educational events in the past.

The park design was meant to be a naturalistic setting with larger enclosures than many zoos for most of the animals. This was especially true for large herbivores, which have enough dedicated room that they are not usually close enough to attendees for close viewing. This aspect of park design struck Alex in particular, who noted in her journal:

On Wednesday during class we went to [Animal Park], which has animals native to [the Midwest]. It reminded me of a zoo in one sense, however it seemed like the animals had much more room to roam-even though they were still in contained areas.

While the animals had more room to maneuver, Alex still was excited by the opportunity for close observation: 
The first few that we saw included the gray wolves, and bison in the distance. Some of the birds we saw included Great Horned Owls and a bald eagle-I'd never seen one up close! The animal I chose to focus on closely was the "Greater Sandhill Crane," which was right behind the fence!

I liked seeing the black bear up close too; at first we saw it from afar, and then we were able to get a close view from another spot.

Overall, I really enjoyed this field trip - as it gave me the opportunity to see native animals up close that I don't normally see.

The close-up view of the animals was especially important to four participants who had an unanticipated opportunity. Taylor, Kit, Sam, and Chris happened on group of caretakers grooming the raptors. As Kit described it:

Lastly, [Sam] and I were on our way back to the main entrance and we saw some of the wildlife park workers. We decided to follow them because they looked up to something interesting. We eventually stood and watched them for about an hour in the bird exhibits. The workers had explained to us that they were cutting/trimming each of the bird's beaks and talons. They said they had to do this because in the wild they naturally wear down, however, in captivity they don't move around enough to do so. It was so interesting to watch them capture the bird in their hands, maneuver the bird to the correct position, cover the bird's head with a towel (to calm and relax it), and cut the beak and talons. They were wearing gloves the entire time because the birds' talons were sharp and could puncture human skin easily. They also used an electric nail sander tool to trim down both 
the beak and talons. One of the workers gave us more insight and told us that the talons are like human fingernails, and if they are cut too short they can bleed like a dog's nails would.

As Kit recounted it, the entire encounter was spontaneous. She happened to see a group of employees who "looked up to something interesting." The quick decision to follow led to an important learning experience. One event was enough to expand the participants' knowledge of bird physiology and how their needs differ in captivity versus the wild. It also helped a few participants move past their fears. To Taylor, this was a highlight of the field trip even as she acknowledged that it was a little uncomfortable:

Another really cool experience here that I had is that I was able to watch the hawk, owl, and a smaller bird get their nails and beak trimmed and fed a dead mouse. This was super cool, and a little freaky, too.

Chris elaborated on how an intriguing opportunity in the field can help overcome discomfort and lead to further learning:

I think that what stuck with me most, though, was the opportunity to watch the caretakers catch and trim the talons and beaks on the birds of prey and raptors. I'm terrified of birds, so I watched from a long distance, but while we were watching the caretakers explained to us the importance of maintenance like that for these birds, because birds in the wild are much more active than these birds are, so they naturally wear down their beaks and talons. Since the birds at [Animal Park] aren't as active, while it may seem invasive and unnatural to do this, if they didn't the birds risk injury and infection that could potentially be life threatening. 
Based on work by (Morag \& Tal, 2012), single field trips are often more effective for cognitive gains than affective ones. Kit, Taylor, and Chris' unplanned experience with the birds showed how a single field trip experience could be important for multiple learning goals.

The opportunity to observe the talon trimming was only available, and only necessary, because the birds were in captivity. How the animals came to be in the park, and the ethics of keeping them there, was also a question of concern for some participants. Notably, Alex began to wonder about the animals' origins and how long they lived in the park:

I wonder if they found all these animals in the area right around the park, or if they're from further away. I also wonder how long the animals stay in the park, if they change them out every so often.

The provenance of the animals in the park was something that sparked curiosity in several participants, some of whom had the opportunity to ask caretakers during the trip (the park commonly houses rescue animals). For Cameron, the lives of animals in captivity became a growing concern that started with his observation:

Now the bear is sitting next to the log staring at the fence line. He is lifting his head and sniffing at the air. It seems he has picked the scent up of something unfamiliar. Can he smell the scent of humans entering the forest?

These observations stayed with Cameron as he continued to think about the black bear, and he wrote a journal entry on the trip:

[Animal park] was not as fun as my previous visits. When you study the animals it makes you realize that they are not happy.

I wondered if animals that are bred in captivity lose their instincts their ancestors were 
born with? I noticed when I observed the black bear he seemed confused, as if he did not understand why he was there.

People want to see these animals up close so I guess it is a necessity. To make humans care for these animals, they must see them up close. So I guess that these animals are taking one for the team. I guess you can call it a necessary evil. The animals are extraordinary to view, but it comes at a cost.

These ethical questions arose unprompted during the course of the field trip. For several participants, the opportunity to watch the birds being groomed was an important learning opportunity, one that even transcended some degree of phobia. For Cameron, the trip lead to a growing awareness of the trade-offs of this type of opportunity, even as he reluctantly decided that the benefit might outweigh the cost. These ethical considerations are included within the category of Human Impact in line with the categorization of Jordan et al. (2009). They could also be considered a scientific Habit of Mind, in line with the general education goals at Oak Savanna University.

Habituation and domestication. In addition to noticing the impact of captivity on animal behavior, participants remarked upon the distinct conduct of wild animals that are habituated to people and that of domesticated animals. In both cases, participants spent time in dedicated observation of animals that they knew well (in the case of pets) or animals that they see regularly (mainly squirrels). The result was the formalization of previous casual observations and the chance to learn new details about familiar animals. 
Cameron, as with animals in captivity, noted that the habituation of wild animals to people is not necessarily desirable. Still he appreciated the ability to watch squirrels closely in a way that would have been difficult if they were skittish. As he said in a journal entry:

When viewing nature I think it is helpful to view animals that have become accustomed to human activity. Although this is not always a good thing, I noticed that I saw some great squirrel interaction. The squirrels were sometimes only five to ten feet away from me, which gave me a great view of a squirrel in action.

Oak Savanna residents widely consider the local squirrels to be unbothered by proximity to people. Students on campus often remark on them, and Payton noted their behavior in a journal: It was a beautiful day today and I decided to go and observe some squirrels around campus. The squirrels at [Oak Savanna University] have always fascinated me. They are very calm around people and seem to have adjusted to the busy campus life. There are a few who seem to still scurry away when a human approaches, but most of the time they are not fazed by a human walking by.

The habituation of squirrels is a common observation, and both Cameron and Payton took advantage of it, but Payton took the idea a step further. He used the observation notebook to compare behavior of squirrels on campus to those in a nearby park. He wanted to know if the squirrels on campus really differed in behavior to other squirrels in busy areas:

Ifound a spot to sit right behind the Japanese style structure they have at the park. There seemed to be quite a few squirrels out and about around the trees and on the grass. They were definitely more timid than the squirrels at [Oak Savanna], and kept their distance. I even brought some peanuts to snack on, just to see if they would come any closer. 
While this was not a formal study, Payton extended his observations to include aspects of a research question. This was a meaningful experience for him, one that he revisited in the interview.

There was always a thought in my mind . . how did the squirrels react differently? Because, .. you walk through [Oak Savanna] and the squirrels are not very afraid of you, and they're not ... afraid to come up and ask for food, or they don't run away right when you're stepping by them. And you always felt like... I see squirrels at home and if I take two steps near them . . they're going to scurry away. . . So I was just kinda curious ... [the park] is pretty close. I didn't know if any of the squirrels might've ... just waltzed on over there and ... I had been there before ... with my girlfriend last semester. And there was a squirrel that came up pretty close to us, we had like a picnic over there, I don't know if it was just the food that drew them, but ... He come up pretty close. I was kinda curious just to see what their reaction would be, and when I went again, it was kind of a different story. So it was just neat to kinda observe the different . . what their activity was like ... even if there was a difference in look or anything. So how they moved around, how they reacted to me being there, so. I did notice ... these squirrels that are on campus are so used to humans. And even in [Park] does have quite a few people walking around... I feel like some of the squirrels might be used to it, but then there's other squirrels who aren't, and they're gonna be more afraid. But they're actions, you know what they would do, were pretty similar . . how they would like search for acorns and eat them ... those were all very similar, just how they responded to human interaction that was different. . . it was really cool, actually. 
In this passage, Payton connected quite a few different ideas. He had a casual understanding that squirrels on campus were acclimated to people, but also acknowledged that this might be the case in any busy, urban area. This stemmed from reminiscence about a picnic that lead to a more formal observation and a conclusion: while general squirrel behavior remained the same, the squirrels' behavior towards people did not. While Payton's conclusions based on his formal observations did not differ from his initial casual observations, Payton still learned more about distinct behaviors of animals that otherwise might have faded into the background or seemed uninteresting (the specific squirrel behaviors are discussed in more detail in Habits of Mind).

While Payton extended his knowledge of tree squirrels, Chris had a similar experience when she observed a pet that she knew quite well. Chris chose to observe her horse when he was alone and when he was interacting with a much younger horse. The observation did result in some knew observations about anatomy, as Chris noticed how the horse's muscles moved while he was chewing, "ate peppermint (jaw muscles flex, kind of a circular motion with bottom jaw when chewing)," but what she really took away from the experience came from watching the older horse and the younger horse together. While these were animals that she knew quite well, she came to a new understanding about how the older horse engaged in play. As she noted in her interview:

. . background story on him - he really never matured, cause he was kind of a show horse his whole life. So he didn't ever really get to be a horse. So that's what he's doing now at home, it's his job. So he goes out with the baby horse and they play like they're both babies. And it's just the cutest thing ever. But, you know, it's ... just the social aspect of it. Because, then, when he comes inside and he's right next to you, the 24-yearold retired horse who is like, 'oh, whatever. You can sit on me. I don't care.' He's totally 
different... He's so mellow and calm. But then when he's out with the 2-year-old, he's crazy! So I think the social aspect of it, for me ... that makes sense. But I'd never really put much thought into it.

For Chris, the formal observation was less about the specific behaviors observed, but rather why they were occurring. Like Payton, she had the time to think about what she'd observed informally in the past, and she incorporated new ideas into her framework for understanding horses. Largely she contributed the behavior of the older horse to his interactions with people, spending time as a show horse. She continued:

Because... I know now kind of how to anticipate going out in the pasture with the 2year-old and the [older] horse better ... in a different way. . cause that could be a safety concern... I mean I think it's just like a better understanding of where he's coming from.

Chris saw the observations as a way to better understand animals that she loved and her impact on their behavior in a way that could improve her ability to care for the animals.

Participants prioritized their time during observations in different ways, but for several participants, the time they spent thinking about a smaller number of observations led to consideration of how people influence their surroundings in both large and smaller ways. While their observations sometimes reinforced foundational concepts in ecology, they often served as a stepping-stone for participants to notice previously unseen aspects of their immediate surroundings, both the landscape and the animals within it. The increased attention to detail leads to the third category of their developing ecological knowledge, Habits of Mind. 


\section{Habits of Mind}

As definitions of ecological literacy developed over the last 30 years, long-lists of ecological concepts gradually began to include more holistic views of understanding (McBride et al., 2013). Definitions began to focus on not just on the established science of ecology, but also on how that scientific knowledge developed (Berkowitz et al., 2005; Jordan et al., 2009; McBride et al., 2013). Jordan et al. (2009, p. 497) noted, "Particular habits of mind, such as modeling, dealing with environmental uncertainty, and issues of scale, are integral to scientific inquiry and are particularly suited for an ecological context in instruction." In FBE 300, this aspect of ecological literacy was reflected in the second course goal: emphasize field-based methods as a way of developing knowledge. Course design purposively included both techniques of natural history, through the observation notebooks (Lorsbach \& Jinks, 2013; Stebbins, 2012; Wilcove \& Eisner, 2000), and quantitative ecological studies through the independent projects (Resetarits \& Bernardo, 1998). As an introductory, field-based course, ecological modeling was included through conceptual models (e.g. biogeochemical cycles, ecosystem services) and mathematical measures of community structure (e.g. importance value).

Analysis of student artifacts resulted in the development of a category, Habits of mind. The habits of mind displayed by participants in FBE 300 were further sub-categorized as either Research skills or Dispositions. While frameworks for environmental literacy often include dispositions towards environmental action (McBride et al., 2013), in this context, the dispositions related to dispositions towards science including participants' scientific self-efficacy.

Research skills. Participants spent the first part of the semester categorizing plant diversity and distribution along a transect line in New Woods Nature Preserve. At the end of this project, participants spent a day using instruments to explore abiotic conditions along the 
transect. This included equipment for measuring: temperature, soil moisture, visible and UV light intensity, wind speed, and relative humidity. Students were encouraged to use their combination of experiences to develop testable questions and hypotheses they could explore in the second half of the semester. Students developed these independent research projects in groups of two to four with the facilitation of both instructors. Facilitators provided feedback on question formation and overall design, such as sampling protocols, through individual discussions with each group. Instructors also provided information on available equipment and standard operating protocols as necessary (e.g. calibration of $\mathrm{pH}$ meters, standard procedures for extraction of soil nitrates). Through their artifacts participants displayed a set of developing research skills centered on question formation, sample preparation and instrumentation, and the use of data to draw conclusions.

Question formation. The intent in this course was to use the data collection and open explorations at New Woods in the first part of the course to spark student interest and to generate questions that could be addressed in small groups in the second half of the course. Broadly considered this effort was successful as participants indicated that they based their research questions on topics that they found personally interesting, however they did not make concrete links between observations, experiences, and question formation. As Taylor noted in her interview:

We all agreed, really, really easily ... that we wanted to do soil. And then, I don't really know how we came up with the question. We just kinda did, I think. I think we just kinda did it ... We felt that it [soil] was the easiest to . . actually . . collect samples for and there were lots of different way to go about using it and testing it. 
Taylor described a fairly informal decision-making process in which the group members found a topic of general interest at least partly because they could think of multiple different ways of exploring it. However, there was not a strong connection between observations in the first half of the class and question development in the second half. Payton had a strikingly similar response in his interview:

We originally thought about testing soil from different area[s], and seeing what the nitrogen level was. We kinda wanted to go to different landscapes, so the forest, partition right near a pond. We were thinking farm grounds . . that was our general idea. We wanted soil from the very beginning. Just because we thought it was a cool concept and just thought we could do a lot of different stuff with it.

Ultimately, while participants used their time in the field to develop ecological content in a variety of ways, their observations served mainly to spark interest in a general topic.

Much as both Payton and Taylor's groups used class experiences to generate an overall topic of interest that was fairly broad, they used feedback from the instructors in similar ways to narrow their topic of interest and to write more specific questions. While the processes were similar, their reactions were not. Taylor described a relatively straightforward, easy-going approach in her interview:

[Based on previous course experiences] We were able to make it [research question] more specific, I think. We had created one question and then, after you guys looked at it, we were able to sit down again and make it more specific and more focused on one part of soil versus a general aspect of it. I think that, I don't know, we just kinda went with it. While Payton described a more worrying process in his journal: 
It was stressful choosing a question to research since we aren't fully aware of the subject material. It was very beneficial to have our professors guide us along in our decisionmaking. They were also able to narrow down our ideas and helped us pose a hypothesis of what could be manageable to study and run tests/experiments.

For both Payton and Taylor the role of the professor was to help them narrow their topic of interest to a testable question, but whereas Taylor saw this as something to roll with, Payton found the process stressful because he wasn't "fully aware" of the subject material. This indicates that even with almost two semesters of inquiry-based science (FBE 300 and the prerequisite 100-level course), students may still view their research projects as a way to verify their knowledge, rather than as a way to develop it.

Sample preparation and instrumentation. As FBE 300 required a inquiry-based laboratory course as a prerequisite, all participants in the course had previous experiences designing and implementing independent research projects. At the 100-level, these labs are largely evaluated by means of a formal laboratory report. This was also true in FBE 300, but the additional requirement for a weekly journal provided a secondary data source that indicated how participants felt about the process. Participants used their journals as a way to chronicle their efforts, indicate what they had learned, and note areas where they were still unsure about their design.

Participant writings showed an increased appreciation of the complexity hidden by seemingly straightforward questions, starting with the effort to collect samples. Part of this was the unexpected physicality of the tasks, as Kit described when collecting soil: 
My group and I went to [Park]. There we found four white pine trees that we were going to use to collect our data. As a group, we wanted to test the soil to find out if it is affected by the fallen pine needles ( $\mathrm{pH}$ and acidity).

[Chris] and I used soil corers to get samples of the soil from the ground. I have to tell you, it was pretty hard. At some locations the soil was not soft at all. It seemed like cement. I had to use all my body weight to try and get the soil corer into the ground. Participants also adjusted their understanding of what constituted a single sample, as Alex noted: Last week, we took samples at three places at each evergreen tree, at $1 \mathrm{~m}, 3 \mathrm{~m}$, and $5 \mathrm{~m}$ from the base of the tree. However, each "sample" actually consisted of 4 soil cores combined into one-since soil is heterogeneous.

Alex's response was an example of the integration of field-based techniques and concepts, a key goal of the course. Rather than skills and concepts being separate, they informed each other, as the sample collection impacted Alex's understanding of soil and vice versa. Even standard procedures for sample preparation provided students with an opportunity to think through concepts when they were paired with thoughtful journaling, as evidenced by Sam:

Since we collect data for our lab report this week I decided to write my reflection journal for the week on that. For our lab we decided to test the nitrogen levels of soil at different elevation levels on the same hill.

...The next day we went in early to help start the process for drying out the soil. We had to pull out all the large roots and rocks that were in the soil. This was confusing to me because wouldn't the roots hold some of the nitrogen that is present in that area of the 
soil? Also wouldn't they be helpful to keep with the soil in an effort to fully determine the soil's abilities?

In this way, Sam used the journal to organize her thoughts about how her sample preparation technique related to what she already knew about nitrogen, soil, and plants. Notably, the question was not only rhetorical. Students knew that we collected journals regularly, and Sam in particular used them to pose questions for the instructors as she worked through concepts outside of class.

All of the projects required tools and techniques with varying levels of sophistication, and students found satisfaction in both low-tech and more involved processes. Kit noted the enjoyment that comes from being literally down-and-dirty in a scientific endeavor:

Back in the classroom we took each of the samples and sifted them through a sifter. The soil was dry enough to do this luckily; otherwise we would have had to wait till next class to do so. We sifted through the soil because this allowed us to separate the soil from any other things that were in it. Some of the things that we sifted out included roots, branches, leaves, grass, and rock sediment. It was dirty to sift through the soil, but actually lots of fun.

This type of experience was important as it showed a side of science that was far removed from the image of a sterile lab environment. In contrast, Kit found the calibration of electronic sensors to be more of a chore:

We have been able to calibrate the Vernier [equipment] and measure the $\mathrm{pH}$ and concentration levels of each of our soil samples. (I must say calibrating the Vernier may have been the hardest and longest part of being able to measure our data samples).

While Kit found the calibration process more difficult, it had potential value beyond learning a technique. The use of unfamiliar laboratory equipment was transformative for Sam: 
The first thing that made me feel like a real life scientist was when we measured out the soil and the $\mathrm{K}_{2} \mathrm{SO}_{4}$ and put them in beakers to be placed in the soil shaker. I had never seen a machine like that before. It was amazing to me that the soil needed to be shaken like that for so long in order to be able to measure the nitrate and ammonium levels.

We had to use a new syringe and filter for each soil sample because otherwise they would become tainted. Then we measured the nitrate and ammonium levels of the liquid using the testing probes and the probe reader. This made me feel important and professional too.

Access to the equipment, and the confidence that she knew how to use it, was essential to Sam's experience during the independent project. One of the advantages to a field-based course for students in FBE 300 was the combination of lab and field experiences that allowed participants to see multiple aspects of scientific practice, expanding their notion of both science as a process and their role within that process.

Drawing conclusions from data. The journals in FBE 300 were also valuable as snapshots into participant thinking as they gathered their data. Whereas the lab reports showed the collective conclusions of the group experience, the journals allowed individual students to reflect their changing ideas as the projects unfolded. They provided space to think about what they needed to add to the report or how their impressions might change as they gathered more information. Once the projects were complete, the journals served as a way for students to determine what they learned through the process.

Student writings showed that they tried to make sense of their data as they collected it including drawing initial conclusions, which they qualified when they saw a need for more data 
or analysis. For Bobby, this meant being careful to consider data that had not yet been collected, "From this data [on nitrates in water] alone our hypothesis is correct but this may change when we observe the ammonium levels in our water samples." Alex showed similar restraint as she discussed the early stages of data analysis:

Although we were able to recognize these initial trends, we still need to conduct tests to determine if our data is "statistically significant." At least we've completed our data collection and we'll be able to do this next step and then analyze and write the discussion of our results during the next class period.

In these passages, Bobby and Alex displayed an emerging subtlety in their thinking about their data, acknowledging that data can appear to support a hypothesis without telling the entire story and distinguishing between an apparent trend and a statistical difference.

As participants progressed with their studies, they began to reconcile their initial ideas with their statistical analyses. Taylor noted in a journal entry:

Looking back at where we started, we were able to collect a lot of good and useful data for our report. When we went ahead and analyzed our data, we found that nothing was statistically significant.

It would have been nice to have had statistically significant data and more of a trend, but in reality there are always common errors while collecting data.

Taylor determined the lack of significant difference was a result of their sample collection and questioned their research design, and she was disappointed by the result, however, she didn't simply dismiss the data. She saw it as "good and useful" even if it did not support her group's initial ideas. This might be because ultimately the project for Taylor wasn't about the end results. As she noted, "I definitely feel that this research project helped give me a deeper understanding 
of soil as well as the environment around me." Much like Taylor, Chris saw the research projects as a way to develop ecological understanding, "By putting together this report, I have gained an insight into gathering information and putting into words just what that information means.” As Taylor and Chris developed specific skills, they also saw how the experience impacted their content knowledge. This metacognitive benefit was similar to the tendency of Alex and Bobby to qualify their results as they progressed through the project in that it would not have been acknowledged if the lab report were the only assessment of the fieldwork. The journal provided a crucial space for participants to think about the project as they were experiencing it, and it provided an equally crucial way for the instructors to see their thought processes.

Scientific writing. While participants derived benefits from designing and implementing the project, it did not automatically follow that they would see a benefit to writing the final report. While Chris saw the act of writing as a way of solidifying her understanding, that could have been achieved through journaling as well. Ultimately, both Chris and Payton saw specific gains from the process of developing a research report. For Payton, the benefit was less about developing ecological concepts and more about understanding how scientists use writing in their careers,

I have never been a fan of scientific writing to me it is so dry and repetitive. I am so used to writing narratives, stories and lesson plans that are more descriptive and vivid. These don't require so many technical terms, or a significant amount of citations/research. I was initially disappointed that we had to write a lab report and didn't quite understand why it had to be done, but getting the full experience in this [course] helped me to understand how important lab reports are in the science field. 
However, it is important for them [educators] to have experiences in both of these writings. Being a special education major, I might work with high school level students that will need help in writing lab reports. This class has been a stepping-stone in making me feel more comfortable with science experiments and lab reports.

In this way, Payton positioned himself squarely as a pre-service educator, but saw writing as a part of how scientists work. This is an important insight into seeing science as a developing body of knowledge, rather than as a static set of facts, an important aspect of the course and of ecological literacy more broadly. Likewise, he tied his newfound understanding to his future career as an educator. Making this connection explicit is essential and it ties directly to the fourth learning goal for the class, making connections to education. Chris also saw scientific writing as directly related to her career as an educator, but she connected through her personal educational goals:

I hope to pursue further degrees in early childhood education, and I hope that my experience writing this report will help me to write journals in the education profession based on research that I will conduct, so that I can contribute to the further of education. Chris tied science as a field of active research directly to the field of education in a powerful way acknowledging the dynamic nature of both.

Through their independent projects and their journals, participants in FBE 300 displayed a growing set of skills related to scientific research in terms of question formation, sample preparation and instrumentation, drawing conclusions from data, and scientific writing. While many of these skills were generally applicable across quantitative research domains, they were grounded in ecological concepts. Moreover, participants acknowledged the field-based projects as a way of developing their ecological content understanding, which was an important goal of 
the course. The journals served as a way to demonstrate their developing research skills beyond what was shown in the lab reports themselves.

Participant research skills paralleled their developing ecological concepts in relation to the framework for ecological literacy developed by Jordan et al. (2009). They related to what was referred to as the "general comprehension of the process of science" (p. 497). These are broadly applicable and focused more on conceptual modeling and descriptive statistical approaches. Some of this was a deliberate choice when designing the course to focus on fieldwork, although other of Jordan's habits of mind, such as issues of scale, could be more explicitly addressed within the structure of the class. This tradeoff needs to be acknowledged when looking at what can be reasonably achieved in a single semester course for non-major science majors.

While skills related to design were important in terms of ecological habits of mind, they only told part of the story. Dispositions towards scientific thinking are equally important and are considered in the next section.

Dispositions. Traditional notions of scientific habits of mind focus on skills that people need in order to think about scientific information and to make decisions based on that information (Jordan et al., 2009). These models include a range of concepts from an understanding of nature of science to deeper dives into quantitative reasoning. An overall willingness to engage with science as a field is an underlying requirement to develop these habits of mind that is not always explicitly stated. For non-science majors, this willingness to pursue scientific interests cannot be assumed. As such, a disposition towards engaging with ecological content is considered an aspect of a scientific habit of mind for the purpose of this dissertation. Participants in FBE 300 showed dispositional gains across multiple key areas including their 
science self-efficacy and their tendencies towards being observant and questioning of their surroundings. Crucially for pre-service educators, they also connected these gains to their future teaching careers.

Self-efficacy. Self-efficacy manifested within FBE 300 in multiple ways. As noted in the section on research skills, participants saw an increase in confidence in their ability to plan and execute an independent project. They also showed gains in their assessment of their skills as field researchers. This section focuses on their belief in their ability to learn and engaged with science more broadly. These gains were not uniform for all participants. Rather, they were more pronounced for students who had less interest in field-based ecology at the start of the course.

At the beginning of the semester, Chris viewed science as a topic that was outside of her interest and native ability:

I tend to automatically get frustrated with all science "things," as I did today.

I have always just assumed that this was due to the fact that I wasn't a scientifically thinking person, and I was okay with that. After today, though, I realize that I have a bad perception of science not because I'm bad at it, or that it doesn't click with my brain... From Chris' point-of-view at the beginning of the semester, science was a topic of niche interest that was to be endured, rather than something that was personally enjoyable. This conceptualization of science was a hurdle that Chris tried to clear, as she knew that active engagement was necessary to enjoy the course:

I typically approach my classes with an open mindset and a blank slate. Sure, I may hear others' opinions of a certain class, and they might think it was the worse class ever, but I know that if I walk into class on the first day with that pre-conceived notion in my mind 
already, I'm going to have a hard time immersing myself in the content and enjoying the class.

I'm glad that I prepare for classes in the way I do (not much at all) because if I didn't, I probably would have come in to [FBE 300] with a totally different mindset based simply on my experience with [100-level prerequisite]. I didn't enjoy that class, and knowing that this class was structured similarly, I had to really force myself to clean the slate and start fresh, and I'm glad I did.

Starting from a deficit of interest, Chris also had previous negative experiences that impacted her at the beginning of the class. Over the course of the semester, Chris displayed increasing confidence in her abilities to understand science in multiple journal entries:

I'm able to understand concepts now with ease that I had always avoided like the plague before...

[and that connection] has given me a lot more confidence in my scientific thinking as both a teacher and a student.

Chris' increases in self-efficacy did not stem from a single experience, but rather they built over the course through a combination of her fieldwork and her opportunities to tie her experiences to that of her future students. By the end of the semester, Chris had a very different attitude towards science education:

I was not excited at all about the idea of so much field work, especially given my health this semester, but I've found myself really enjoying the field trips, and loving all of the 
inspiration I've drawn from them for when I'm teaching. As the course comes to a close, I'm excited about teaching science, which is not something I would have said in August. Both positive personal experiences and a genuine desire to get past her fears for the sake of her future students combined to create a powerful learning experience for Chris. These changes were not likely to manifest without repeated exposure to experiences in the field. If the course had been built around a single field day, bad weather or a bad experience could have furthered Chris' negative opinions, and she would not have been exposed to the variety of ways that fieldwork could be incorporated into early childhood education:

I think so far that's my favorite part of this class. It's sort of a challenge to be creative and innovative... I especially like the idea of taking my lesson plans outside of the classroom, whether that means going out on the playground and observing the birds or squirrels, or walking around the school, looking at the "environment" in the building. Taylor had a similar journey in FBE 300. While she was not as science-adverse as Chris at the beginning of the course, she clearly identified as someone who was not "outdoorsy," a potential barrier to a field-based course that was equally high:

I'm not a very outdoorsy type so this field trip already had me hesitant, and of course the weather didn't help.

Before this trip I looked back at the syllabus and noticed again earth science was a topic to be covered and it made me take a step back and think about what we would be doing this semester. I came to the realization that this semester I would be stepping out of my comfort zone. 
Starting with a specific dislike of insects and a hotter than-average late summer, a field course could have been potentially miserable for Taylor. She also looked to her future students as a reason to move past her initial discomfort, "I also realized that this could be a good thing because when I become a teacher I hope to provide new experiences for my students.” Much like Chris, Taylor realized that fieldwork could be useful for her students and that it was something that could be incorporated in stages, rather than requiring advanced wilderness skills. She reflected on this transition during her interview:

I don't really know how bad ... I don't really know what I thought it [FBE 300] was gonna be. I just knew I didn't like being ... I don't like bugs! And I, my family doesn't go camping or hiking, so . . . I never really have been . . . deep into the woods. So . . all right, we'll see what happens ... I don't think I had in my mind . . okay this is like the worst scenario... It was you took a trail. You walked up, and you walked down.

You were talking about... the field trips the other day. And Ifeel like now, like I'd be more comfortable taking students into the woods. Or . . taking them on a little hike up a trail because I know that ... I mean it's not bad and once you figure out ... the proper things to do with them ...

For Taylor, a disinclination to work outside coupled with a lack of outdoor experiences lead to a fear of the unknown. Without experiences that countered her initial reticence, Taylor was unlikely to ever volunteer to provide field-based experiences for her future students. By working through the experiences herself and finding them to be both more manageable and somewhat more enjoyable than she expected, she gained the confidence to work outdoors with her students, at least in an initial way: 
Ifeel like leaf identification could be something really cool to do. Cause that was really cool... I feel like our whole class, actually, really liked that part. I feel like that could be something cool and teaching kids about soil, and how it's not dirt! And there's more to it. I think that could be something cool.

[Tree identification] was a cool skill to be able to have cause there are so many different trees and, I don't know, my grandparents have a bird identification book. And so now it's just like oh, okay, there are two things I could maybe somewhat do.

This was in line with research with in-service educators, who indicated that personal experience was essential to overcoming their reluctance to engage in fieldwork (Mannion et al., 2013). Taylor elaborated on what experiences increased her self-efficacy in a journal entry: Everything I have learned and reflected on from this class has not only changed my views, but has inspired me to one day use the world around me to teach my students. I feel that my writing abilities, observation skills, identification skills, and perspective have changed a lot his semester, but for the better. I am excited to use my new skills and knowledge in the future and share it with my future students as well.

Taylor again pointed out the centrality of reflection as a way to develop both skills and dispositions. Without an avenue for self-evaluation, the link between personal experience and future classrooms may have been lost.

Observant. In addition to improving their traditional research skills, participants in FBE 300 reported becoming more observant of their environments. While observations are an essential part of research, in this context they were dispositional. This stemmed from participants' acknowledgment that the most important requirements for being observant were 
dedicating the necessary time and effort. Bobby noted the deliberate nature of observation in both her interview and again on her final exam:

It was interesting 'cause especially . . at the [nature preserve]. While we were ... just sitting and looking out; I would notice much smaller, more detailed things than I would if I had just glanced at it.

When I went to these places I actually had time to stop and observe the small details that are important to each ecosystem.

Sam contrasted this disposition with Oak Savanna students more generally:

I remember one day in the spring last year, from when I got on the quad 'til I entered [education building] I counted 20 people with their heads down texting. It makes me sad that technology is becoming more absorbent of, not only our time, but also more absorbent of what we observe and take in on a regular basis.

Payton found that the once he became more observant, he would make the effort even when he was engaged in other primary activities:

Being a runner I get the privilege of seeing all different aspects of nature while on my runs. I've started to make a point to try and take in the nature around me.

I've also begun to notice the small things.

As the participants became more observant, they were quite consistent in what they saw. As Taylor noted in a journal entry, "I feel this class has broadened my knowledge of ecosystems and the world around me. I find myself stopping to look at plants more and thinking about the types of trees around me." Payton said something similar in his final exam, "I began to identify 
trees on my runs with out realizing it." These thoughts were echoed by Chris, "However, I think I have started to become more observant of nature around me. I find myself wondering the species of trees on my way to class ...” And Sam:

... the other day, there was . . a cute little baby leaf on the ground and my roommate was like "oh, we have a little leaf, let's ... let's pick it up and throw it away." And I picked it up and I was like, oak leaf!

Plant identification skills were a natural outgrowth of the project at New Woods, but continuing to notice the trees around them might be the more significant gain. Without realizing it, participants were describing a decrease in what Wandersee and Schussler (2001) referred to as plant blindness, a tendency to not even notice plants in the environment.

Taking an active interest in local plants is especially important for pre-service educators as plant disinterest and plant blindness are documented for grade school children and teacher intervention is considered an important corrective measure (Patrick \& Tunnicliffe, 2011; Strgar, 2007; Wandersee \& Schussler, 2001). This is a connection that the participants in FBE 300 made independently, as they often put their field experiences in the context of their future careers. Chris noted that being observant personally was necessary for incorporating nature education with young students, "I think that by becoming more observant of the world around me and the impact that these things have on my life will be an integral part of incorporating nature into my classroom." Sam viewed it as setting a good example, "I do try to . . take what I learned and apply it. 'Cause I would want my own students to do that someday." While Payton viewed observation as a foundational skill and a way of generating student questions: 
I think those [observational skills] are pretty important for students to have deep observations rather than just looking at the apple... "oh that's an apple." And .. what can you tell about the apple... what different colors are in the apple?

Rather than, . . like I mentioned earlier, just looking at something and saying oh this is just an apple... what more about the apple can you tell, so that's why I think that .. . deeper observations are better to teach at a younger age, then they can build upon that as they grow in science classes.

They're able to gather more questions about it . . . they can make up more questions like why is that apple... why doesn't it have the yellow color? Why do you think that is? Or, .. . how long do you think it will take for the apple to ... rot away?

While being observant was a disposition in this context, it was a disposition that was reinforced as participants made connections between their observations and their developing ecological understanding. Chris noted how her dedicated time in the field impacted her understanding of erosion, I sat in the spot for a long time, because while I've seen lots of evidence of erosion before, I've never really taken time like this to look at the effects of erosion on the land. This was an eye opening experience for me because I could clearly see why erosion is a problem for farmers, landowners and people in general.

This was as sentiment echoed by Payton, who connected to competition: 
When I would go out to the field I would notice things we had discussed in class

happening right in front of me. I saw interspecies competition when two squirrels fought over a tree. I saw erosion all over [town].

In addition to reinforcing ecological concepts, participants also viewed observations as a way of generating further questions, not just for their future students, but also personally. For Bobby, her growing ecological awareness led to an increase in curiosity, "With help from this course I have become more aware of the environment I am in. Observing different places and paying attention to detail make me wonder about the reason things happen the way they do." This was furthered by Alex, who noted, "[I] probably never looked this closely before, but ... I think ... just noticing the little details of things ... brings up more questions ..." This tendency to take observations and contemplate them further was itself a dispositional gain. As students became more observant of their surroundings, they also became more questioning of them.

Questioning. Participants engaged with scientific questions in multiple ways. As part of their research design skills, they worked to formally craft testable questions. The writing guidelines of the observation notebooks required students to include ideas or questions that they developed during the observation period. Outside of questions asked of the instructors, the observation notebooks were the most common way for students to display questioning behaviors. The notebooks served as an indication of what the students found interesting at the time. Chris, for example, was particularly interested in a tree that she was studying:

I wish I had a tape measurer to see what the radius of it is, but I'd have to guess it's about 30-40 feet tall. I would love to know how far the root structure extends out from the base of it as well. I imagine it's probably pretty large given the size of the tree. Is there any way to determine tree age of a tree other than looking at the rings in the trunk? 
She expressed curiosity and a tendency towards estimation, but did not take it further to try to find the answers to her questions. This was the most common way for students to react in the field. Their curiosity peaked briefly, but they did not normally follow through. Occasionally students did seek out further information either during their observation periods or after they were finished, Kit evidenced this:

Pondering question what makes certain trees change color (in the fall) faster than others?

Answer found: As chlorophyll stops being produced (shuts down for the winter because of less sunlight), the tree produces anthocyanins (red colored). Depending on which point of the fall leaf cycle the tree is in determines the leaves' color. Some trees produce anthocyanins faster than others (skip yellow \& orange color stage) and go straight to red.

This was desirable in terms of extending student understanding, but it represented an undercapitalized learning opportunity. The questions from the observation notebooks were intended to be an opportunity for natural history exploration, rather than answered through a quick Internet search. There were a few exceptions, however, as some students sought to answer their questions through more observation.

Payton represented the most questioning of the participants, and he deeply engaged with the observations:

... I feel that I've learned a lot just by doing the 30-minute observations. Each observation I took very seriously, I would really take whatever I was observing and take the time to look at every angle and aspect of it . . Things you might miss if you are just walking by. 
In addition to writing thorough observations, Payton informally crafted a series of comparisons. He watched squirrels in multiple locations over a series of observations spaced throughout the semester. The result was a fair amount of detail on certain squirrel behaviors:

I took a walk down to [Park] which is only about a 5 minute walk from my house in [town]. I wanted to observe some squirrels again and see if there was a difference in their actions within a month. I also wanted to observe their behaviors compared to the squirrels at [Oak Savanna University].

One of the coolest things I saw was a squirrel cracking open an acorn. The squirrel was mainly brown/dark brown and had a thick, bushy tail. It was also a tad larger than the rest of the squirrels that I had seen at the park. It was holding the acorn in both of its hands. It would bring it up to its mouth and begin biting the shell of the acorn. The sound of the squirrel's teeth gnawing on the shell of the acorn made a loud sound that seemed to echo throughout the park. The squirrel was holding the acorn like a basketball with both of its hands. It brought the acorn to its mouth and would bite around the top of it, it finally got the top open and he began biting into the acorn from the top. He was eating the nut inside of the shell. It seemed that the squirrel was using its tongue as well to dig out the nut from inside the shell. Once he couldn't get any more of the inside of the nut out from the shell, he began to rotate the shell in his hands and break it apart more. He was able to easily do this and proceeded to eat the rest of the acorn. Then he went back on the search for more.

These observations lead Payton to more questions and other ideas for data collection: 
Also it made me ask, when do the squirrels begin to hibernate? There was clearly not as many squirrels on campus as usual, some might have already begun to hibernate. I also was wondering if squirrels hibernated on campus or if they had other places such as [Park] where they had more places to hibernate.

It would be interesting to take some data down of how many squirrels are on campus during October, then doing the same data collection in November, and December. It would be interesting to see the numbers and if there is any correlation to as the weather gets more consistently cold and lower if squirrels are seen on campus.

Ultimately Payton could determine the answer to the hibernation question quickly, and that would display a desirable increase in content knowledge, but the disposition towards answering the questions through more observation was fully in-line with the intent of the observation notebooks as a tool for natural history.

During FBE 300 all participants showed dispositional gains, although they were not evenly distributed. Increases in self-efficacy were more pronounced for students who showed lower confidence at the beginning of the course, whereas a tendency towards questioning behaviors was more likely for students who inherently enjoyed work outdoors. Most importantly all participants made progress. The diffuse nature of the dispositional gains argues for incorporation of a variety of experiences and assessment techniques that engage students with different backgrounds and interests. While the observation notebooks were underutilized in terms of their natural history potential, the widespread increase in participants' self-assessment of their observation skills regardless of personal preferences indicates they still contributed significantly towards the learning goals of the course. 


\section{Conclusions}

The attributes of an ecologically literate person have been discussed for over 30 years (McBride et al., 2013; Risser, 1986). Attempts to list what a person should know about ecology or how they should be able to use that knowledge runs the risk of being vague to the point of not providing meaningful input to educators, or so specific as to be both completely prescriptive and overwhelming. Recent work, including Jordan et al.'s (2009) framework threads this needle by providing limited "to know" lists as support for overarching statements on how ecological concepts should be connected and applied. However, when these lists are unpacked, they frequently rest on a significant amount of information deemed essential. For Jordan et al. (2009), eight main threads and thirteen "fundamental ideas," ranging from "organisms" to "evolutionary processes," support one domain of the three-domain framework (p. 497-498). As such, anyone designing an ecology course has to yield considerable editorial discretion: how much should be covered, to what depth, through which techniques?

FBE 300 was designed to provide opportunities for pre-service educators to develop their ecological literacy through a combination of field techniques including nature study and ecology research projects. This fieldwork was paired with classroom experiences and thoughtful reflection to work towards four learning goals: to develop foundational concepts in ecology, emphasize field-based techniques as a way of developing knowledge, increase familiarity with local ecosystems, and make connections between FBE 300 and pK-8 science education. Jordan et al.'s (2009) framework for ecological literacy was used to evaluate progress towards these learning goals with an emphasis on the first two. The authors identified three main domains: "possession of scientific habits of mind in ecology," "understanding of ecological connectivity and key concepts," and "appreciation of the links between human actions and the environment" 
(p. 497). Overall students in the course made progress towards all four learning goals in a way that aligned with the main domains of Jordan et al.'s (2009) framework. Through student writings and interviews, participants displayed a growing understanding of local ecology including the impact people have on both the landscape and animal behavior, an appreciation for fieldwork and corresponding laboratory techniques, and increased dispositions towards fieldwork and field-based $\mathrm{pK}-8$ education.

While student gains aligned broadly with the framework, the end result was a big picture point-of-view that best represented a foundation for future learning, rather than an end point. Of the thirteen "fundamental ideas" listed by Jordan et al. (2009), FBE 300 explicitly covered only nine (“organisms, species concepts, regional and global processes, population interactions, biodiversity, food webs, trophic levels, energy flow, biogeochemical cycling"), and these were to varying depths (p. 498). This decision was based on a deliberate choice to spend more time in the field focusing on fewer topics. At the end of the semester, participants saw the greatest growth in areas that matched the depth of their field experiences, especially if they could observe the phenomena at multiple sites, including: local plant biodiversity, issues related to erosion, and dynamic community interactions. Depth of understanding was linked to first-hand experiences and time dedicated for reflection. These results were in line with work with elementary students by Ballantyne and Packer (2009) who emphasized length of experience and the importance of reflection as important field-based practices. This is both a strength and a limitation of the fieldbased approach. While directly observable phenomena were the most memorable and personally impactful, they were inherently limited in scope.

Importantly even within the areas that participants displayed the greatest conceptual understanding, their ideas were nascent and some misconceptions persisted. This was neither 
ideal nor surprising, as the participants had limited ecology experience prior to the course, but it needs to be kept in mind within the broader conversation about ecological literacy. For granular analysis, Jordan et al.'s (2009) framework was less successful at capturing growth within the course compared to using the framework as a big picture look at gains across domains. The authors' emphasis on higher-order synthesis did not reflect the foundational development that was most prevalent for course participants. This is an important consideration when using an ecological literacy framework as part of course evaluation.

While students in FBE 300 were not a representative sample of pre-service educators, they were typical in that they had limited prior experience with ecology in both the classroom and the field. In fact, they may have had more experience than average (Blatt \& Patrick, 2014; Young \& LaFollette, 2009). Likewise, they are unlikely to have another similar field-based experience before they graduate (Powers, 2004). Ultimately, no single class is enough to meet the standard definitions of ecological literacy (Powers, 2010), which is why recommendations consider a lifetime of educational experiences. However, pre-service educators entering college without a strong ecological foundation are unlikely to completely address any perceived deficit while undergraduates. As such, the most important gains may be their developing habits of mind. Pre-service educators need ecological content knowledge, but also the belief that they can continue to learn on their own, the desire to do so, and the commitment to share their experiences with their future students. This is also a lot to ask of a single course, but it is an area where the field-experiences in FBE 300 were very successful. As such, focusing on a smaller number of topics linked to extensive field experiences is recommended. Active reflection about the learning process is seen as crucial for pre-service educators to link their field experiences, classroom discussions, and their future careers. To support these efforts, future work on the best way to use 
individual, out-of-class observation periods as a way to deepen in-class field experiences is warranted. 


\title{
CHAPTER VI: SENSE OF PLACE
}

\begin{abstract}
This chapter explores the degree to which pre-service educators in a field-based ecology class for non-science majors expressed a sense of place, including both place meaning and place attachment, in connection to their field sites and to the local region. Participants articulate ecological, aesthetic, and recreational place meanings that deepened over the course of the semester. Students attributed their conceptualizations of the local area to specific course experiences; both structured and unstructured time in the field was significant for place meaning. Place attachment was expressed to a much lesser extent throughout the semester and was more likely to be related to meaningful experiences that students experienced prior to the start of the course. To the extent that place attachment developed as a result of the fieldwork, it was in the form of an increased sense of place satisfaction; students interested in outdoor recreational activities conveyed greater interest in local outdoor exploration.

Keywords: sense of place, ecological place meaning, place attachment, place-based education
\end{abstract}

\section{Education for Ecological Literacy}

While there is not a single definition of ecological literacy, common to several frameworks are concerns about ecological content understanding, ecology as a science, and the interactions between people and ecosystems (Berkowitz et al., 2005; McBride et al., 2013; Jordan et al., 2009). Jordan et al.’s (2009) framework defines these three primary areas of ecological literacy as: "possession of scientific habits of mind in ecology," "understanding of ecological connectivity and key concepts," and "appreciation of the links between human actions and the environment” (p. 497). The authors suggested a working definition of what constitutes 
ecological literacy, but they left the best way to move from the framework to course structure as an open question. Drawing more widely from the literature on environmental education and sustainability education, community of practice (CoP) appears as a common organizational structure that is potentially well suited for developing ecological literacy (Aguilar, 2016). In order to form a CoP, people must collaborate towards shared objectives using common skills and practices (Cobb et al, 2003; Cook \& Buck, 2014; Wenger, 1998; 2011). One way to incorporate $\mathrm{CoP}$ as a structure for education is to provide opportunities for students to join an existing $\mathrm{CoP}$ in a meaningful way (Cook \& Buck, 2014; Lave \& Wenger, 1991; Roth \& Lee, 2004). A wellstructured, field-based ecology course with a CoP framework has the potential to highlight all three of Jordan et al.'s (2009) areas of ecological literacy; key concepts and scientific habits of mind are necessary to participate in an ecological $\mathrm{CoP}$ and that participation highlights people's relationship to the environment. (Ecological literacy and CoPs are discussed more fully in Chapter Three: Review of Literature, Chapter Four: Community, and Chapter Five: Developing Ecological Literacy.)

Both a CoP framework and field-based pedagogy closely relate to the principles of placebased education. Place-based education and place-based pedagogy focus on curricular outcomes that connect students' lives and the concepts they are studying without dictating a common instructional design (Gruenewald, 2003; Pyle, 2001; Smith, 2002). Fundamental to this goal is active learning grounded in local issues and areas (Smith, 2002; Smith \& Sobel, 2010). Placebased education has been tied to environmental education since the 1990s (Sobel, 1996; Zandvliet, 2014) and to the study of natural history (Lorsbach \& Jinks, 2013; Pyle, 2001). Placebased ecology education is a natural application of place-based pedagogy that centers on the science of ecology, both concepts and practices, as it can be studied locally, with field-based 
courses including work in local ecosystems. As such, field-based ecology courses with a CoP structure fall under the broad category of place-based education.

\section{Place-based Education and Sense of Place}

By its nature, place-based education is rooted in a location, whether that is a civic community, a specific ecosystem, or both. To this end, it would make sense that a place-based educational experience would result in a deeper understanding of and connection to that location. The combination of a conceptual understanding of an area, "place meaning," and a personal connection to that area, "place attachment," collectively forms a "sense of place" (Kudryavtsev, Krasny, \& Stedman, 2012; Kudryavtsev, Stedman, \& Krasny, 2012, p. 231; Russ et al, 2015; Semken \& Butler Freeman, 2008; Stedman, 2002). While the connection between place-based education and development of sense of place in education is logical, explicit sense of place is not always a goal for place-based courses (Kudryavtsev, Stedman, \& Krasny, 2012); however, inclusion of sense of place as an explicit learning outcome for environmental education and other related scientific fields is becoming more common (Kudryavtsev, Krasny, \& Stedman, 2012; Kudryavtsev, Stedman, \& Krasny, 2012, p. 231; Russ et al, 2015; Semken \& Butler Freeman, 2008; Warkentin, 2011).

While sense of place does not have a single definition, common models include place attachment and place meaning in combination or individually (Kudryavtsev, Krasny, \& Stedman, 2012; Kudryavtsev, Stedman, \& Krasny, 2012; Manzo, 2005; Russ et al, 2015; Semken \& Butler Freeman, 2008; Stedman, 2002). Place attachment is matter of connection, which can be formed through a sense of "place identity," belonging to a place, and by "place dependence," seeing a place as the ideal location for a preferred activity (Kudryavtsev, Stedman, \& Krasny, 2012, p. 231). Place attachment might also include "place satisfaction," an understanding that a place is 
sufficient to meet ones needs, even if it is not ideal (Stedman, 2002, p. 564). Place meaning focuses on conceptual representation of a place, and therefore has a nearly infinite list of possibilities (Kudryavtsev, Krasny, \& Stedman, 2012; Kudryavtsev, Stedman, \& Krasny, 2012; Manzo, 2005; Russ et al, 2015; Semken \& Butler Freeman, 2008). For sense of place in ecology education, some of the more important possible place meanings may be ecological, cultural, and aesthetic (examples from Kudryavtsev, Stedman, \& Krasny, 2012, p. 231). Ecological place meaning specifically has been defined as "the extent to which ecosystem-related phenomena are viewed as valued or important characteristics of places" (Kudryavtsev, Krasny, \& Stedman, 2012, Kudryavtsev, Stedman, \& Krasny, 2012; Russ et al., 2015, p. 74). Sense of place is considered important as a way to foster environmentally friendly attitudes and behaviors, although the literature on that connection is not well established (Kudryavtsev, Krasny, \& Stedman, 2012; Kudryavtsev, Stedman, \& Krasny, 2012; Russ et al, 2015; Semken \& Butler Freeman, 2008; Stedman, 2002). Regardless, teaching explicitly for sense of place is of interest, and literature indicates that lecture and direct experience can be used to foster sense of place (Kudryavtsev, Krasny, \& Stedman, 2012; Kudryavtsev, Stedman, \& Krasny, 2012; Russ et al, 2015; Semken \& Butler Freeman, 2008). While place-based education in general remains more common at the pK-12 level (Semken \& Butler Freeman, 2008), place-based courses are of interest at the post-secondary level for in-service educators (Mannion et al., 2013; Miele \& Powell, 2010), pre-service educators (Membiela, DePalma, \& Suarez Pazos, 2011; Warkentin, 2011), and general education students (Semken \& Butler Freeman, 2008).

\section{Sense of Place in Field-based Ecology 300}

In this case study, sense of place in a field-based ecology course for pre-service educators (FBE 300) was evaluated. The course had a CoP organizational structure with an explicitly 
place-based instructional design. While the course focused on ecology as a science, place-based pedagogical choices were highlighted in discussions throughout the course. Place-based pedagogy was discussed specifically in connection to inquiry-based science education and citizen science. Students were encouraged to connect course concepts to their future practice through reflective journals, observation notebooks, a lesson plan, and nature passports, which was an on-going project that required students to find and experience art and media with ecological themes.

\section{Research Question}

As a general education, placed-based ecology course, the development of a sense of place was not an explicit learning objective in FBE 300, but the course was designed to increase awareness of local ecosystems, which could in turn increase ecological place meaning (Kudryavtsev, Krasny, \& Stedman, 2012, Kudryavtsev, Stedman, \& Krasny, 2012; Russ et al., 2015, p. 74). As a course for pre-service educators, the ability for students to make connections between FBE 300 and pK-8 education was an explicit learning goal that related to both ecological literacy and place-based education. From the research and the learning goals of the course, one research question related to sense of place (SP1) emerged:

SP1: Do students express a sense of place during FBE 300 ?

The emergent question stemmed from the third guiding question for this dissertation, "Do preservice educators develop a sense of place in temporary collegiate environments?"

\section{Findings}

While FBE 300 was designed as a field-based class and fieldwork is inherently linked to place, the degree to which participants developed a distinct sense of place was an open question. Open coding was performed on class artifacts including journal entries, observation notebooks, 
and interviews to generate approximately 17 codes (See Table 4). Axial coding resulted in two major categories, Place meaning and Place attachment, each with supporting sub-categories that worked together to create the theme, Sense of place (See Figure 3). Student artifacts showed previously established place attachments stemming from their personal experiences prior to class as well as the beginnings of place attachment related to fieldwork in the course. Participants showed a stronger sense of growing place meaning that was related to their increased conceptualization of the local region as an ecological, aesthetically, and recreationally important place. This growing conceptualization was at least partly the result of an inherent interest in the exotic over the familiar.

Table 4

Alignment of Data Sources with Emergent Questions Regarding Sense of Place

\begin{tabular}{lcccc}
\hline Question & Exams & $\begin{array}{c}\text { Observation } \\
\text { Notebooks }\end{array}$ & Journals & Interviews \\
\hline SP1 & $\mathrm{X}$ & $\mathrm{X}$ & $\mathrm{X}$ & $\mathrm{X}$ \\
\hline
\end{tabular}




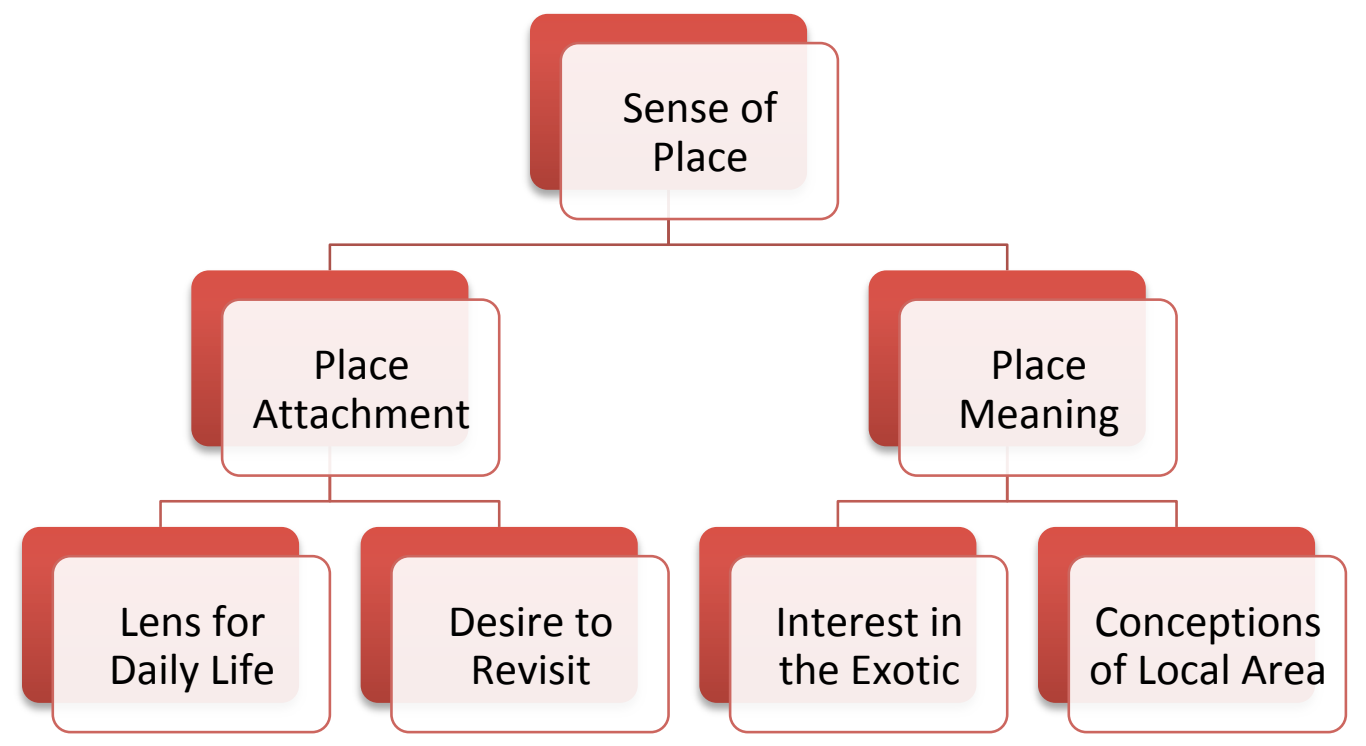

Figure 3. Organizational scheme for the theme, sense of place, with major categories and subcategories.

\section{Development of Sense of Place}

Place attachment. Place attachment is one of the central components of sense of place (Kudryavtsev, Krasny, \& Stedman, 2012; Kudryavtsev, Stedman, \& Krasny, 2012, p. 231; Russ et al, 2015; Semken \& Butler Freeman, 2008; Stedman, 2002). It can be expressed as a place identity, which is a sense of belonging to a specific location, and as place dependence or place satisfaction, the idea that a specific place meets specific needs. Place attachment is considered an important potential contributor to environmentally supportive behaviors (Brehm et al., 2006; Kudryavtsev, Krasny, \& Stedman, 2012; Kudryavtsev, Stedman, \& Krasny, 2012; Russ et al., 2012; Stedman, 2002). The degree to which place attachment is developed in courses that focus on the development of sense of place is unclear with some studies showing significant gains in both place attachment and place meaning (Semken \& Butler Freeman, 2008) and others showing that place meaning is easier to develop (Kudryavtsev, Krasny, \& Stedman, 2012). In FBE 300 participants expressed place attachment by using specific places as a Lens for daily life, which 
correlated to place identity, and by expressing a Desire to revisit, which related to place dependence or place satisfaction (Kudryavtsev, Krasny, \& Stedman, 2012; Kudryavtsev, Stedman, \& Krasny, 2012; Russ et al, 2015; Semken \& Butler Freeman, 2008; Stedman, 2002). While certain participants showed strong place attachments, these were largely developed prior to the course from childhood or through impactful personal experiences. FBE 300 only weakly contributed to place attachment; however, developing place satisfaction indicted a potential for increased place attachment over time.

Lens for daily life. Participants' greatest sense of place attachment was established prior to the beginning of the course. Students expressed aspects of place identity in terms of strong ties to the places they considered home. Identity also formed through meaningful personal experiences, such as study abroad for Sam. In both cases, students used their important places as a lens for daily life. Participants' important places served as a place for comparison in both offhand and explicit ways.

Sam exemplified the way that place identity could be used as a lens to filter other experiences. She spent a semester studying in Spain where she also had the opportunity to travel regionally. This was a life-changing trip that influenced how she approached her daily life and her experiences in FBE 300. As she noted in one early journal entry:

Since I am missing my friends and Europe I decided to write about some environmental related thing I noticed while I was over there.

Compared to Spain, France was kind of a dirty place. There was trash in the streets and old smashed smelly leaves everywhere. France was full of colors and life, but I loved Spain more. 
Sam's writing indicated the extent to which she was attached to, and identified with, Spain. She often commented on her study abroad experience and used it as a point of comparison for new places and experiences. While she enjoyed her travels throughout Europe, she identified with Spain in particular. Her tendency to relate current experiences, including those in FBE 300, to Spain was something she explicitly acknowledged in her interview: My first one [journal] was about Spain and Granada . . and Morocco just cause those were such eye-opening differences that I had . . I kept relating everything to like oh, I saw this in Spain. Or, oh that's very different. And also . . this time last year I was in Spain so I've been thinking about it a lot. And I just . . really wanted to get it out there and talk about it. I talk about that stuff all the time, but it was just really cool to talk about that . . because that was basically taking like what I was learning about and comparing it to what I had seen ... that was related to something that I wanted to talk about in relation to class.

In addition to changing how she viewed other places, Sam's trip to Spain had a lasting impact on her behavior. She particularly noted an over-use of cell phones the she felt made people miss too much of what was happening around them:

After spending four months in Europe without a phone that worked wherever, whenever. It forced me to walk with my head up. I loved this I saw so many amazing sites I would have never seen before, if I were to talk with my head down.

When I came back to campus I noticed the phone-addicted culture we live in here. In this way, Sam's changing place identity as it related to Spain had an impact on her local place meaning in terms of a culture of cell phone use. 
Sam related class experiences to a newly established place identity; conversely Bobby related her time in the course to a place she had left years before, but that she still considered home:

When we watched the video about Hurricane Katrina I was surprised by how much I'd forgotten. I remember watching the news and talking to my family that live in New Orleans, but I didn't understand the severity of the storm. At the time I was in 4th or 5th grade and I remember being told my family was evacuating the city for X amount of time. After that there were images of recognizable places being ripped apart on television and people struggling to stay alive. These memories came back as we re-watched clips from the disaster. I could relate to the girl in the movie because it's my home and I would have never imagined the city could be destroyed and sunk underwater so quickly.

Bobby's life in Louisiana gave her a unique connection to the topics of wetland ecosystems and wetland conservation. This impacted her experiences in the classroom watching a documentary on wetland ecosystem services and Hurricane Katrina. It also impacted her understanding of the importance of Great Egret Wetlands and how that restoration project related to the importance of wetlands generally and to ecological succession (discussed more fully in Chapter V: Developing Ecological Literacy in the Field). Sam and Bobby's experiences reinforce that sense of place can be related to both positive experiences and more ambivalent ones (Manzo, 2005). While Sam greatly enjoyed her time in Spain, Bobby reflected on a very negative experience in a beloved place.

While aspects of both Sam and Bobby's place identities were established prior to the beginning of FBE 300, they were still important in terms of coding for a sense of place identity. Overall, FBE 300 did not clearly impact students' sense of place identity (as opposed to place 
dependence, place satisfaction, or place meaning). However, reflections on place sometimes lead participants to recognize place identities they already possessed. This was true for Cameron, who had strong place attachments prior to the course. In his interview, Cameron realized where he felt most at home:

My spot! Man, it sounds weird. I've never really thought about this. But I guess probably out in the forest. Wow! I ... I don't really like to say that cause I obviously like to sit down and rest, every now and then, but ... I guess out in ... out in nature. Oh yeah. In fact, my buddy in [small town] . . I always have to help him clear trees that fall. And we'll drag 'em and cut 'em up for his firewood, and there's a couple that we've left that have [a] view ... over certain areas, and I'll go and climb up on top of it and just lay and stare...

Cameron's place attachment was apparent in his writing and when talking to him even if he had not fully acknowledged it to himself. His sense of place attachment represented a mini-discovery for Cameron.

Desire to revisit. Place dependence and place satisfaction are aspects of place attachment that relate to a person's view of an area as being well suited for his or her needs (Kudryavtsev, Stedman, \& Krasny, 2012; Stedman, 2002). This type of attachment can be very specific, such as viewing New Woods Nature Preserve as the best place for hiking, or it can be more general, such as preferring a forested setting as best for hiking (Ryan, 2005). In FBE 300, this type of place attachment related to the desire to revisit certain field locations, and the recognition that participants would miss their time there. Cameron summarized this in a journal entry: 
I think it is important to truly appreciate whatever topics you may be teaching. I am going to miss my time in [New Woods] after this class is finished. I hope to revisit this place down the road in the future.

Cameron connected his time in New Woods as an important part of his learning experience. His comments show both a generalized aspect, connected to whatever topics he might teach, and a more specific connection to a particular nature preserve. Participants responded to several locales of interest, for example Alex indicated that she'd like to visit a hiking trail that she didn't have time to explore and to revisit the animal park in the spring or summer.

Of all the participants, Kit expressed the most interest in further exploration at her field sites including the nature preserve, "Overall, I loved being able to explore the nature preserve on my own and make observations. I hope to go back to [New Woods] during the spring when all the plants and trees begin to bloom again;" the wetlands, "I found this [Great Egret Wetlands] all to be very fascinating and I would definitely go back and visit again;" and the botanical garden: In addition, it was cool to find out that there was a rotating sculpture exhibit as well as several sculptures located around the gardens. Overall, this was a great trip and I will definitely make my way back to the garden during my time at [Oak Savanna]. Importantly for establishing place attachment, Kit followed through on her plans to re-visit before the semester even ended. She noted in a journal entry that she went back to hike at an area she had seen in class but that she did not have time to explore:

I was intrigued by the trail that my professor had pointed out to the class... I was about to embark on my adventure. Right away, I was challenged with the task to hike down a large hill. I found it really tough to stop myself from catapulting forward ... I am glad 
that I went on this adventure, despite all the challenges. It will be something that I never forget doing here at college and a view that I will always remember.

This experience was something Kit revisited in her interview:

...We ... were there [New Woods] to do a job most of the time. But ... I really loved the last day that we were there and we could [do] several observations, and we would kind of go off on our own and explore different things that we hadn't seen yet. Or I would want to go back and... hike the trails and see different places too, that we didn't get to see because, I find that enjoyable, so... That [hike] was awesome. Oh, one of my favorite things I've done here, ever!

Like place identity, place dependence was not strongly developed in FBE 300, but students expressed place satisfaction. For Cameron and Alex, this included a desire to revisit specific field locations. Kit went one step further by independently exploring areas she had visited in class. One of the key contributors to place attachment is repeated experience in a place over time (Ryan, 2005). All participants had multiple trips to New Woods in class, and some of them revisited on their own. The degree to which participants continued to use field sites recreationally after the course would be an interesting place for further study to see if the early signs of place attachment continue to grow beyond the limits of the course.

Place meaning. Place meaning is the second key component to sense of place (Kudryavtsev, Krasny, \& Stedman, 2012; Kudryavtsev, Stedman, \& Krasny, 2012; Manzo, 2005; Russ et al, 2015; Semken \& Butler Freeman, 2008; Stedman, 2002). Place meaning is formed as a people develop a conceptual understanding of an area. This conceptualization can be highly personal, and therefore the possible variations and expressions are practically limitless, but they ultimately support and create place attachment (Stedman, 2002). While place meaning is highly 
personal, several common types are recognized in the literature. These include ecological place meaning, aesthetic place meaning, cultural place meaning, and recreational place meaning (Kudryavtsev, Stedman, \& Krasny, 2012, p. 231). Participants in FBE 300 showed a growing sense of place meaning throughout the course by expressing new or expanded Conceptions of the local area. Participants also expressed a distinct Interest in the exotic, which might first seem antithetical to sense of place, but which helped inform students' developing place meanings.

Interest in the exotic. Participants' interest in the wildlife and landscapes that appeared exotic or novel was apparent from the beginning of FBE 300 and manifested in several ways. Students had a tendency to compare unfamiliar, local ecosystems to natural areas seen in movies or to distant ecosystems that they had studied throughout the course of their educational careers. When asked to describe biomes or natural areas or when selecting nature programming, they often chose distinctly non-Midwestern examples. This was not an undesirable outcome, as an interest in the exotic could be important for considering global issues. While the tendency was pronounced and it reinforced the idea that participants initially thought of nature as something that is found "somewhere else" (Russ et al., 2015, p. 85), it ultimately did not hurt, and in some instances may have helped, students' abilities to develop local place meaning.

Examples from exams and assignments. Participants' tendencies to focus on foreign or distant landscapes when thinking of natural areas became apparent from responses on midterm exams. When asked to define and characterize biomes, distant landscapes were the most common examples. Ranked in the order they appeared on the exam, students focused on tropical wet forests (7), deserts (6), and boreal forests (5). To an extent this was inevitable, as the question required students to describe multiple biomes, most of which were not observable regionally. The biomes chosen were not surprising, as rainforests are practically the definition of 
an exciting, distant landscape in environmental education (Lorsbach \& Jinks, 2013; Louv, 2005;

Sobel, 1996), an idea that was born out by Cameron:

My teachers did a very good job of ... I've had a few teachers that were all for the rainforest. You know they made it very clear that we're destroying the rainforest. No I was aware of a lot of it.

As such, rainforests might not only be exotic, but also a topic area where students felt more comfortable with than their metaphorical backyards (Lorsbach \& Jinks, 2013; Louv, 2005; Sobel, 1996). Still, the fact that only two students chose a biome that matched what they saw at a field site (temperate forest) was striking, and it was indicative of where the participants were at the beginning of the semester in terms of what they considered ecologically meaningful places.

As part of FBE 300, participants had the opportunity to explore ecology or nature-related themes in art and the media. Over the course of the semester, students created an on-going project called a nature passport. The goal was to collect "stamps" by engaging with material in each category, nature-related books, visual art, and the media, and relate the material to content from FBE 300 and to their future educational practice. The passports allowed a glimpse into how students conceptualized the material and how they thought it related to $\mathrm{pK}-8$ education, and also an idea of what interested them outside of required course materials. Participants often chose to explore areas that were new to them. Payton and Sam chose to watch a documentary together, and while they chose what might be a familiar ecosystem, seasonal forests, in their discussion of the experience they focused on what was unfamiliar. Payton noted in a journal:

For one of my nature passports I watched a Planet Earth video. It covered seasonal forests. It was an incredibly informational documentary. I actually learned about many 
new species of trees and animals that I had no idea existed. I talk about that more in depth in my nature passport.

Sam's description was very similar and focused on what was completely novel to her:

The video was very informative and interesting; the one we watched was about seasonal forests. The movie showed us all different forests that we didn't even know existed in the world. Also for each forest they showed and explained the lives of the most popular animals in the related forest...

Sam's use of the word "popular" to describe the animals was an interesting choice. Charismatic megafauna were not a specific topic of discussion in class, but Sam seemed to imply that while the forests may have been unfamiliar to her, the animals had some fame.

Non-native organisms were also popular for observation periods. Alex focused on a bird of paradise for a plant study:

Today during class, we visited [the botanical garden]. I really enjoyed this opportunity to see different types of plants that aren't native to our area-particularly the tropical plants. My favorite plant, which I sketched for an observation, was the bird of paradise.

I feel like I'd enjoy coming back here sometime as well as to explore the plants and gardens outside in nicer weather. It was interesting to see such a diversity of plants, and ones that we don't see in our local region.

Alex was one of the few students who chose to do more than one plant study, and she characterized native plants as well, so her interest was not at the expense of learning more about native plants. In fact, she showed quite a bit of interest in tallgrass prairie plants. Rather, it just reinforced the idea that the new and the novel were more likely to be inherently exciting, and 
perhaps a jumping-off point for approaching subjects that might seem a bit dry otherwise. This interpretation was supported by Bobby's choice of documentaries for her nature passport: Well especially with . . paying attention to the issues out . . with the videos I watched for the passport, especially looking into that stuff, I didn't know a ton about global warming, what's going on in the Arctic, or the problem with the bees and the honey. So, I thought that was really cool.

While the documentaries might not be focused on the Midwest, the issues of global climate change and colony collapse disorder were of local relevance, if not of equal threat. These documentaries could easily be used as a starting point for discussing a wider range of local issues. While Sobel (1996) argued place-based education at the elementary level should start local and expand outward, for pre-service educators, starting at a distance and working back might be a very valuable approach, an idea explored further in the next section.

Comparison to media/distant ecosystems. Participants' tendency to focus on exotic locations was not limited to examples on exams or in assignments. When encountering a new field site or a previously undiscovered part of town, several students made comparisons to places they'd seen in movies, read about in books, or encountered otherwise vicariously. For Cameron, this provided an extra sense of adventure when visiting a remnant of oak-hickory savanna, "It [field site] made me feel as if a lion was going to jump out and grab me." Cameron was not the only participant to visit grassland and think of Africa, rather than the Midwest. Kit described a similar sensation on one of her independent excursions:

I felt like I was in a movie, dodging and moving plants out of my way as I walked. It was pretty fun... At the end of our hike we made it to a grassy plain. It reminded me of the scene in "The Lion King." It was so open and beautiful. 
For Sam, thinking of movies and books was a regular way for her to approach new landscapes. This was evidenced as she described Paris in a journal:

I remember when we were up on in the Eiffel Tower looking down I saw a small pond with a beautiful tree that had some fallen golden colored leaves around it. The pond had a group of ducks in it. Some looked as if they were babies. The scene was perfect; it looked as if it came out of a movie.

And as she remembered Great Egret Wetlands in her interview:

And that ... walkway through the water, the one you look at it, it reminds me of if you've ever seen the movie, The Last Song, there's like this big walkway that ... her and her boyfriend walk across and ... it was like, oh I feel like I'm in the movie, my favorite book.

Also as she described her favorite tree, "I was always amazed by willow trees ever since I saw the movie Pocahontas. They are just such an interesting kind of tree to me."

Participants' tendency to compare local ecosystems to exotic landscapes showed the power of their interest in the exotic. Rather than viewing this tendency as a negative, a lack of connection to place, their interest helped provide an "in" where students were able to connect their positive associations with ecosystems they'd only visited vicariously to the field sites they visited in FBE 300. This helped make the field sites simultaneously new and exciting, yet familiar. How powerful these associations could be as a pedagogical tool was evidenced in Sam's changing opinions about taking a multi-hour field trip on a Saturday:

So I was ... actually kind of really bitter about going on that one Saturday trip. I was like, "uh, this is my Saturday. This is homework. This is my Friday night." Blah, blah, blah and then... We got there. We were in the van and you had the orange juice and the doughnuts, and I was like "oh, I guess it isn't so bad." And then we ... got to [Great 
Egret Wetlands] and just ... I don't know how to explain it. But . . that feeling of . . . wholeness, and just ... beauty, and going on forever...

This passage from Sam's interview immediately preceded her thoughts on how the wetland related to her favorite book and movie; her connection was deeply felt and led her to additional learning opportunities. After the interview, Sam wrote an additional entry for a course project, the nature passport, on The Last Song. This was despite the fact that she had already completed the assignment.

There is literature to support the idea that sense of place can develop at a distance. Russ et al. (2015) noted research indicating media can contribute to place meaning and Semken and Butler Freeman (2008) note that education on place, even in a classroom setting, can increase place meaning. Louv (2005) noted an environmental researcher who was inspired in her career by passages from a book. Of critical importance in FBE 300 was that this type of vicarious place meaning deepened actual field experiences. In Sam's case, it was enough to overcome significant resentment at the idea of losing a Saturday. In this way, the interest in the exotic was a tool that helped students begin to conceptualize their local area, rather than a barrier to developing local place meaning.

Conceptions of the local area. Students' conceptions of the local area expanded throughout FBE 300. The choice of field sites and the instructional activities within them were important to this process. Also vital was the inclusion of unstructured time that allowed participants the chance to explore and to feel that they were making their own discoveries. In turn, these discoveries lead the participants to describe the local area as a place of ecological, recreational, and aesthetic importance. 
As an ecologically important place. Participants' ecological content gains are discussed more fully in Chapter V: Developing Ecological Literacy in the Field. Here the extent to which participants saw the Midwest in general, and the local area in particular, as a place of ecological importance is considered as a part of place meaning (Kudryavtsev, Krasny, \& Stedman, 2012, Kudryavtsev, Stedman, \& Krasny, 2012; Russ et al., 2015). Throughout FBE 300, students expressed a growing understanding of the local area as an ecological place. This manifested in two ways, students showed a growing local awareness of organisms and ecosystems that they did not know could be found regionally, and through their experiences they were also challenging the familiar by discovering new aspects of ecosystems and organisms that they thought they knew well.

Local awareness, an increased appreciation for the variety of ecosystems present in the region and the organisms that lived within those ecosystems, was a running thread during the course of the semester. Participants began to view both the state and the local city as areas of ecological importance and of greater personal interest than they had realized. This process began on campus. From the first week of class, they began to notice greater diversity of plants on campus. Payton was surprised by what he could see when he was asked to look, "It was also eye opening to see how many different species there were just around campus." Taylor expressed a similar sentiment when making observations of a small plot of tallgrass prairie plants outside of the science building (emphasis in the original), "The first thing my group did was go to the prairie plants and describe them as well as draw one. There we so many different types of plants to choose from." For Sam, paying closer attention to campus was a continuation of her determination to be more attuned to her environment that she brought back from Spain. This lent a certain passion to her writing (emphasis in the original), "I have challenged some of my friends 
to do this [put down their phones] and they told me they did notice a difference in what they saw on a daily basis. *Open your eyes people!*" Sam expanded on how her desire to be more observant worked with her experiences in class to make her both more aware of and more interested in the plants around her:

I agree with the statement of . . every time you walk outside . . you can notice something different. It doesn't mean that you have to [go] to Europe, but I know I just always talk about that a lot because it holds a big piece of me but . . I agree, like even when I went home ... I notice different things and trees that I would've never known what they were, or had the desire to know what kind of tree they were, so.

After the first week of class, fieldwork moved off-campus. Despite the fact that all of the students in FBE 300 were upperclassmen, many of them had not explored much of the city. Oak Savanna University is not located in a traditional college town, and the participants' somewhat insular experiences were not unusual. Bobby noted how FBE 300 offered the opportunity to see more of the local city, "I think with this class; I've seen more of [town] than I have in ever, since I've been here." On her midterm exam, Taylor expanded on how this increased exposure changed her conception of the city as an ecological place:

By going out to [New Woods] I was able to see a part of [town] I had never seen before. From this I was able to realize how pretty/different [town] could actually be, not just a bunch of farms and factories.

Chris also began to expand her view of the city to include important green space:

Overall, I think the field experience impacted my ideas about [city] in a very positive way. Coming from living in a house built into a heavily wooded hillside to [Oak Savanna's] campus, I never thought much about nature in [city] at all. Now, though, I 
know that there is a huge area in [city] dedicated solely to nature, and the preservation of it.

Payton and Cameron were more familiar with the city as a whole than most of the other participants, but they also learned more about local conservation and restoration areas. For Payton this included Little Northern Wetlands, "The next stop was the wetland preserve. This was something I didn't even realize was in [city]." Cameron was surprised by a remnant of oakhickory savanna, "The field trip made me very excited and gave me insight about an area that [I] never $[\mathrm{knew}]$ existed ... I never knew there was a restored prairie area in the back of the cemetery."

Participants' ecological place meaning expanded outward to encompass not only the campus and the city, but also the region and the state. Bobby wrote at the end of the semester: Going to [Great Egret Wetlands] and [Glacial Dunes Preserve] put into perspective the many types of ecosystems there can be even when I least expect it ... I was also exposed to new plants such as cacti and different birds, frogs, and muskrat.

Multiple people in the class echoed Bobby's sentiment. Cameron, who knew the local region better than any other participant, was equally surprised:

I never really knew that reserves like this exist in [the state] ... [Glacial Dunes] was also an interesting place. It's incredible to think that there is that much sand in one place in the middle of [state].

The fact that Cameron had not found this particular location despite knowing the region well was not surprising. As Kit noted: 
After [Great Egret Wetlands], we went to a small state forest preserve. It was so hidden you would not have known it was there unless you are looking for it. As a class we hiked through a trail (somewhat made by a truck/car).

Increased familiarity with local ecosystems was itself a goal of FBE 300 , and students continued to explore outside their shared field sites. These independent excursions impacted their ecological place meaning as well. Both Alex and Payton contributed to their observation journals while traveling over weekends and breaks. As such they visited ecosystems that were not accessible to the entire class. Payton described an area that felt further removed from campus than the few hours he traveled:

It felt like I had stepped in a transporter and that I wasn't in [the state] any more. It was truly an eye opening experience getting to hike at [state park]. It was incredible seeing this landscape up close and personal.

With his increased awareness came a greater tendency to ask questions. Payton noted how his curiosity made his routines more interesting: ... I'm driving and I see a big hill, I'm like, "I wonder if a glacier formed that?" Little things like that that you don't really think about, in general, that kind of make [the state] a little bit more interesting to drive through now. You ... just have something to look at and think about a little bit more... Some ... things that I wouldn't think twice about, now I might take the time a little bit more to think about ... Whether ... looking at a tree and just waiting, and then you might see like four or five different species crawling around the tree. I didn't even think about that before ... Or, seeing a tree and ... I wonder what kind of . . tree that is. And looking at the ground ... I wonder ... what's under my feet 
right now... Little things like that that I wouldn't think twice about before I took this class...

Sam took advantage of a weekend home to learn more about her literal backyard:

In one of my observations I talked about the wild grass at the bottom of my yard around the pond. And I tried to look it up on the Internet ... different wild grasses common in this area. And ... who would've thought there'd be ... so many wild grasses!

Participants' local awareness mainly arose from experiences with unfamiliar landscapes and organisms many of which they attributed directly to the fieldwork or other projects from FBE 300. By visiting new parks, preserves, and restoration sites, they got a broader view of the landscapes and organisms found in the Midwest. Their ecological place meaning expanded in another way as well. In addition to making personal discoveries, students also took a closer look at organisms they felt they knew well. In this way the act of challenging the familiar formed a second aspect of ecological place meaning.

Participants challenged their previous assumptions about local landscapes and organisms in two main ways. First, through dedicated periods of observation, they began to notice more detail about familiar organisms or phenomena. Secondly, their growing local awareness caused them to re-conceptualize their understanding of the state. This frequently came in the form of qualifying descriptions of the region that, while not precisely inaccurate, were overly broad (e.g. that the Midwest is all farmland).

Chris frequently chose to observe in her yard. This allowed her the opportunity to pay much closer attention to common organisms that she might not otherwise notice. During one observation, Chris noted, "I found it interesting how still it [rabbit] was. I could barely even see it moving when it breathed." This was a small detail, but it was the type of detail that piqued her 
curiosity, as she asked during a separate observation, "Why can't we see spiders and bugs breathe like we can with other animals?" Cameron also used observations of common organisms to ask questions or to note what seemed out-of-place:

Inotice on the corner of the dock a massive spider web where two spiders are hanging out together. Why are there two spiders on the same web? I have never seen this before and it brings up many questions.

Sparrows on the forest floor which seems unusual for a bird.

I notice there are still a great number of worms at the surface level of the soil. It seems a little cold for worms to be on the surface.

While these questions and observations allowed students to think about what they did not know about common organisms, they also served as an indication that common organisms were worth knowing about, an aspect of ecological place meaning (Kudryavtsev, Krasny, \& Stedman, 2012, Kudryavtsev, Stedman, \& Krasny, 2012; Russ et al., 2015).

In addition to using observations to document unusual or previously unobserved behaviors, participants also spotted organisms that they did not see very often or that they did not realize were native to the state. The animal park allowed students to observe native animals that they were unlikely to encounter on their own for multiple reasons including extirpation. Alex was intrigued by a silver fox, "I had never seen foxes that weren't red in color-so I found them to be fascinating." Chris and Bobby were both surprised that black bears were native to the state. While the animal park was helpful for close viewing of animals, the extended time at the field 
sites provided students with their most exciting chance encounters. Bobby recounted finding a raccoon asleep in the trunk of a tree at New Woods,

It was very cool . . like finding the raccoon ... That's not an everyday experience for me ... So if you're outside more ... there will be more things you can see, eventually, and time, if you're really paying attention to it.

These chance encounters also won over Taylor, who did not normally enjoy the outdoors: I really enjoyed sitting and watching over the water because it was interesting to find different animals ... These animals [muskrat and great blue heron] were very cool to see! This was definitely my favorite because it was something I had never seen before, and to me more interesting than identifying trees.

While tree identification may never fully compete with spying a great blue heron, participants were excited about organisms that challenged their notions of plant life as well. Payton was impressed by an oak tree once he knew more about its history: [Michelle] shared some interesting facts with us about this oak tree. It is over 500 years old. The oak tree is very unique because it grows in all different directions. It is so large that some of the branches have to be held up by supports!

At the opposite end of the spectrum, Chris noted that a plant did not have to be special to be interesting:

I know this small plant isn't anything significant, but what interested me about it is that it sticks up through a thick layer of fallen leaves from the mature tees surrounding it. The stem of the plant isn't straight, but looks as if it has grown out of the way of the fallen leaves. 
Building time into FBE 300 for these chance encounters was vital for the course because they were so significant to the students. While observations only sometimes lead to deeper understanding of ecological concepts, they were essential for deepening ecological place meaning. This is in line with literature that indicates that repeated, firsthand experience is important for developing aspects of sense of place (Russ et al., 2015; Ryan, 2005). In terms of course structure, it is a strong argument for dedicating class time for observations in natural areas that students might not otherwise find for themselves even if that means less time for more structured activities.

As participants showed a changing perception of both local plant and animal life, they also showed a critical re-conceptualization of the state itself. Field sites in a variety of ecosystems provided participants with the chance to broaden their ideas of the ecological importance of the region. Several of the field sites were novel to the participants. As Bobby noted, "Most of the ecosystems I knew before were not like these [wetlands and sand prairies] that that's what made them unique and fun." Payton looked at his explorations as a practical way to broaden people's notion of the state, "I believe that there are places in [the state] that can really open the eyes of people and show that [the state] isn't just full of soybeans and corn." Kit also looked past soy and corn to other types of agriculture and non-agricultural systems: We also saw prickly pear cactus, which was so out of the ordinary to see in [state]. However, I have to say, being at this state forest really changed my mind about [the central part of the state]. I have always had the idea that central [state] is one big cornfield. [The state forest] proved that to be false. The forest was full of agriculture with 
tons of native oak-hickory woodland, pine plantations, open fields, grasslands, and sand prairies.

Kit also reassessed her assumptions about the region's topography, "The trail was also extremely hilly, I definitely got my workout in for the day. The climbs were a challenge I wasn't expecting from [the central part of the state]."

While participants' preconceived notions of the region as largely flat, agricultural land were not wrong, they limited participants' views of the importance of the state as an ecological place. As their view of the state expanded to include preserved or restored ecosystems such as wetlands and sand prairies, their ecological place meaning grew as well. This put their ecological place meaning somewhat at odds with their ecological content understanding. Their developing ecological literacy included the impact of agriculture (See Chapter V: Developing Ecological Literacy in the Field), whereas their ecological place meaning decreased the prominence of agricultural ecosystems in their conceptualization of the state. The field sites were deliberately chosen to showcase parts of the state beyond urban centers and farmland, which may have contributed to participants perceiving more intact natural areas than the state can boast as a whole. This juxtaposition was not necessarily inappropriate, as it allowed participant to connect their understanding of the dominant agricultural and urban landscapes with their increasing awareness of the importance of intact or restored ecosystems. Ultimately both the conceptualization of the state as an area dominated by an agricultural system that contributes to environmental problems and the conceptualization of the state as a place with important restored or conserved ecosystems are necessary to understand why such restorations are worth the money and effort they require. 
The fact that students looked beyond the immediate area and considered the state regionally and as a whole was especially important for them as college students. Most of the participants will move when they graduate, but a regional ecological place meaning may stay with them in a way that one tied to a temporary, college home might not. Participant responses showed promise for consideration of place as they graduate and relocate. Both their tendencies to apply their conceptual understandings as they traveled and the extent to which their conception of the state as a whole began to change indicated a potential for continued development of ecological place meaning. This tied back to participants' interest in the exotic. By finding the exotic in the local, they found increased interest in the local as well.

As an aesthetically important place. As participants expanded their notion of the area as an ecologically important place, they also re-assessed their ideas of the region as an aesthetically important place. Participants became more aware of green space in the city and scenic state parks outside of it, and sometimes finding the beauty was simply a matter of noticing an iridescent insect. The aesthetics of the local area were seen as relaxing and rejuvenating and sometimes as a source of strength. In this way the cultural ecosystem services students experienced (Millennium Ecosystem Assessment, 2005) helped develop place meaning.

Students found beauty throughout the state during their semester in FBE 300. While the course focused on the central part of the region, Sam and Payton independently visited more distant parks. Much as these independent excursions helped solidify the state as a whole as an ecologically important place, they also showed the aesthetic importance of the state outside the immediate region. Sam described a trip to a state park with her family:

While we were out on the trail we got to see a small waterfall and a deer. The waterfall was flowing between two trees and rushing down a few stories high. We went along a 
river so we saw the high points and the low points of the river. We saw some beaver dams. My favorite thing we rode past though was this huge sunflower field. It was so beautiful. I loved it!

In this passage Sam focuses on both common sights such as deer and the more unexpected waterfalls and sunflower fields. Together, they worked to highlight the varied aesthetics of the region. Payton had a similar experience at the opposite end of the state, "We hiked on a couple different trails and they were breath taking! . . Being at [state park] made me want to see more of the natural beauty of Earth." Sam and Payton drew on these experiences in their observations and their journals as part of their work in the course, but importantly their explorations also served as an inspiration to keep traveling and discovering on their own.

Within FBE 300 the choice of field sites was as significant for the conception of the region as an aesthetically important place as it was for the conception of the region as an ecologically important place. While students found beauty in all of the field sites, each had a personal moment or place that were especially meaningful. Sam described Great Egret Wetlands:

I think the wetland area was my favorite. It was so beautiful in a way that I can't even explain in words. The water glistened in a way that showed its beauty. My favorite part was looking out at the beautiful bridge...

Kit was enamored with the area around New Woods:

I started my hike with a panoramic scenic view of the [River] Valley. Needless to say it go me super excited for what the other views...

However, the scenic view around me was gorgeous. The trees were all changing colors from the fall weather. There were so many red, orange, and yellow leaves it was 
absolutely breath taking. The trail was also covered in leaves. Most of them were still colorful and not yet brown/dead.

Fieldwork at the varied sites helped change participants opinion of the city as well. As Sam noted, "This fieldwork has shown me that [city] is a beautiful place ... I believe that this has shown me that [city] has much more natural beauty to offer. .." While Sam saw more beauty around her, Chris saw beauty in the city perhaps for the first time, "I also see a lot more beauty in [city], where before I saw a dirty ugly city."

Regardless of their favorite spots, the participants benefited from unstructured time within them. Cameron and Taylor both remarked how much they enjoyed having a day at New Woods to just observe as they wished, without the pressure of data collection. As Cameron explained,

Our class went back to [New Woods] for a final observation. After all the work is done for our final lab, it is nice to go back out there and take in all the beauty without having to accomplish anything.

Taylor echoed these thoughts, noting the benefit of the time to relax and listen, "I really enjoyed having the chance to just sit and observe. While sitting and observing, it not only was relaxing, but it was very interesting to listen to the sounds of nature and sights of nature." Kit found a sense of contentment at Great Egret Wetlands, "I was so at peace, I could have stayed there all day and been in heaven." While the unstructured time was vital, the fact that it was paired with more formal fieldwork was equally important. As much as the students appreciated a chance to relax, the locations were more meaningful because of their ecological sense of the area. Payton expressed this dual meaning: 
I have been to [location] a few times while being at [Oak Savanna]. As a runner

[location] is one of our favorite spots to run. It is truly beautiful, especially in the fall.

However, I always just had looked at it as just a pretty sight. I never had really

appreciated it as a natural landmark.

Kit expressed this sentiment as well in her interview:

I loved that. It was just so pretty. I took so many pictures. My computer's full of [scenic

drive], but it was ... like the perfect time, too. Because we went as a class and ... learned about it.

In terms of course structure, this argues for a balance between formal fieldwork and open time to explore. Participants' ecological place meaning and aesthetic place meaning informed each other.

As a recreationally important place. As participants described the land around them, they say the local area as a recreational place. For some participants this was as simple as noting that they saw people fishing at Great Egret Wetlands or that they saw runners at New Woods or the many ways that students used the quad. For other participants, the time in the field encouraged them to find further natural areas where they could explore on their own. Payton arranged a hiking trip on an off-campus weekend:

This weekend I went to visit my girlfriend in [college town]. We wanted to explore the area more, and had done some research on all of the different nature parks to explore. We decided to take a trip to the [state park].

For Payton this trip further developed his ecological, aesthetic, and recreational place meaning. The trip inspired him to think about local land formations and also about the importance of finding recreational spaces wherever he moved after graduation. Kit reported a similar 
experience. She arranged to re-visit class field sites so that she had time to hike the trails. When she went home for a weekend, she continued research into hiking opportunities. She elaborated in her interview:

Just like opening our eyes to . . [Great Egret Wetlands], too, was beautiful, and I would've never known that was there, nor would ever go back because I wouldn't have explored that. Since we went actually to those [nature preserves], when I was home I was ... looking at different state parks I could go to and . . hike around. So, I don't know, this class is definitely . . . brought out . . a hobby of mine, almost. To like hike and just explore by myself even is kind of fun.

Payton, Kit, and Sam were active outdoors regularly even prior to class. Their fieldwork, in this case, expanded rather than created their interests. That expansion was still significant, however. Both Payton and Kit were inspired to find new areas to hike, and they were determined to continue to do so after class. Regular recreational use of an outdoor area has been associated with place attachment (Brehm et al., 2006; Ryan, 2005; Stedman, 2002), and place attachment has been seen as a potential contributor to protection of outdoor spaces (Brehm et al., 2006; Russ et al., 2015; Stedman; 2002). In FBE 300, Cameron showed this connection most clearly.

Cameron knew the local area well and expressed a sense of place throughout the course. He had a pre-established recreational place meaning, and he engaged in a variety of outdoor activities in the area, as he described in his interview:

In high school, I grew up . . my buddy is kind of a ... country boy . . . and we did a lot of canoeing on [small river] ... did a lot of that. So I'm real familiar with that river. It's not too eventful. I mean it can get high and kind of dangerous ... I've been fishing in about every area that we went to ... You know I've pulled out some pretty nasty catfish 
from [lake] with my friends... I've eaten fish at - my buddy owns ... some land in [rural town] ... where I've eaten blue gill and ... crappie and bass out of those ... I. . . grew up playing in the woods. [I] can get you through the woods from [town] to [town], pretty easily.

During the course, Cameron would often look to the recreational opportunities of the field sites, noting about one site, "I thought the area was very pretty and would be an excellent location to do some fishing or bird watching." As such, Cameron had a vested interest in the local area. As he continued in the course, his place meaning and his place attachment caused him to question the actions of those around him:

I look on the ground and notice a few beer cans my buddy has left on the forest ground. [My friend] is littering his own land. It's unbelievable when you see things like this. He is a hunter and he is polluting his own land.

In this case, Cameron made a clear connection between ecological place meaning, recreational place meaning, and place attachment; if his friend was not going to litter simply because it was bad for his property, then at least he should consider the implications for his hunting. In general participants' environmental behaviors were not directly studied, thought Cameron's concerns showed the potential for connecting environmental attitudes with sense of place. While FBE 300 focused on ecology, rather than environmental science, the extent to which ecological place meaning contributes to pro-environmental behavior even without an explicit focus on environmental problems is a possible area for future study.

\section{Conclusions}

Extended time in the field allowed participants to expand their place meaning. These place meanings were well developed in terms of ecology, aesthetics, and recreation, and they 
resulted in a re-conceptualization of both the city and region in which Oak Savanna University resides. Unstructured time in the field was essential to gaining an appreciation for the local natural regions; however, structured fieldwork added depth to those place meanings. Throughout FBE 300, place meaning developed to a greater extent than place attachment. This was in line with research by Kudryavtsev, Krasny, \& Stedman (2012). For a collegiate population, a more developed place meaning made logical sense and was likely more important than local place attachment as the students largely planned to move from the area upon graduation. Place meaning was likely transferable, as participants showed signs that it extended beyond their field sites to the region and the state more broadly. While not all of the participants enjoyed outdoor recreation, those who did, especially Sam, Payton, and Kit, already showed the initiative to seek out new natural locations throughout the state. To the extent that participants formed place attachments, these might also be transferable in the future. Participants frequently cited a type of location of particular interest, for example a wetland, which could be found broadly. Cameron in particular showed a connection to "the forest" rather than "New Woods Nature Preserve." Attachment to an overall type of location, rather than a single location, has been linked to a more professional understanding of natural areas (Ryan, 2005) and it may reflect the degree to which participants' expressed place attachment was informed by their developing ecological place meaning.

While participants' expression of sense of place during FBE 300 included several ways of conceptualizing place meaning, place attachment was expressed to a lesser extent. The seeds of place satisfaction were found in students' desire to revisit and independently explore field sites. While seeking out new state parks and other recreational areas were considered an important part of place meaning, these behaviors also related to place attachment in the form of 
place satisfaction. Participants began to see the region as a place that supported their interest in the outdoors.

Participants connected their developing sense of place directly to specific field experiences that were a unique part of FBE 300. Important experiences included time for selfdirected observation at multiple field sites and repeated structured experiences at a single site. Explicit reflection on course experiences and how they related to their conceptualization of the local area was critical for participants to make connections between their disciplinary content understanding and their conceptualization of the local area. This sense of place was significant as an outcome of a field-based ecology course. 


\title{
CHAPTER VII: EXPERIENCING A FIELD-BASED ECOLOGY CLASS AS A PRE- SERVICE EDUCATOR
}

\begin{abstract}
This chapter explores how participants' experiences in a field-based ecology course were shaped by their identities as pre-service educators. Participants evaluated their experiences through the lens of developing professionals by identifying how field-based pedagogy was modeled within the class and reflecting on how it impacted both their content understanding and their ability to use field-based approaches with their future students. Participants used their reflections to suggest $\mathrm{pK}-8$ learning experiences that incorporated the locations, techniques, and content emphasized in the course. Participants' ability to translate these suggestions to formal field-based lesson plans was influenced by their relative comfort levels with both ecological concepts and national science standards. Participants' experiences over the course of the semester were used to develop a model of field-based ecology for pre-service educators that incorporated their developing ecological literacy, sense of place, and community of practice.

Keywords: pre-service educator; field-based pedagogy; grounded theory

\section{Ecology in Education}

Ecology education has been common at the collegiate level since the 1950s and the K-12 level since the 1960s (Marcinkowski et al., 2013). A basic understanding of ecological principles was considered necessary for an informed citizen to engage with environmental issues; however, the degree to which ecology as a science, rather than environmentalism as an ideology, was taught at the K-12 level has been a matter of on-going concern (Hungerford, 2010; Klemow, 1990; Mappin \& Johnson, 2005; McComas, 2002; 2003; Powers, 2004). To help address these issues, ecologists have made efforts to engage with educators by suggesting workable models of 
ecological literacy (Berkowitz et al., 2005; Jordan et al., 2009; McBride et al, 2013; Powers, 2010; Risser, 1986).

Despite the on-going conversation, ecology education remains at the margins. Time dedicated to ecology education, especially for field-based learning experiences, is limited at the K-12 level both in the United States and internationally (Blatt \& Patrick, 2014; CutterMackenzie \& Smith, 2003; McComas, 2003; Puk, 2003; Tal, 2008; Young \& LaFollette, 2009). This limitation is also seen at the collegiate level (Powers, 2004). Absolute time spent on instruction is not the only measure of quality ecology education, but it is an issue considering the relative complexity of some models of ecological literacy (Berkowitz et al, 2005; Jordan et al., 2009). The foundational knowledge required is not something that can be covered in a single semester (Powers, 2010).

Regarding pre-service educators, the question of ecological literacy is of particular concern, as they are in the position to either mitigate or perpetuate issues across multiple generations. Studies on the ecological content understanding of pre-service educators have indicated that participants were not well versed in all of the aspects of ecology that they might be expected to teach (Desjean-Perotta, 2013; Puk \& Stibbards, 2010; Zak \& Munson, 2008). While the results of the studies were not necessarily dire, they showed considerable room for growth particularly in terms of complex ecological interactions. The degree to which participants could articulate ecology as a science, in addition to ecological concepts and connections, was not even addressed.

The extent to which educators incorporate outdoor learning experiences is also a concern in ecology education. Building concepts through in the field is seen as a way to provide concrete experiences appropriate for young learners (Sobel, 1996) and to provide local context for 
complex problems at upper grade levels (Smith \& Sobel, 2010). However, for these opportunities to be incorporated into curricula, educators must feel comfortable teaching outdoors. This presents a challenge as pre-service educators might show an aversion to working outdoors (Hug, 2010; Powers, 2004), and in-service educators might avoid fieldwork due to safety or administrative concerns (Mannion et al., 2013). This is another area where content knowledge of ecology is important, as a lower degree of content knowledge has been linked to low comfort teaching in the field (Hogan \& Berkowitz, 2000).

Field-based professional development for in-service educators has shown promise as a way to increase both in-service educators' comfort with field-based pedagogy and their intent to incorporate field-based approaches with their classes (Hogan \& Berkowitz, 2000; Mannion et al., 2013). Comfort in the field has also been linked to educators' willingness to engage students in spontaneous learning in the field (Mannion et al., 2013; Skamp, 2009) and to move beyond standardized curricula (Powers, 2004). In turn, this flexibility increases educators' willingness to be "co-learners" with their students, further encouraging novel investigations (Knapp, 2005, p. 280; Krapfel, 1999; Mannion et al., 2013; Sayers, 2004). While Hogan and Berkowitz (2000) noted that being open to learn along with students is "not the end goal" of field-based professional development (p. 22), it could provide a vital stepping-stone for educators with less ecology preparation.

\section{Conceptions of Ecology Education in Field-based Ecology 300}

The generally limited ecology preparation of pre-service educators combined with the success of field-based professional development for in-service educators argues for more fieldbased ecology experiences for pre-service educators. Such experiences could increase both content knowledge and comfort with field-based educational approaches. This case study 
explores the impact of a semester-long field-based ecology course, FBE 300, for pre-service educators. Participants' ecological literacy is explored in Chapter V: Developing Ecological Literacy in the Field. In this chapter, participants' conceptions of ecology education and their intent to teach field-based ecology are explored. Participants' conceptions are then used to develop a model of field-based ecology education for pre-service educators.

\section{Research Question}

As FBE 300 was an ecology course for pre-service educators, learning goals for ecological literacy included both content (explored in Chapter V: Developing Ecological Literacy in the Field) and pedagogy. Specifically participants were to make connections between FBE 300 and pK-8 science education. Related to the learning goals of the course, a research question specific to ecology education (EE1) was developed:

EE1: How do participants characterize ecology education and their intent to teach ecological concepts?

The emergent question stemmed from the second guiding question for this dissertation, "To what extent do pre-service educators plan to incorporate field-based natural history and ecology education into their future practice?"

\section{Findings}

FBE 300 was designed as a course for pre-service educators with explicit reference to science pedagogy and structure. Whether or not participants would connect the structure of the course to their own future practice and whether they would develop an understanding of the field of ecology education remained open questions. To evaluate these aspects of FBE 300, open coding was performed on class artifacts including journals, observation notebooks, exams, and interviews to generate approximately 90 codes (See Table 5). Axial coding resulted in two major 
categories, Field-based pedagogy and Planning for the future, each with subcategories that together formed the theme, Experiencing class as a pre-service educator (See Figure 4).

Table 5

Alignment of Data Sources with Emergent Questions Regarding Ecology Education

\begin{tabular}{lcccccc}
\hline Question & Exams & $\begin{array}{c}\text { Observation } \\
\text { Notebooks }\end{array}$ & Journals & Interviews & $\begin{array}{c}\text { Lesson } \\
\text { Plans }\end{array}$ & $\begin{array}{c}\text { Nature } \\
\text { Passports }\end{array}$ \\
\hline EE1 & $\mathrm{X}$ & $\mathrm{X}$ & $\mathrm{X}$ & $\mathrm{X}$ & $\mathrm{X}$ & $\mathrm{X}$ \\
\hline
\end{tabular}

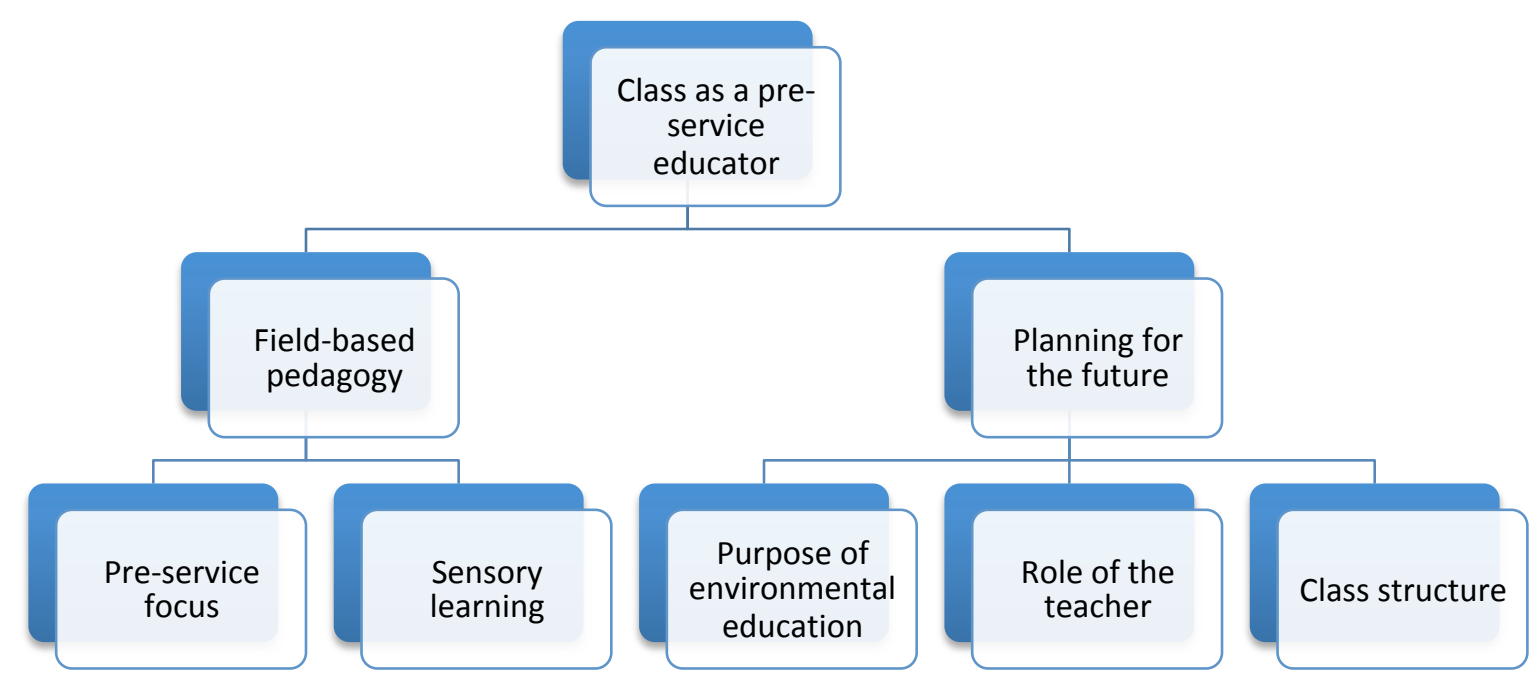

Figure 4. Organizational structure for the theme, experiencing class as a pre-service educator, with major categories and subcategories.

All of the participants in FBE 300 planned on entering education as a field. This was a large part of their personal context, providing a lens through which they viewed both the instructors' pedagogical choices and the personal relevance of course material. Through consideration of Field-based pedagogy participants described instructional choices within the class that they felt most related to their career goals and that directly impacted their learning. By 
Planning for the future, participants extended and applied class concepts to their future classrooms, indicating their perceptions of both environmental education, including ecology education, as a field and their roles as environmental educators.

\section{Field-based Pedagogy}

FBE 300 was a field-based class designed for pre-service educators. Students identified both of these aspects of course design as conditions that impacted their learning throughout the semester (Corbin \& Strauss, 2015). Field-based pedagogy can be considered through two subcategories, Pre-service focus and Sensory learning.

Pre-service focus. The pre-service focus of FBE 300 was viewed as a way for students to connect course content with their future careers. Participants articulated the benefits of both explicit reflection built into the class and modeling of student-active pedagogy. These aspects informed each other as the reflection helped students articulate the purpose of the instructional choices. Both were seen as contributing to both their learning process and their ability to articulate how course content could be adapted for their future students.

Participants noted that their experiences in FBE 300 were designed to demonstrate specific educational approaches. From the beginning Cameron focused on the field-aspect of the class, noting in an early journal, "The first class of [FBE 300] was an interesting and eye opening experience. I believe our professors are demonstrating the importance of conducting classroom time outside of the classroom." Payton elaborated on the purpose of the outdoor classwork:

One of the biggest differences between [FBE 300] and all of the other classes I've taken here at [Oak Savanna] is the amount of hands-on activities we get to participate in... That's where [FBE 300] stands out. We get taken out to the field on a weekly basis. We 
get hands-on, real world experience consistently... What would be beneficial [is] if every class tried to incorporate some type of hands-on, real world experience.

In Sam's interview she went a step further, indicating specific experiences that she thought could be used appropriately throughout $\mathrm{pK}-16$ education:

These ... science for teacher classes ... are taught to college kids, at a college level, but implement teaching styles that you can use when you're the teacher some day. And so I really like that with ... even the other [100-level inquiry] science class that I took in here ... Obviously I was functioning at a college [level], but the projects and things that we were doing ... I could use, take them down, modify it to any level that I wanted ... I love the notebook. I love the reflections, and I love the observations, mostly. Just because that's something that I would've never really thought [about]. And it's ... such a simple — like literally, here's a notebook! ... It's very simple. You can even hand them a piece of notebook paper every day, ... they don't need a notebook. . And then, what else have we done, like the inquiry lab. And ... those kinds of things. So yes, I do think that they. . . very much could be directly correlated.

Cameron, Payton, and Sam articulated the bridge between the content of the course and their wider perspectives, or as Payton phrased it, the "real world."

The connection between instructional design and participants' future roles as educators was broadly recognized, but that did not always make it comfortable. Kit described early experiences with tree identification in her interview:

And we were like, "oh my god, I feel so frustrated." You knew you weren't alone in it and that made me feel a little bit more... relaxed in knowing that okay, I'm not the only one that doesn't know what I'm doing... In the moment I really did not like it, but when 
we came back in and we ... talked about it . . as a perspective as a future teacher I understood. And I probably would've done the same thing. My students probably would've been annoyed with me and kind of frustrated too. But I think it was . . good for us to see that...

Alex expressed a similar reaction:

I can understand ... how you're teaching us that we should be teaching ... inquiry... kind of the way to go about it. I think... through that frustration and figuring it out that helps you understand it . . better, almost, than if we had just been given the terms.

Kit and Alex ultimately found their experiences valuable, but the value may have been missed if they had not taken the time to consider not only what they were doing, but also why they were doing it. In this way, the built-in reflection opportunities in the course were essential to meeting class outcomes. For the participants, this was another way that the class recognized their needs as pre-service educators. Payton elaborated in his interview:

Well I think at first my first reaction was ... this is a lot ... I mean obviously ... we had time to do it. So it wasn't like I was stressed about doing it all. But ... the observations, . .. why do I have to do these ... and journals ... I think those are okay. I've always been ... a fan of reflection. I think that's important just to kind of . . sit and . . think about . . . what you just did, and why it's important. And how you want to ... advance on the knowledge you gained from that...

For Payton early in the course, the observations journals were a hurdle to get over, but with experience and reflection, they became a positive aspect of his learning experience. Kit saw written reflection as something that could provide continued benefits: 
These journals have provided a great way to reflect on what I have accomplished in each class as well as over the entire course. I hope to continue journaling throughout my professional career to be able to allow reflection and growth as a student/teacher. The consistent nature of the reflection was a recurring thread in student responses. Alex noted that reflection was reinforced throughout the course, which suited her generally contemplative nature:

I enjoyed the observations and I'd say and the journaling and the nature passport ... I enjoy writing and journaling on my own, so that ... it was neat that that could tie into this class. And just ... the reflective part of all those three, I think. And to consider how it all connects . . or it can connect to my future teaching.

The participants' statements echoed findings in other areas of professional development, where explicit reflection was key to connecting personal experiences with abstract concepts such as nature of science (Sadler, Burgin, McKinney, \& Ponjuan, 2010; Schwartz, Lederman, \& Crawford, 2004) and in tying professional development experiences to classroom curricula (Garet, Porter, Desimone, Birman, \& Yoon, 2001; Penuel, Fishman, Yamaguchi, \& Gallagher, 2007). The connections students made between the structure of FBE 300 and their concept development and future careers would have been easy to miss without regular reflective writing.

The modeling and reflective aspects of participants' experience within the course closely tied to the concepts of community that were described in detail in Chapter III. Participants saw their experiences as both active preparation for the future and meaningful work in the present. Together those aspects informed and reinforced their experiences as pre-service educators. The extent to which they will incorporate similar experiences with their future classes is not known, but important groundwork was established. As Alex noted in her journal: 
Overall doing this [nature passport] project caused me to branch out and explore different nature-related topics that I might not have otherwise. Writing each passport reflection also helped me consider how I could incorporate these experiences into my future teaching.

Sensory learning. The pre-service focus was a condition that participants identified as key to their experience in FBE 300. This was tied to the field-based nature of the course through modeling of nature-based educational strategies, but modeling and reflection could be built into any content course. In contrast, Sensory learning represented conditions that influenced participants' developing ecological literacy and their sense of community that were related to fieldwork. All participants in FBE 300 attributed value to fieldwork paired with lecture and to active learning in general. This led them to consider opportunities for fieldwork for their future students as well.

Paired fieldwork and lecture. FBE 300 was designed for fieldwork to be a central part of instruction rather than a supplement. This was accomplished by including outdoor work, either on campus or at a field site, on approximately half of the instructional days. Class followed a Monday-Wednesday format with Mondays used for fieldwork and Wednesdays used for supplementary instruction, data analysis, and other indoor work. Participants cited this layout as an effective way to deepen learning. Payton described it this way in a journal entry:

I think it is important to have that healthy mix of fieldwork and in class work. Especially for this type of class. The set up of Monday fieldwork and Wednesday class work has been helpful in the process of learning plant identification. It helps to go to the field and then Wednesday if we have any concerns or questions we can ask them in class. 
Kit noted that the pacing was important, as too much time between observation and discussion would have been less effective. As she said in her interview:

I liked how... on Monday, most of the time, we would go out, and then on Wednesday we would have like lecture and then working time. I felt like that was a good balance and we were able to . . connect the things that we were learning, lecture, . . what we'd previously done or what we were going to see next time. And it wasn't . . too long spread out that we would forget.

The combination instruction was viewed as essential, as neither piece would hold as much value without the other. Sam explained this on her final:

This class would not have the value and strength that it holds without the marriage it has between lecture and fieldwork. They would work with each other. The lectures would provide us with information and then we would go in the field and see it and experience it in real life, but sometimes we would see something in the field and then come back to class and make sense of it during lecture. Just talking about ideas and concepts is one thing, but seeing them and working them is another. However you should know the reasons as to why you are working them and why you are seeing what you are seeing ... The marriage between the two is helpful and necessary. I know I would not have gained the positive learning experience I have from this class without the two of them. Participants all saw value in the fieldwork for varied reasons. For Kit, the experiences were meaningful because they matched her preferences, as she noted in her interview, "I could . . . incorporate what we were learning in lecture to ... what I was seeing or doing ... I think it as enjoyable because I personally just like it." While this result was not surprising, it was important to note that people who did not enjoy being outdoors also saw value in the experience. For 
Taylor the benefit of different modes of instruction was important enough to overcome her general dislike of outdoor work, as she said on her final:

By having a class with both lectures and field experiences, I feel I learned the material in two different ways . . Overall, I feel they both worked together, because they went handin-hand with learning the material and both played an important role in learning the material in different ways.

The value of the experience was enough for Chris to overcome some initial apathy as well. She described in her interview the moment when she first started to become comfortable with fieldwork:

Honestly when we got out of the classroom. When we were able to - not the first couple times, because that was a little bit much. But, after that, when I was like okay ... I understand why we're doing this. And then, we're coming back to the classroom, and what we're talking about, it is . . relevant, one hundred percent relevant to what we're doing out in the field. And I can, actually, see what we're doing.

Bobby also found the immediacy and the immersion important for skill development; "I found that touching, smelling, and looking at other characteristics helped lead to a name as well. If there weren't descriptions and I couldn't see the tree in person, I would have been more confused."

The paired fieldwork and discussion ultimately led participants to make strong connections between lecture and discussion topics with what they could see and measure. While this is the goal of any laboratory course, for many students the clarity of the connections was a new experience. As Chris noted in her interview: 
I think it was just making connections for me. Like . . your lectures, I was able to see things that I had actually seen in the woods, and had my hands on, and been ... off the path and looking at ... directly involved with. Whereas, in all of my science classes before I've never had that experience. . I can remember 10th grade chemistry, I'm like I have no idea what this is. I can't see any of this, so I really don't care about it . . But this was, I think, the first-ever real science experience that I've had, that was like I see it. I understand it. This is why this happens.

Alex also indicated the importance of directly observable phenomena:

Just being able to ... see how it works directly, like with concepts like erosion ... biodiversity and seeing ... all the different aspects, where ... talking about it in lecture wouldn't have been quite the same.

The benefit of fieldwork could have been limited to what students could see and touch, but some participants made larger conceptual leaps. Participants articulated why their experiences were important pedagogically, as in modeling and acceptable frustration, but also for understanding less tangible scientific concepts. Connections made in FBE 300 helped Cameron put past classes with more that were previously too abstract into context. In his interview he noted that he felt that he the fieldwork helped him better understand his 100-level biology and chemistry courses, I think when you actually go out there and do it through inquiry. . you remember, you have those memories in your mind of when you went out and collected data, or ... whatever you did for that class or project or experiment . . No question about it. Just like [Dr. S] said ... we learned things in this class that we'll never forget, and that's true. And it's ... also has helped me ... things I remember, that I learned in [chemistry course] to never leave my mind, too. It's helped other classes. 
While everyone in the class had previous laboratory experience, the fieldwork was different for them conceptually.

As with the modeling and reflection aspects of FBE 300, participants extended the importance of pairing fieldwork with lecture beyond their personal experience. They saw the combination as potentially powerful for their future students. In this way, they directly associated field-based pedagogy with both their content understanding and the content understanding of their future students (connecting this theme to both Developing ecological literacy and Community). Chris said this first in a journal entry,

I think this is my first content class in my life where I was actually able to make connections with the fieldwork and what's going on with the lectures in class... I think that the authentic, hands-on way the class is taught has given me a lot of great ideas for authentic lesson plans and the importance of incorporating inquiry-based science into my curriculum.

While in her journal she focused on student-active inquiry, she expanded in her interview to address the impact of outdoor observations for her future students:

... Just like I said, like getting them out of the classroom . . . and having those experiences, those really authentic experiences, that they're actually learning while they are having the experience. So, if we're outside . . I can get them all . . looking at something and be talking to them while they're looking at it. While we're passing it around, touching it, feeling it, smelling it, whatever it is . . It's those really authentic learning experiences that, I think, will make the connection and then, we can come back inside and talk about them and they'll have so much more to say about it. 
For Taylor this potential resonated when she contemplated the individual needs of her future students:

I mean hands-on learning ... is a really big thing with special education, so I feel like any field trips that takes them somewhere that they could connect to would be helpful . . . When I was in elementary school and . . learning with hands-on activities . . I'm a very visual learner so I feel like being able to see stuff and . . touch it, and use your senses is just the way to do it, especially with special education students when they may have sensory issues, or . . they all learn at different paces, so being able to go out and... actually do something instead of just sitting and listening is really helpful. I feel . . like when you're sitting at a desk you have to do things step-by-step, you're just sitting there versus when you're outside you can use . . most of your senses, and be able to . . take it in that way versus just listening to a lecture where you don't really retain much, necessarily. And then . . if you were outside you could touch, hear . . see . . all that, and it just goes in a different way.

Chris and Taylor were speaking of hypothetical future lessons, but they were doing so with an understanding of how working outdoors could benefit their student populations of interest. This was especially valuable in terms of providing a compelling reason to overcome their initial reluctance to work outside themselves. For Taylor, her conception of the benefits of field-based work for her students was in line with comments from Blank et al. (2003), who noted that fieldwork provided distinct advantages for students who struggled in more traditional classroom settings. While this does not guarantee that Taylor implements fieldwork with her future students, consideration of the possibility is still an important first step as if she tries fieldwork, she may find benefits that continue to reinforce the approach. 
Active learning. While the pairing of fieldwork with lecture was considered especially beneficial for learning, participants in FBE 300 preferred active learning modes across the board even when they were not making connections between different aspects of the course. Students frequently used the phrase "hands-on" to describe the type of learning they felt was most beneficial for themselves and for their future students.

Participants had varied reasons for preferring active learning approaches, with Chris finding them more "authentic" and Bobby noting they were more "impactful." Active learning was seen as less boring, even if the topic area did not rise to the level of inherently interesting. Taylor phrased it this way in a journal, "I feel that these feelings [comfort within the course] have changed because I much rather learn by doing than sit and be lectured [to].” She was equally direct in her interview:

I mean I'm not a very big science person, and I don't like seeing that it [FBE 300] was called ecosystems. I don't really know what I had in mind for that. And then when . . we got to the class and we started doing . . . all the field work, and learning about ecosystems and everything else that . . comes along with that. That's, I think, where . . I figured. . . out. . . what the class was about. And realized, okay, it was not going to be boring about stressed ecosystems ... I always know that these . . science classes, in general, are always more like hands-on and inquiry-based.

Even students more interested in the subject matter recognized that they did not have unlimited attention spans, and active learning was necessary to stay invested in a lesson. This was something they connected to their future students. As Cameron noted in a journal: 
Even if the attention span is completely gone, I must find activities and experiments that my students find fun. For example, the soil cores we used for our experiment kept my attention and even gave me a little opportunity for some fun.

Ultimately this increased interest level was tied to increased learning. Kit noted in her interview: And students are more excited to learn that way, too ... they don't want to sit in front of a textbook and just ... read it. Or have a lecture on the material ... they want to do stuff and explore. And I think that's how they learn better anyways.

The fact that participants considered the possible benefits and preferences of their future students was important in terms of potential implementation. Payton noted that outdoor experiences would directly benefit students with diverse needs:

I think, with special education ... they benefit from hands-on stuff, too, rather than just sitting and being lectured, because a lot of students have trouble paying attention, or their minds might be in other places. So getting them out, actually... out in the environment and ... they'd actually be able to go out and... look at the ground and see what they see. And see the birds flying above, and I think that'd be really beneficial for students with special education. Making those observations for them, I don't think it would be too difficult for them ... I think, obviously you might have some kids who can't read or write, but ... they can see something and they can kind of describe it to you a little bit.

A similar thought was expressed by Taylor and was in line with recommendations for ecology education if not with current actual practice (Blank et al., 2003). 


\section{Planning for the Future}

One of the primary motivations for the development of FBE 300 was to give participants the tools and the motivation to incorporate ecology education into their future classrooms. To this end, how they characterized ecology education and their stated intent to implement ageappropriate ecology lessons were of key interest. These were summarized through participants' statements on the Purpose of environmental education, the Role of the teacher, and their ideas on appropriate Class structure. Participants' initial thoughts in these areas were part of their context within the class. These thoughts shifted over the course of the semester as students incorporated new experiences and concepts into their existing framework.

Purpose of environmental education. From the onset of the course, participants shared their ideas on the purpose for environmental education. In this case, the term environmental education more accurately described their usage as it is an umbrella term that includes, but is not limited to, ecology education. Students most commonly indicated that environmental education was important for awareness and for action, and they did not necessarily distinguish between ecology as a field and environmental science. Environmental education for awareness included an understanding of how ecosystems worked, an appreciation for their value, and an understanding of how humans impact them. In this way, environmental education for awareness paralleled students' developing ecological literacy. Chris, Sam, and Kit illustrated these three aspects. As Chris noted in a journal entry,

[I] can easily see... how important it is to be informed about the environment and ecosystems that surround us . . as I do believe that it's important to at least try to instill in children from a young age a basic understanding of the way the natural world works so that we are able to live the way we do. 
Sam put this in context of awareness as she noted that a citizen science approach, "also allows for people to become more appreciative of this amazing earth we live on." Kit summarized human impacts, "I think it is important that my students/any student is given this opportunity. They will then gain a better appreciation and more knowledge about their ecosystem, environment, and how they affect it/it affects them."

Education for awareness was subtly connected to participants' sense of place and the tenets of place-based education. This was illustrated in Chris' highlighting "ecosystems that surround us" and Kit's use of "their ecosystem" when referring to her future students. Specificity of environment is fundamental to place-based educational programs and education that does not look at a big picture "environment" in the abstract (Semken \& Butler Freeman, 2008; Smith, 2002; Smith, 2007; Smith \& Sobel, 2010; Sobel, 1996; Sobel, 2013). Cameron made the connection to local areas more explicitly when he emphasized local environmental issues during an observation, "As a teacher I should always take human pollution into consideration when exploring wildlife areas around [state].”

Education for action was differentiated from education for awareness by including a call for a problem to be fixed. Participants mentioned education for action less commonly than education for awareness, but the specificity of some of the problems illustrated the influence of FBE 300 by paralleling participants' developing ecological literacy and growing understanding of the local area as an ecologically important place. In a journal entry, Bobby tied formation of dead zones to local use of fertilizers, applying information from her independent research project: 
I would also be interested in looking for ways to prevent the nutrients from making dead zones. If there were preventatives for small gardens or golf courses it would help the water's environment and life. It's important to keep them healthy.

Payton showed continuing concern for erosion problems exacerbated by land use around the river, "Hearing this information made me realize how it's extremely important to stay on top of these issues to prevent further damage to the river."

Further concepts of environmental education were identified, but they were mainly of concern to one or two participants. Alex saw environmental education as a way to lay the groundwork for recreational appreciation, "I think it is important to expose students to these early environmental education experiences to simply recognize aesthetic beauty and develop an appreciation and enjoyment for nature." Cameron noted the importance of environmental education in making a person "well-rounded." Sam viewed environmental education through the lens of science education. On her final, she explained how local observations could serve as a starting point for further inquiry:

In science we use Bloom's taxonomy in a way to allow students to use inquiry to expand on and build their skills and level of knowledge [to] understand science surrounds our everyday lives. We need our students to know how to make sense and have a solid understanding of science.

As my students develop strong observational skills I would then bring them up the ladder of Bloom's taxonomy. I would ask them if based on their observations they knew what could cause certain situations. For example, say the students observed a tree that was brown and leaves were starting to look bad. Possible higher level thinking questions: 
"Why is the tree brown? It's dying or it gets not enough water. "Why do you think that?" It hasn't rained in a while. "What could we do to help the tree maybe?" We could water it. "How often should we water it?" Maybe once a day. "Do you think that's all we should do?" We could give it fertilizers and added nutrients. "Why is this tree important?" It gives off oxygen for us to breathe.

Cameron and Sam both touched on broader topics in environmental education, whether or not they were aware of it. Cameron's thoughts on what makes a "well-rounded" education touched on the nature of a liberal arts education and the role of environmental science within it. Sam's focus on asking and answering fundamental scientific questions connected to the debate of whether environmental education focuses on science or environmentalism (Hungerford, 2010; Klemow, 1990; Mappin \& Johnson, 2005; McComas, 2002, 2003; Powers, 2004).

Role of the teacher. An important part of FBE 300 was participants' self-identification as pre-service educators. This aspect was covered in more detail in Chapter III as part of their formation of a community of practice. In this section, the ways that students conceptualized the role of a teacher are considered. The most common roles for a teacher cited by the participants were as a facilitator and as a source of knowledge. Both facilitation and knowledge were seen as ways to engage students and to increase $\mathrm{pK}-12$ students' interest in science broadly and environmental education more specifically.

Bobby saw teacher facilitation as important for students to form lasting memories. She supported this idea with her background as a student working on inquiry-based projects. As she defined inquiry, "I think it's giving tools to students so that they can discover on their own terms, with the help of the teacher." She worked to incorporate aspects of this into the lesson plan she 
designed for the course. Her emphasis on the skills she wanted future students to take away mirrored her thoughts on what was personally effective:

... skills for just [to] discover, I mean inquiry skills . . And just being observant, and being able to compare and contrast, and . . being able to learn on your own, and be responsible and organized with that .. If you have a project like this, you have to make sure that your time is planned out correctly, and you're looking at the right information and. . you don't have a teacher telling you what to do through it. There might be guidelines, but you can kind of branch out and stuff, too.

Chris also saw the ability to inspire independent learning in her students as essential to being a teacher. To Chris this was what made learning "authentic" and generated interest:

I plan to incorporate authentic experiences into my curriculum by providing students with the opportunity to take their learning experiences where they want. This will be done with projects-lots of projects! Having students create and shape their own learning while I guide them through the experience, asking questions that spark curiosity and get the students thinking in a big-picture way.

The need to facilitate rather than dictate was considered appropriate across grade levels. Cameron went as far as to view it as necessary for success as an educator, "Finding ways for students to engage in science inquiry investigations will be an important factor that determines my success as a teacher."

While participants recognized the importance of student-active science, they also took the need to develop content knowledge seriously. For Sam, this was a matter of personal responsibility in the classroom, "You got this job; you better know your curriculum. So yeah, 
there are going to be things that maybe I know more than others. Yes, but . . . I would hope that I would know it." For Cameron content knowledge was also a matter of pride:

As a teacher I must strengthen my knowledge as best as I can in order to be able to answer as many questions as my students ask me. Not being able to answer every question will be difficult to accept from an ego standpoint.

While understanding the material was both a matter of pride and obligation, it was largely rooted in the desire to increase future students' interest in science. As Cameron explained, I believe my job is to educating young minds about how interesting and exciting science can be... Methods such as these [hands-on and visual] can help gain the interest of young minds . . . As a teacher it is my job to hook students into the information I am presenting.

Cameron recognized that not all of his future students would find science as exciting as he did personally, and he saw his knowledge base as a way to capture their interest. After some early successes in FBE 300, Chris arrived at a similar conclusion, even though she did not have a strong inherent interest in science:

After reflecting on today I have set a new goal for myself: I want to put in time to acquire the knowledge about biology and ecosystems now so that I can someday confidently and accurately convey an interest and enjoyment for science to my students.

Payton approached the same idea from a slightly different angle. He saw content knowledge as a way to provide the flexibility to follow his students' interest, "What aspects of nature is that specific student drawn to? Is it animals, plants, trees, insects, fungi, etc. This would allow me to gauge what my students are interested in and base my next lesson plans on those interests." 
Viewing teachers as sources of knowledge could lead to didacticism, which is why participants' focus on using knowledge to generate student interest was of such importance. Conversely regarding knowledge as a way to capture students' imaginations, while also viewing teachers as facilitators, could be a powerful combination to support student-active approaches. Participants' views of their knowledge were also of significance when considering the use of field-based techniques specifically. Comfort with ecological concepts has been linked to comfort with teaching outdoors (Hogan \& Berkowitz, 2000).

A small number of participants also articulated their role as teacher-learners. While this was not widespread among the participants, it was important because a single semester course is not enough to fully support ecological literacy (Powers, 2010). Sam, while viewing knowledge of the curriculum as a responsibility, also saw advantages in learning with her students. As she said in her interview:

I think kids find a lot of value and truth about the world when a teacher does say ... "I don't know the answer to that question. Let me get back to you." Because when everyone knows everything they're going to be like "uh, I don't know anything” or . . get discouraged or . . feel like they're not perfect and you are, and they need to know that you're not.

Chris also viewed her role as someone who models the learning process for her students. In her interview she described the learning that arises from finding something unfamiliar while working outdoors:

A lot of inquiry skills because they're learning . . . does it have legs, does it move, does it breathe, what is it . . I think that's a really authentic experience. They're going to remember forever going and digging up this giant worm and then bringing to me, and 
you know we looked it up together... It puts us on a level playing field, too. I'm not always ... "oh I know everything because I'm the teacher." It kind of makes it more of a learning experience for me as well.

Sam saw fieldwork as well suited to these types of encounters. As she continued in her interview:

But I think that that also allows for expanding the curriculum like "Hey, we found this bug that we don't know what it is ... let's look it up." And then maybe let's ... look up information about the bug. And ... then you take it into English class like "let's write a poem about this bug that we found" . . write about the descriptions. Write about where it's from ... what it does... When you don't know what it is, it allows you to actually expand it a lot more than maybe what you already had.

Sam and Chris' recognition of fieldwork as a good way to learn along with their students was an important outcome within the course, and displayed a delicate balance. Previous research indicated that educators are more open to this type of unplanned learning if they feel comfortable in the field (Mannion et al, 2013; Skamp, 2009), which can help them move past standard curricula (Powers, 2004). In turn, this flexibility leads to more opportunity to be "co-learners" with their students (Knapp, 2005, p. 280; Krapfel, 1999; Mannion et al., 2013; Sayers, 2004). However, ecological content understanding is associated with comfort in the field (Hogan \& Berkowitz, 2000). Ultimately, this may provide a target for expanding pre-service educators' ecological literacy. If their college courses are not sufficient to provide them with a depth of ecological knowledge, they need to provide enough of a foundation for them to be confident in their ability to go into the field and learn with their students. 
Class structure. As pre-service educators, participants in FBE 300 often interpreted their experiences through the lens of their future students. This was seen in their conceptions of environmental education and their roles as teachers. As they considered Class structure, they commented directly on matters of future implementation of course-related topics. The influence of FBE 300 and previous experiences that participants connected to the course were apparent in three avenues of instructional design, Choosing content, Choosing technique, and Choosing location, as well as one aspect of course management, Preparing for contingencies. These analytical groupings were useful, as they showed the properties of course design of most concern to students, but they were all closely interrelated and participants made connections between them.

Preparing for contingencies. As participants reflected on their experiences and considered field-based educational experiences for their students, they thought about contingencies that might arise both in and out of the classroom. At times this was done in an offhand manner, as when Taylor took the time to write the question, "Is this bee harmful?" during an observation, but other ideas warranted more consideration. Payton, who consistently thought about implementation issues throughout the course, used his journals to consider specific types of issues that he might face in the future:

A student might keep interrupting, your class phone might ring, a question could be asked that stumps you while you are teaching. We should be preparing for those instances. That's why physical, real world experience is so beneficial... When we go to the nature preserve anything can happen. For instance, when we were at the preserve on [date], we encountered a large black rat snake while doing our survey. It is just difficult to be able to role-play something like that in the classroom. 
While not all of these potential issues were tied to fieldwork specifically, Payton acknowledged that being away from the classroom might provide an extra layer of challenge. Notably, he did not consider these reasons to avoid taking students outdoors, but rather he highlighted the importance his own fieldwork played in his ability to plan ahead. This was in line with research from Mannion et al. (2013), who noted that extended professional development in the field helped educators move past their concerns about what they could not control. Experiences in FBE 300 were important conditions that influenced Payton's plans for future fieldwork, a point he made even more strongly in a later journal entry:

This is great to be a part of first hand because I feel that it gives us beneficial experiences as future educators. Every week we get to go on a field trip. It preps us to be prepared for field trips in our future classrooms ... All of these instances are preparing us to take our future students on field trips.

Payton identified important preparation for working with future students throughout his field experiences. For others in the class, the opportunity to work with fourth-grade students on campus for a class period was particularly meaningful. Bobby found the event very challenging, as she was accustomed to working with younger students:

[Being more aware of local environment] was beneficial when the students came to [Oak Savanna] for the day. I was nervous about being with fourth graders because I've observed for younger grades. I was assigned a few boys that were friends and this made my job a bit difficult. . . Even though this was a challenging group I learned a lot. I know they had a fun time with our class, but I should be addressing some rules and find out how to get students like them to focus their attention on their research. 
Bobby continued to think about the experience and what she could have done to help her students maintain focus. She noted in her interview:

I think about it, too, and what I could've done. So, yeah. I still think about it. And, I've been thinking of things I could do to make that experience different, if I were to do it again. Maybe just come in together, holding hands or something. When we switched different areas . . . trying to focus them a little bit more and spreading them out instead of going in a circle. Maybe in a line so they weren't all together.

While the work with the fourth grade students was somewhat stressful for Bobby, it was still a significant learning moment. Alex's experience paralleled Bobby's in that she was more accustomed to younger students and did not always feel that she held her students' focus: It was difficult at times to get the boys in my group to focus their attention on the task, as a few boys in the group were friends and goofing off. After this experience, when we were debriefing in class we talked about how some of the behavioral issues could be prevented if as a teacher you put together groups ahead of time, separating students who might cause these issues when together.

We also talked about how different students would often be interested in observing different things, however in one's own classroom, a teacher could better differentiate instruction by allowing students to go explore nature within a specific area, allowing those who want to spend more time in a certain spot to do so, while guiding other students with shorter attention spans/less interest to several spots and asking guiding questions along the way to engage them. 
The debriefing of the event in class was important for Alex to process the event and tie it to her future classroom. In her interview she focused on how she could structure her outdoor work with students:

... definitely. . . getting outside and I like the idea of . . using a hula-hoop to even just observe .. . a small area and having kids do like some type of . . journal and drawing and observation, I feel like I could definitely do something along those lines.

While Alex experienced some of the challenge of working with students in an outdoor setting, she ended the semester in a place of some confidence, an important indication for future implementation.

Overall, both participants' time in the field on their own studies and their direct work with elementary students were important as they developed their sense of themselves as fieldbased educators. Their ability to think through potential challenges with a degree of experience was important for developing a realistic sense of confidence, one where they recognized potential concerns working in the field, but also felt that they could handle them. As Chris noted in her interview:

You know they [fourth grade students] at first did not want to be involved, and they just wanted to be outside and run around, because they'd been . . structured all day. But then we were able to ... I was like "what do you guys want to look at next?" And then . . they were able to take me where they wanted to go. And then, I kind of asked a couple of questions about it. We'd talk about it a little bit, and they'd be like, "all right, let's go over here." And I'm like, “yeah, let's definitely go" . . being able to let them kind of lead where we went, but then facilitate really great discussion. I think that was cool for me to see. 
Chris continued this line of thought when discussing her future students:

But... for me that's... why it's so important before we go outside... I'm big on safety, always have been ... so just safety guidelines . . We don't put things in our mouth. We don't . . touch things . . . ask me before you're going to touch something, if you don't know what it is. Things like that . . and then ... follow through. If you don't follow the guidelines, you're not going to be able to participate in this.

Chris statements were essential for future implementation. She had the awareness that fieldwork provided certain challenges that a classroom setting did not, but she also felt confident in her ability to establish guidelines that will allow her to handle them. This combination of assessment of a situation and having a plan for action could be critical for a successful first field-based experience with young students, and a successful first experience could be critical for a second experience.

Choosing location. Participants' preparation for contingencies in the field suggested that they gave serious thought to the possibility of working outdoors with future students. This was important as an indication of intent, which also was supported by their specific consideration of the benefits of fieldwork, either as a field trip or schoolyard exercise. Participants connected their choice of location to their developing ecological literacy by assuming what was beneficial to them would be beneficial to their future students. Likewise, their choices also indicated their ecological place meaning. Students' enthusiasm for fieldwork was tempered by some consideration of the expense of field trips as well as their own comfort working with future students outdoors, but ultimately they saw enough benefit to outweigh the costs.

Participants indicated positive aspects of working with students in an outdoor setting. 
For Chris, outdoor work was part of her vision of authentic learning. As she noted on her final exam, "I also plan to incorporate a lot of nature based instruction, whether it be students digging in the dirt, finding bugs in the playground or looking at the clouds for weather patterns." While Chris could conceptualize how to teach some of these activities inside, she still saw the benefit of concrete experiences outdoors. As she indicated in her interview:

Well, my lesson plan idea with ... the [quadrant] squares . . I think, would be so cool to do. And I could do that with so many different things, you know inside and outside the classroom. But ... the importance of those authentic, out of the classroom, real, handson learning experiences... I mean getting them outside and getting their hands in the dirt.

As Chris focused on early childhood education, Payton saw a particular benefit in how fieldwork could be used to meet diverse student needs:

Students with special needs sometimes tend to feel uncomfortable in the classroom setting. Bringing them outside might bring in something that they student is used to and makes them more comfortable. It might also be more fun and interesting for the students and make it easier for them to learn.

Payton's conclusion echoed arguments for a leveling effect of fieldwork, where certain barriers to classroom instruction are of less consequence with the concrete experiences of fieldwork (Blank et al., 2003). Alex also emphasized the need for concrete experiences in early childhood education as she discussed her lesson plan. Her original draft included one outdoor, observational experience that was then compared to observations made when watching a video on a distant locale (desert), she ultimately revised her lesson to contain two local experiences (schoolyard and forest preserve). As she explained in her interview: 
And then, when I was getting peer feedback [on the lesson plan] they were suggesting... what if you used ... a video, like a Plant Earth, and . . compared that to ... the schoolyard or some type of . . field trip experience. But, I don't know, I might switch it to . . . a forest and a wetland . . because I feel . . it's kind of abstract, especially for younger students, to be ... trying and taking . . a video. So I was sort of rethinking that ... that was my main thought on how to change it.

The feedback that Alex received from other participants indicated that while participants argued for the benefits of fieldwork, there was still a lingering tendency to try to find ways to work around field trips in favor of schoolyard, or sometimes indoor, experiences. This could have several explanations, but cost and unknown school culture were important considerations. Taylor tied both of these ideas together during her interview in reply to the suggestion that one way for students to consider the problem of pollution was to take a field trip to clean up litter: Depending on the area ... I mean it's a field trip, so budget, but then yes. I mean ... when I become a teacher, if I could do a field trip, I think I'm going to want to do it, especially if I have a special ed class, but I think it's going to depend on a lot of things. Especially like the school, too, and where we'd go and I don't know. I think it would take a lot into it, but if I could do it, sure!

These types of practicalities were of concern all semester, but their experiences in the class helped allay some hesitancy. Payton noted in his interview that important experiences were worth their potential costs, but that not all field trips needed to be expensive:

But obviously... something you guys have shown me this semester is that, it's a lot easier to find cost efficient things than I would think you know. I used to think... "oh everything costs money." Every ... field trip's going to cost some sort of money ... no 
matter what, but then going to the different places that were just free and we could just walk right in and no problem. It just kind of changed things around a little bit ...

Critically, Payton supported these musings by investigating other low costs field trips, even planning a field trip to a zoo with free admission as part of his nature passport project.

Through the field experiences in FBE 300, participants saw potential benefits of learning outdoors for their students and the personal benefits to themselves in terms of concept development (ecological literacy) and awareness of local landscapes (sense of place). As Bobby noted on her final exam, "These places will encourage me to scout out unique ecosystems in the area that my class can observe. The way our class got involved in different areas of [town] was very beneficial for the content we learned." Kit made a similar comment in a journal entry, "When I am a teacher, I hope to do a similar activity with my class. I think that getting hands-on ... your environment and out of the classroom is extremely beneficial to the learning process."

Choosing technique. Participants reinforced their choices of location with a strong emphasis on the skills that they practiced throughout the semester. This resulted in consideration of the benefits of student-driven lessons that focused heavily on observation. In this way, they connected practices used in FBE 300 with ecological content and pedagogical choices.

As participants discussed their preferred teaching approaches, an emphasis on observation became apparent. Participants saw observation as a way to incorporate student choice into lessons and to build an environment for inquiry. Payton described this approach on his midterm exam:

Science is very much an inquiry-based subject if taught in the correct way. I would love to incorporate inquiry into my future classrooms. Doing inquiry would allow me to see the different ways students perceive nature. One specific inquiry project I have thought 
about is doing an observation project. Students would be allowed to go out and observe any type of nature they would like to and write some observations about it. It would be interesting to see what each of the students observe in nature.

Allowing the time and the space for observation was seen as a key way to develop curiosity and to encourage students to think more deeply about the places around them. Bobby noted the potential for observation to lead to further questions on her midterm, "In my future classroom students should be able to explore nature in a safe environment. They have many questions they could come up with by observing and finding curiosity in the way things work."

The curiosity that arose from observation could then be used to extend observations into deeper inquiries. Alex described how she could use observations as the beginning of a more extended experience on her final:

As students' skills in observing different ecosystems developed, I would encourage them to expand their understandings of their observations by choosing a certain aspects to focus on. Fostering each student's individual learning based on their interests when observing. For example, if a student seemed especially interested in a specific tree, plant, or animal, I would encourage them to do more focused observations of what peaks their interest the most. In addition, they could do further research to gain a better understanding of what they're observing.

Kit thought of observation and identification as tools to stimulate curiosity, and also as a way to think about research design. She tied her personal experiences from both middle school and FBE 300 to suggest a way to increase students' contribution to a plant identification project:

In middle school, before my class went to the river to collect leaves, my teacher gave an entire lecture about how to identify plants and what type of leaves to look for. If I was a 
teacher I wouldn't have given any instruction (or very little) besides safety precautions and telling them their goal is (in this case to identify plants) ... After my class and I went out and identified, I would bring them back to the classroom and ask them to write down the procedures that they created/followed. We would have a class discussion about what was difficult, easy, and how they would have liked to have gone about the process differently.

Here Kit saw a way to take a previously highly structured task and adapt it to emphasize a scientific habit of mind.

Participants tied their choice of using observation to stimulate further inquiry directly to personal experiences in FBE 300. For Kit, this was a way to make an experience she had in middle school more open to student ideas. Alex noted that she focused on observation in her lesson plan because it was something she personally enjoyed, "I really like the observation component for this course, I've enjoyed a lot, so I feel like I wanted to tie that into a lesson plan somehow." For Cameron, having personal experience with fieldwork and observation journals impacted his confidence in providing the same for his future students:

I think just going out there in the field and learning how... things work. How to handle yourself, that type of thing, is going to help me to take students on field trips in the future ... I think that really helped, too. What to look for, what to have them look for. The journals that type of thing, how they can do their own research, design their... own experiments. Yeah, all that stuff.

As with choosing location, experiences in FBE 300 directly impacted participants' choice of technique that they wished to incorporate in the future. This outcome was seen from all students 
in some capacity and across multiple data sources. The pattern also extended to participants' choice of ecological concepts that they wanted to explore with their future students.

Choosing content. In addition to location and technique, participants prioritized content, including both concepts and skills, they felt was important for their future students to learn. The influence of FBE 300 was clear here as well; as participants drew very literal connections between what they were studying and what they thought would be appropriate for their pK-12 students. The direct transfer of topics likely stemmed from multiple places, including their ability to see how the topics could be made age-appropriate for their students, personal enjoyment, and the limited extent of their experiences in ecology.

Adaptation for younger students. Participants in FBE 300 were preparing to teach pK-12, with a preference for $\mathrm{pK}-8$. In general they felt that most of the concepts and skills emphasized in the course could be adapted to a grade level they were interested in teaching. Taylor, who was not always comfortable with fieldwork, felt the topics and techniques were well suited to elementary standards as she noted in her interview,

... Everything in the class ... I learned about, so I feel that's a lot of stuff to take into my classrooms, maybe not right away. And maybe not my specific lessons, but little aspects and points of it here and there, yeah. I mean, obviously, observations . . learning about all that. I think maybe ... the general basis of ecosystems and habitats and community dynamics. I feel like those are general concepts of an elementary school science education, anyway.

Alex emphasized the immediate nature of the content, and how that made it more aligned with early childhood pedagogy for both science and social studies: 
I think it's [observation in local ecosystems] important because ... in future science classes, but ... it kind of . . overlaps with social studies in a way, just to have . . a general understanding of . . the community and the environment that you're around... In early childhood we talk about more ... concrete experiences, where ... it's not as maybe developmentally appropriate to talk about ... the ocean or the rainforest if you don't live right there ... not that you can't, but emphasizing ... what's right there is probably good to start with.

Here Alex connected content choice with a sense of place in a way that corresponded with Sobel's $(1996 ; 2013)$ thoughts on place-based early childhood education. While Alex made the connection most explicitly, Kit made similar statements as she discussed how remote science topics can seem and how fieldwork gives students first-hand experiences that are personally meaningful:

I think not only obviously, teaching them the knowledge, but have it relate to them in some way. I think that doing ... hands-on activities allows for that to happen. Because they're experiencing it themselves ... but not all subjects ... if we're talking about the planets ... that's probably very unrealistic. So finding a way that you can ... relate the subject to them personally, I guess. Not always ... in the science aspect, but like ... them as a human, and they'll remember it better as well.

Here Kit noted that not all subjects, such as distant planets (Kit's example), will feel immediately present to students, but she found it important to help students connect with science topics on a human level as much as possible.

Locally responsive. What made science age-appropriate to Alex and Kit also made it personally relevant. In this way, choice of content was influenced by ideas of concrete 
experiences in place. Other participants also reiterated the importance of a locally responsive curriculum rooted in the students' lives and their local areas. Cameron thought this could help older students find an interest in science:

I feel like a lot of middle school and younger kids don't know much about science and you can make it so that it's a great subject, and you can .. push them towards it. Maybe they can find a career, down the future road, in science. I think you need to know about them. You have to ask questions about them. Know where they come from, like what you're doing with me right now. Know a little bit about their personal lives, their background, what interests and hobbies they have.

For Taylor, taking the time to get to know her students was a way to enhance their comfort. I could give them . . . a list at the beginning of what's going to be covered. And get background knowledge from them and figure out what they like and what they want to learn about and kind of ... I mean I'm going to have a developed curriculum already because I'm going to have to, but I feel like I could adapt it to the students' wants and likes and dislikes.

She felt this approach was successful in FBE 300 to engage students who were less inclined to fieldwork:

I feel like kind of what we did this semester. Just kind of continuing with it and doing hands-on activity to get them comfortable and just kind of taking it step-by-step to get them more comfortable, and asking them why they're uncomfortable. What'll make them more comfortable? Getting a feel of where they're at. What they want.

While Taylor and Cameron wanted to let their future students' interests guide their choices, they knew that they would need to align with school curricula and standards. However, participants 
generally felt that content from the course would fit in well with their future curricula, and they often saw ways to incorporate what they had found personally meaningful.

Concepts from FBE 300. Participants found many concepts and skills from FBE 300 to be applicable to their future classes, but those that they commented on most frequently related both to what they found enjoyable and to the relative emphasis on the skills and concepts within the course. Both factors likely explained the prevalence of plant identification projects that were suggested. Plant identification skills were seen as flexible in terms of implementation and closely related to participants' own experiences at New Woods (discussed in more detail in Chapter IV: Community of Practice in Field-based Ecology). Payton noted this in an early journal entry, "The whole time during the class period I was thinking about how it would be very beneficial to do this [plant identification] in my future classroom." Chris elaborated on her midterm exam, "Some experiences I would specifically like my students to have are categorizing and identifying flowering plants from non-flowering plants, a basic understanding of life cycles, and the basic understanding of ecosystems." Kit, Alex, and Taylor expressed similar thoughts, sometimes with further elaboration, such as on Kit's midterm, "I want my students to be given the opportunity to learn scientific concepts such as plant identification and ecosystem interactions and services."

Other topics of interest were also tied to experiences throughout the semester. Payton used his observation notebook to suggest possible projects for his students:

While doing this observation [of seasonal changes at New Woods] I though it would be a great activity to do in class. Students could hypothesize why they think certain trees keep their leaves longer. Then they could do a research project. It could also include field experiences and they can make up class observations. 
Cameron saw the potential for incorporating a documentary from class into his teaching, "This concept [wetlands and storm surge] is a great way to create a lesson plan, which encompasses information about weather and ecosystems while discussing the tragedy of Hurricane Katrina." Alex found inspiration in a particular book she read for her nature passport:

I just completed my nature passport project, which was a lot of work, but I enjoyed doing. In terms of books I read, I chose to read and review three children's books related to nature, all of which I could incorporate into my future teaching. My favorite was $\underline{\text { On }}$ Meadowview Street, in which a girl persuades her dad not to mow around a wild flower that she sees growing in her yard. She eventually turns her/restores her entire yard to a meadow, and it becomes a natural habitat to many animals.

Not all suggestions for future content came directly from experiences in the class; Cameron often made novel connections:

As a teacher I could compare plumbing state code to the insects found in [state]. Pipe has to be buried a certain depth in order to stop freezing. Do insects have to bury themselves a certain depth in order to survive?

Participants also found inspiration in other college courses, $\mathrm{pK}-12$ experiences, and experiences with their families; however, drawing directly from FBE 300 was most common. This was likely the result of limited experience with ecology education. As such, topics and skills common to the course dominated ideas for future curricula. This was not an unexpected, nor an undesired result; connecting class concepts with pK-8 curricula was a learning objective of the course. Participants did this quite well in written reflections, observations, and exams. However, as pre-service educators in the early stages of curricular planning, participants' 
flexibility in applying principles of ecology education was limited, which is a topic considered in the next section.

\section{Future Planning in Action}

All participants articulated the benefits of fieldwork or a desire to incorporate it with their students, but planning for fieldwork only partially penetrated their actual lesson planning. This was apparent from both an assignment that required them to develop inquiry-based lesson plans and their nature passports, which included reflection on how their experiences connected to their future classrooms. When tasked to create an inquiry-based lesson plan that reflected the content and style of FBE 300, the majority of participants incorporated outdoor work through either a schoolyard experience (two participants), a field trip (one participant), or both (two participants) (Table 6); however, three lessons were constructed so as to take place entirely indoors despite the potential to have outdoor elements. The nature passports showed a similar pattern, with half of the participants suggesting field experiences that related to their projects, another two participants indicating related, but not necessarily ecological, outdoor work (e.g. having students create a sculpture garden), and two not incorporating significant suggestions for field-based or other outdoor work. 
Table 6

Lesson Plan Topics and Instructional Techniques Developed in Field-based Ecology 300

\begin{tabular}{lll}
\hline \multicolumn{1}{c}{ Topic } & \multicolumn{1}{c}{ Location } & \multicolumn{1}{c}{ Technique } \\
\hline Characterizing plants and animals & Schoolyard & Observation/Identification \\
Compare/contrast habitats & Schoolyard/Forest & Observation \\
$\begin{array}{l}\text { Causes of seasonal variation in } \\
\text { climate }\end{array}$ & Indoors & Data mining/Analysis \\
Pollution and water filtration & Indoors & Model development \\
Ocean acidification & Beach/Indoors & Model development \\
Fossil identification & Indoors & Observation/Identification \\
Sensory nature walk & Schoolyard/Wetland & Observation \\
Discovering ecotones & Local ecosystems & Observation \\
\hline
\end{tabular}

In all, seven of the eight participants suggested outdoor work as part of either their lesson plan or their nature passports, but only three of eight participants consistently suggested concrete ideas for fieldwork in both of the assignments. The seeming contradiction between what participants prioritized in their written reflections, and what they included when tasked with suggesting concrete ideas for lessons could be explained partially by the emergent nature of student understanding. In FBE 300, participants were developing an understanding of ecological concepts and ecological pedagogy at the same time, and they did not always know how to combine the two. For Cameron, this created a disconnect where he often suggested field trips for students, but sometimes he also suggested describing experiences that he found meaningful, rather than providing similar ones for his students, as illustrated in a passage from his final exam, "I can foster this enthusiasm by telling my students stories about my experiences in the forest." In his lesson plan, he had a hard time combining content he wanted to explore (chemistry) with field-based approaches. This led to a stepwise development of an idea where he progressed from 
a focus on the periodic table to ocean acidification through modeling to ocean acidification through modeling with an associated field trip. Ultimately the difficulty of connecting content and pedagogical approaches resulted in Cameron, who had the strongest local place attachment, creating a lesson that was designed to be taught on a coast.

A second challenge came from working with the Next Generation Science Standards, which were new to many of the students. Participants found their plans curtailed when they could not teach the concept they were interested in at the grade level they were planning for. Bobby originally chose topics that could have outdoor elements, composting or exploring pond water, but subsequently switched to fossils. As she indicated in her interview, the standards influenced her choice of a topic, which ultimately led to an indoor lesson plan:

Well, I couldn't find . . the standards online [related to composting or ponds], so that made me switch to fossils. Which I still find interesting, but . . That's probably why I changed it...

Usually [I start] from an idea . . but with this . . I had trouble finding what I wanted to do. So I did look more at the standards.

In this case, Bobby's original content of interest did not work out the way she intended, and the standards provided another hurdle. She was not familiar enough with them to look for her concepts at a different grade level, nor to consider how the topic of fossils might be approached outdoors.

Participants also sometimes struggled to connect their favored techniques with the content they chose for their formal lesson plans. This was true for Kit, who wrote a middle school lesson related to the causes of the seasons. She found the topic personally interesting, but hard to do in a way that emphasized her preferred approaches of student-led observation and 
project development. In her original plan, students developed concepts through class discussion and on-line research projects. Kit was aware that she struggled to connect the topic with more active learning approaches. As she indicated in her interview:

It's about the seasons... I was interested in it and so I figured that my students would be as well. So it's just ... a topic that I found interesting to learn about, I guess . . I'm ... . actually still in the process of making this a good lesson ... because I feel like it's really not yet.

I asked [Sam] for her opinion and... I'm trying to make my lesson so that it's hands-on and students ... remember it ... [Sam] and I talked . . because it's more research based, and she was saying maybe to break it up, how... students each take a season like I had before, but ... present on theirs during that season. So that it's more ... relative to what they were experiencing then. But that's not ... I mean that's a good idea, but it's not more inquiry... it's not like super hands-on. And I feel like it's very hard to make a lesson that's research inquiry.

Kit understood the limitations of on-line research as a memorable learning experience, but found seasons to be a hard topic to approach experimentally. She later adjusted her lesson to use data mining as a way for students to develop an understanding of seasonal differences in different parts of the world. While she incorporated a new focus on data analysis and drawing conclusions, she did not include field-based elements. This was largely true for her curricular suggestions in her nature passport as well. Similar to Cameron, Kit focused on student exploration in her reflective writing, but fell back on more familiar, indoor techniques in other assignments. 
Incorporating both concepts and pedagogy from FBE 300 into formal lesson plans proved to be a challenge. Those participants who were most successful created lessons very similar to their personal experiences adjusted for developmental level. Participants who chose topics that were further afield struggled more to include fieldwork, but they largely realized that the lessons were not coming together as intended. While participants did not fully incorporate the fieldbased aspects of the course into their lesson plans, they made progress throughout the semester. In the model of a community of practice, they developed as legitimate peripheral participants (Lave \& Wenger, 1991), but did not yet achieve full participation as field-based ecology educators (Brown et al., 1989; Wenger, 1998). This was not a surprise, as FBE 300 was a single semester course, and participants had limited ability to work directly with pK-12 students.

Students' experiences as pre-service educators were central to FBE 300. By the end of the semester, all participants had made significant gains across multiple aspects of ecology education. This influenced their desire to teach ecology outdoors irrespective of their occasional struggles to develop field-based lesson plans. The push and pull of their interest in outdoor ecology education and their nascent understanding of place-based pedagogy and ecological concepts were central to the development of a model of field-based ecology education for preservice educators in FBE 300.

\section{Developing a Model of Field-based Ecology Education for Pre-service Educators}

Each of the data chapters in this dissertation described a major theme related to the participants' experience in FBE 300: Community of practice, Developing ecological literacy, Sense of place, and Experiencing class as a pre-service educator. Throughout the course, these themes were informed by each other, with participants' position as pre-service educators forming the central link that tied all of the themes together. In the terminology of Corbin and Strauss 
(2015), Experiencing class as a pre-service educator was the core concept around which all the other categories (themes) were integrated. Their identities as pre-service educators informed their approach to the subject matter by providing them with a motivation to engage with ecological and pedagogical concepts, to persevere in uncomfortable field conditions, and to stretch their conceptions of themselves both as science students and as students who felt comfortable learning in the field. Pre-service education was an essential part of the participants' context; it also provided the necessary rationale ("conditions") for expanding that context to include ecology education (Corbin \& Strauss, 2015, p. 165).

Some of these shifts in context were subtle, Taylor began and ended the semester as firmly not an outdoor person, but she expressed a willingness to include field-based experiences in the future if they could benefit her students. Cameron, Kit, and Sam also showed subtle shifts, but for different reasons as they identified as outdoor people. As a student who was already interested in both ecology and outdoor exploration, Cameron saw field-based techniques as a way to deepen his personal content understanding and to inspire his students. Kit and Sam also saw opportunities to incorporate their love of the outdoors in scientifically meaningful ways. Bobby's work with the fourth grade students led her to try to expand her comfort zone to include older students.

Other shifts in context were more profound, Payton, Alex, and Chris all saw great potential benefits of field-based techniques for their future students and regularly planned to use them. For Chris, this was enough to overcome initial reluctance to both field techniques and science in general. All of the students expanded their notions of what the Midwest had to offer in terms of ecosystems. Whether participants showed minor shifts or more significant adjustments to their ideas of field-based ecology education and their roles as ecology educators, the changes 
were supported by the actions that led to them to develop a community of practice, their ecological literacy, and their sense of place (Figure 5).

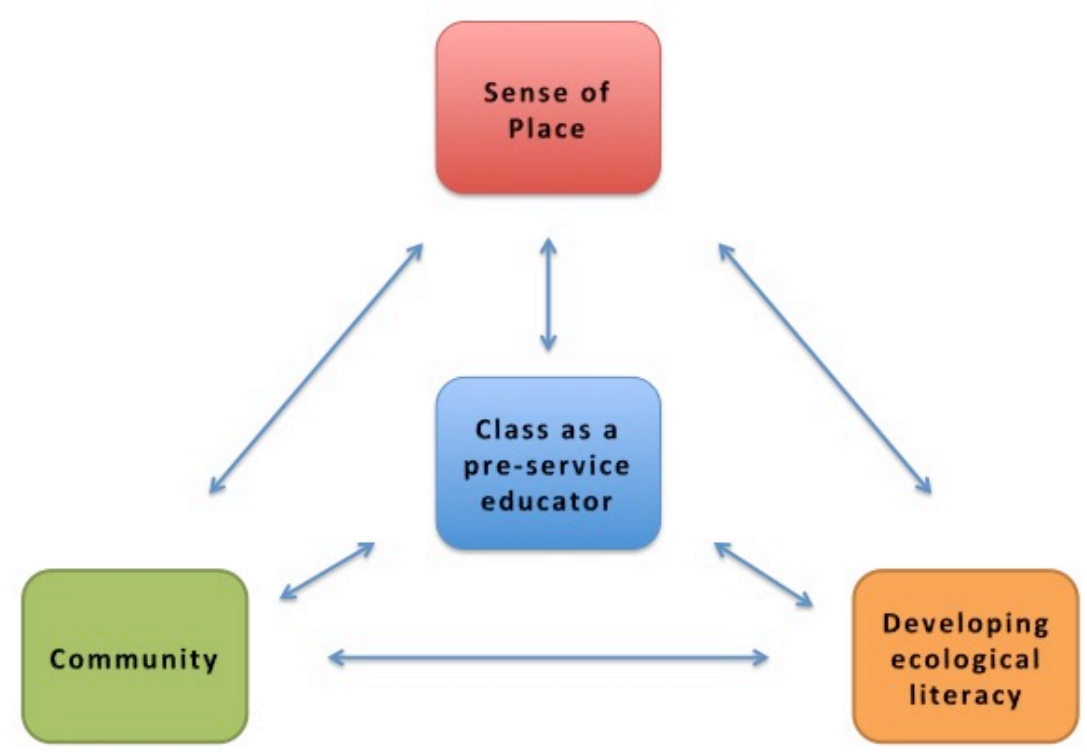

Figure 5. Model of field-based ecology for pre-service educators in Field-based Ecology 300 In grounded theory, a model is developed of how participants' context and conditions (reasons for actions) continually adjust through the actions they take (Corbin \& Strauss, 2015). This feedback loop is referred to as process. Figure 5 is a visual representation of how participants' experience of class as a pre-service educator shifted and adjusted throughout FBE 300. In this model, each theme represents a hub of action taken by the participants. For example sense of place was not something participants passively possessed; rather they developed it actively. Through fieldwork, reflection, and observation, participants developed a greater sense of place meaning and, in some cases, place attachment. Additionally, each theme influenced every other theme. Actions that helped students form a community of practice also contributed to 
their emerging sense of place; the reciprocal is also true, developing sense of place reinforced the community of practice. Experiencing class as a pre-service educator is centralized as the core concept. It was the unifying theme present for all participants from the beginning of the course to the end of the semester, and it represented that context and the conditions that shifted as a result of all of their actions within the class.

Not all participants moved through the model in the same way. Pathways were flexible enough to allow for different, but equally meaningful experiences over the course of the semester. Sense of place was especially important for Cameron, whereas community was paramount to Payton. Chris' developing ecological literacy increased her confidence and inspired her to be an enthusiastic science educator for her future students. Throughout the semester, students shifted their understanding of ecology as a field, ecology education, and their role in both. Progress was made incrementally through 30-minute observations periods and data collection at New Woods. It was also made suddenly when a participant experienced something personally profound, such as Sam's first trip to Great Egret Wetlands. Regardless of where they started the semester, all participants saw a shift in their context over the course of the semester. These shifts should not be taken as the end of the process, rather they formed a foundation for personal and professional development that hopefully can extend beyond the boundaries of one course and one semester.

\section{Conclusions and Recommendations}

As a field-based ecology course for pre-service educators, FBE 300 was designed to increase participants' ecological literacy and comfort with place-based pedagogy with an ancillary goal to foster a sense of place. The framework chosen for the course was that of a community of practice (CoP). Students developed to a greater or lesser extent in all of these 
areas throughout the semester, as could be expected for a single college course. As such, FBE 300 was seen as a step in participants' progression as educators and ecologically aware citizens, not as a goal or destination. Each facet of the course progressed somewhat differently, and led to separate suggestions for both course improvement and further study.

\section{Community of Place}

The CoP aspects of the course were probably the best developed. Participants began the semester with a strong identity as pre-service educators that provided the common goal necessary for a $\mathrm{CoP}$ to form. The $\mathrm{CoP}$ grew through participation in a citizen science project at New Woods Forest Preserve. The efforts required for data collection and analysis at New Woods fostered a sense of collaboration and gave meaning to the work involved. Participants felt these aspects of the project were beneficial enough to suggest citizen science approaches for their future students. The CoP framework supported participants' developing ecological literacy across all Jordan et al.'s (2009) domains. This was somewhat at odds with the review of literature on CoPs as frameworks for environmental education by Aguilar (2016), which found affective goals to be more common than cognitive ones. The increased cognitive benefit was likely due to efforts to closely pair fieldwork with lecture and discussion.

Overall the $\mathrm{CoP}$ framework and the citizen science aspects of the course were beneficial to students and should be retained for future offerings of FBE 300. The sequencing of topics within the course (Table 5.1) were generally successful, as students noted the benefits of paired lecture and discussion. The one exception involved the topic of community ecology, which was positioned too late in the semester and should be adjusted to more closely match the introduction of the citizen science project and the first days of data collection. This would provide the context necessary for participants to better understand the significance of the data they collected for the 
forest preserve as they were collecting it. The placement of community ecology at the end of the semester was not intentional, but rather it was an artifact of other lecture/discussion topics that were given priority during the course of the semester. This was a relatively minor problem that could be easily addressed in future semesters.

\section{Ecological Literacy}

Throughout the semester participants increased their ecological content understanding across all four learning goals of the course, as well as the three domains of Jordan et al.'s (2009) framework for ecological literacy, including concepts and connections, habits of mind, and human impact. However, student progress was best visualized when using the framework to generate a big picture conception ecological literacy. Participants had too little common experience in ecology at the beginning of the course to use the framework for granular analysis. Important cognitive and dispositional gains would be lost if an instructor was too focused on detailed ecological understandings. As such, the course was most important as a way to build a foundation of content understanding while developing students' confidence in their abilities to continue learning in the future. The most important habit of mind developed within the course was participants' belief that they could learn ecological content and their desire to do so for the benefit of their future students.

As a field-based course, considerable editorial discretion was required when choosing concepts to include in the class. The structure of the class was designed to maximize time in the field while still allowing for class days to expand on topics through lecture and discussion. While this meant that content coverage could not be as comprehensive, the approach was viewed as valuable by both the participants and the instructors and should be retained. The greatest depth of concept understanding occurred when students could observe phenomena at multiple sites and 
reflect on it at length (e.g. erosion). This argues for length of exposure as a key to developing ecological literacy in a field-based class.

Throughout the semester, the role that active reflection about observations played on student content understanding became increasingly clear. The observation notebooks and journals were both powerful tools, but they were not used as effectively by all participants. While both were collected at various points in the semester and overall feedback was given, more explicit instruction on how to use them is warranted. This could include individual meetings with the instructor to discuss participants' developing notebooks and to plan how to deepen the gains from observation periods. Ideally this would happen at least twice within the semester, as multiple meetings may also help students space their observations more evenly.

\section{Sense of Place}

Participants' extended time in the field help them develop their sense of place. This was true for both place meaning and place attachment, although place meaning developed to a much greater extent, which was in line with research by Kudryavtsev, Krasny, and Stedman (2012). Participants became more aware of what constituted an ecosystem and the diversity of ecosystems within a short distance of Oak Savanna University's campus. This contributed to their growing understanding of both the city and the region as an ecologically important place. Place meaning developed through both unstructured and structured time at multiple field sites. The unstructured time help establish place meaning, and the structured time added depth.

A sense of place tied to the area around Oak Savanna University had the potential to add dimension to students' undergraduate years, but from an educational point-of-view, it was important for participants to see sense of place as inherently meaningful regardless of current location. Student reflections indicated that their place meaning was likely transferable to where 
they live after they graduate and relocate. This was evidenced by their desire to find similar field sites near the schools where they will teach so they can give their students similar experiences and provide a more complete view of the variety of ecosystems within the state. This was a positive outcome that could be extended in the future. More research needs to be done to see how students used their unstructured time to develop sense of place. This could be a good source of student interview questions or written reflection prompts in the future.

\section{Class as a Pre-service Educator}

Participants were reflective on their own learning process throughout the course of the semester. They recognized the benefits of the class structure, particularly the modeling of fieldbased pedagogy and the formalized avenues for reflection. The pairing of fieldwork with lecture provided a learning environment they felt was fundamentally different and more beneficial than other lab courses. This was because the class followed a just-in-time model where lecture and discussion were used to supplement fieldwork and not the reverse. Overall this impacted the degree of content that could be included in the course, but it provided a consistency of experience that participants found particularly valuable.

Participants' ability to apply concepts and pedagogies from the course varied not only by individual, but also by assignment. Suggestions for field-based pK- 8 education that they discussed in their reflections and their observation journals did not always appear in their nature passports and lesson plans. This was likely the result of their discomfort with both ecology and the national science standards. The added benefit of consistent, extended experiences in the field in all other areas of FBE 300 argues for a more extended approach to the lesson plans. While participants were able to interact with fourth grade students during one class period, this event was somewhat spontaneous and did not include extended preparation. The lesson plans 
themselves were allotted more time for development, but they were not implemented with students. A combined approach could be very useful. Either during an in-class session or as an independent trip, participants could observe in a local professional development school and interview both students and classroom teachers about ecological topics they would like to explore in class. This could be paired with more extensive work with the standards to develop an age-appropriate lesson that met local needs. Participants could then pilot the lessons at the local school. Much like the citizen science project, this could provide a degree of authenticity to their planning and it would further embed them in a CoP as ecology educators.

\section{Final Summary}

After a full semester of field-based experiences, the pre-service educators in FBE 300 formed a CoP that supported their progress as both ecology students and ecology educators. While some of their gains were modest in terms of established frameworks, they were significant compared to where the students started at the beginning of the semester. This argues for recognizing the benefit of a field-based structure, while tempering expectations for any given course. Participants benefitted from consistent field experiences, both structured and unstructured, with dedicated avenues for reflection. Most importantly for their future practice, participants gained and an appreciation of the benefits of field-based instruction for $\mathrm{pK}-8$ students, confidence in their ability to incorporate field-based ecology, and a desire to do so. 


\section{REFERENCES}

Achieve, Inc. (2015). Next Generation Science Standards. Retrieved from http://www.nextgenscience.org/

Aguilar, O. M. (2016). Examining the literature to reveal the nature of community EE/ESD programs and research. Environmental Education and Research. doi:10.1080/13504622.2016.1244658

Ardoin, N. M., Clark, C., \& Kelsey, E. (2013). An exploration of future trends in environmental education research. Environmental Education Research, 19(4), 499-520.

Balgopal, M. M., Wallace, A. M., \& Dahlberg, S. (2012). Writing to learn ecology: A study of three populations of college students. Educational Education Research, 18, 67-90.

Ballantyne, R., \& Packer, J. (2002). Nature-based excursions: School students' perceptions of learning in natural environments. International Research in Geographical and Environmental Education, 11(3), 218-236.

Ballantyne, R., \& Packer, J. (2009). Introducing a fifth pedagogy: Experience-based strategies for facilitating learning in natural environments. Environmental Education Research, 15, 243-262.

Berkowitz, A. R., Ford, M. E., \& Brewer, C. A. (2005). A framework for integrating ecological literacy, civics literacy, and environmental citizenship in environmental education. In E. Johnson \& M. Mappin (Eds.), Environmental Education and Advocacy: Changing Perspectives of Ecology and Education (pp. 227-266). Cambridge: Cambridge University Press. 
Blank, L., Brewer, C., Lee, O., Luykx, A., Barker, S., Slingsby, D., . . Bybee, R. W. (2003). Ecology education when no child is left behind. Curriculum and Instruction Faculty Publications, 3, 383-390.

Blatt, E., \& Patrick, P. (2014). An exploration of pre-service teachers' experiences in outdoor "places" and intentions for teaching in the outdoors. International Journal of Science Education. doi:10.1080/09500693.2014.918294

Brehm, J. M., Eisenhauer, B. W., \& Krannich, R. S. (2006). Community attachments as predictors of local environmental concern: The case for multiple dimensions of place attachment. American Behavioral Scientist, 50(2), 142-165.

doi:10.1177/0002764206290630

Brody, M. (2005). Learning in nature. Environmental Education Research, 11(5), 603-621.

Brown, J. S., Collins, A., \& Duguid, P. (1989). Situated cognition and the culture of learning. Educational Researcher, 18, 32-42.

Chawla, L. (2006). Learning to love the natural world enough to protect it. Retrieved from https://www.ntnu.no/documents/10458/19133135/Chawla1.pdf

Cobb, P., McClain, K., de Silva Lamberg, T., \& Dean, C. (2003). Situating teachers' instructional practice in the institutional setting of the school and district. Educational Researcher, 32, $13-24$.

Common Core Organization (2012). Learning less: Public school teachers describe a narrowing curriculum. Retrieved from http://www.commoncore.org/ourreports.php

Comstock, A. B. (1939). Handbook of Nature Study (24th ed.). Norwood, Massachusetts: Comstock Publishing Company, Inc. 
Cook, K., \& Buck, G. (2014). Pre-service elementary teachers' experience in a community of practice through a place-based inquiry. International Journal of Environmental \& Science Education, 9, 111-132. doi:10.12973/ijese.2014.206a

Corbin, J., \& Strauss, A. (2015). Basics of qualitative research (4th ed.). Los Angeles: Sage.

Corcoran, P. B., Walker, K. E., \& Wals, A. E. J. (2004). Case studies, make-your-case studies, and case stories: A critique of case-study methodology in sustainability in higher education. Environmental Education Research, 10(1), 7-21.

Creswell, J. W. (2009). Research design: Qualitative, quantitative, and mixed method approaches (3rd edn ed.). Los Angeles, California: Sage Publications.

Crimmel, H. (2003). Teaching in the field: Working with students in the outdoor classroom (H. Crimmel Ed.). Salt Lake City, UT: The University of Utah Press.

Cronin-Jones, L. L. (2000). The effectiveness of schoolyards as sites for elementary science instruction. School Science and Mathematics, 100(4), 203-211.

Cutter-Mackenzie, A., \& Smith, R. (2003). Ecological literacy: The "missing paradigm" in environmental education (part one). Environmental Education Research, 9(4), 497-524.

D'Avanzo, C. (2003). Application of research on learning to college teaching: Ecological examples. Bioscience, 53, 1121-1128.

DeBoer, G. E. (1991). A History of Ideas in Science Education: Implications for Practice. New York and London: Teachers College Press.

Dentzau, M. W. (2011). The impact of an out of school environmental education program on student understanding of the longleaf pine ecosystem. (Specialist of Education), The Florida State University, 
Desjean-Perrotta, B. (2013). Raising a generation of environmentally literate children: Are preservice teachers ready? Childhood Education, 89(4), 260-267.

Dillon, J. (2003). On learners and learning in environmental education: Missing theories, ignored communities. Environmental Education Research, 9, 215-226.

Dillon, J., Rickinson, M., Teamey, K., Morris, M., Choi, M. Y., Sanders, D., \& Benefield, P. (2006). The value of outdoor learning: Evidence from research in the UK and elsewhere. School Science Review, 87(320), 107-111.

Erdogan, M., Usak, M., \& Bahar, M. (2013). A review of research on environmental education in non-traditional settings in Turkey, 2000 and 2011. International Journal of Environmental \& Science Education, 8(1), 37-57.

Feinsinger, P., Grajal, A., \& Berkowitz, A. R. (1997). Some themes appropriate for schoolyard ecology and other hands-on ecology education. Bulletin of the Ecological Society of America, 78(2), 144-146.

Garet, M. S., Porter, A. C., Desimone, L., Birman, B. F., \& Yoon, K. S. (2001). What makes professional development effective? Results from a national sample of teachers. American Educational Research Journal, 38, 915-945.

Griffith, A. B. (2007). Semester-long engagement in science inquiry improves students' understanding of experimental design. Teaching Issues and Experiments in Ecology, 5. Gruenewald, D. A. (2003). The best of both worlds: A critical pedagogy of place. Educational Researcher, 32(4), 3-12.

Hane, E. N. (2007). Use of an inquiry-based approach to teaching experimental design concepts in a general ecology course. Teaching Issues and Experiments in Ecology, 5, 1-19. 
Hogan, K., \& Berkowitz, A. R. (2000). Teachers as inquiry learners. Journal of Science Teacher Education, 11(1), 1-25.

Hollweg, K. S., Taylor, J. R., Bybee, R. W., Marcinkowski, T. J., McBeth, W. C., \& Zoido, P. (2011). Developing a framework for assessing environmental literacy. Washington, D.C.: North American Association for Environmental Education.

Hug, J. W. (2010). "Eeew! There's dew on my toes": Common charcteristics of preservice elementary teacher learning in environmental education and instructional strategies for science teacher educators. In A. M. Bodzin, B. S. Klein, \& S. Weaver (Eds.), The inclusion of environmental education in science teacher education. Dordrecht Heidelberg London New York: Springer.

Hungerford, H. R. (2010). Environmental education (EE) for the 21st century: Where have we been? Where are we now? Where are we headed? The Journal of Environmental Education, 41, 1-6.

Illinois State Board of Education (2015). New Illinois Learning Standards- Science. Retrieved from http://isbe.net/nils/science/default.htm

Jordan, R., Singer, F., Vaughn, J., \& Berkowitz, A. (2009). What should every citizen know about ecology? Frontiers in Ecology and the Environment, 7(9), 495-500.

Kelley, S. S. (2009). Investigating engagement, thinking, and learning among culturally diverse, urban sixth graders experience an inquiry-based science curriculum, contextualized in the local environment. (Doctor of Philosophy), Portland State University,

Klemow, K. M. (1990). Science education: A tale of three conferences. Bulletin of the Ecological Society of America, 71(2), 94-100. 
Knapp, C. E. (2005). The "I-Thou" relationship, place-based education, and Aldo Leopold. Journal of Experiential Education, 27(3), 277-285.

Korfiatis, K. J., \& Tunnicliffe, S. D. (2012). The living world in the curriculum: ecology, an essential part of biology learning. Journal of Biological Education, 46(3), 125-127.

Krapfel, P. (1999). Deepening children's participation through local ecological investigations. In G. A. Smith \& D. R. Williams (Eds.), Ecological education in action: On weaving education, culture, and the environment (pp. 47-64). Albany, NY: State University of New York Press.

Krasny, M. E., \& Bonney, R. (2005). Environmental education through citizen science and participatory action research. In E. Johnson \& M. Mappin (Eds.), Environmental education and advocacy: Changing perspectives of ecology and education (pp. 292-319). Cambridge, UK: Cambridge University Press.

Kudryavtsev, A., Krasny, M. E., \& Stedman, R. C. (2012). The impact of environmental education on sense of place among urban youth. Ecosphere, 3(4), 1-15. doi:10.1890/ES11-00318.1

Kudryavtsev, A., Stedman, R. C., \& Krasny, M. E. (2012). Sense of place in environmental education. Environmental Education Research, 18, 229-250.

Lave, J., \& Wenger, E. (1991). Situated learning: Legitimate peripheral participation. New York, NY: Cambridge University Press.

Lederman, J. S., Lederman, N. G., Bartos, S. A., Bartels, S. L., Meyer, A. A., \& Schwartz, R. S. (2014). Meaningful assessment of learners' understandings about scientific inquiry--The Views About Scientific Inquiry (VASI) questionnaire. Journal of Research in Science Teaching, 51(1), 65-83. 
Lederman, N. G., Lederman, J. S., \& Antink, A. (2013). Nature of science and scientific inquiry as contexts for the learning of science and achievement of scientific literacy. International Journal of Education in Mathematics, Science and Technology, 1(3), 138147.

Lisowski, M., \& Disinger, J. F. (1991). The effect of field-based instruction on student understandings of ecological concepts. Journal of Environmental Education, 23(1), 1923.

Lorsbach, A., \& Jinks, J. (2013). What early 20th century nature study can teach us. The Journal of Natural History Education and Experience, 7, 7-15.

Louv, R. (2005). Last child in the woods: Saving our children from nature-deficit disorder. Chapel Hill, NC: Algonquin Books of Chapel Hill.

Mannion, G., Fenwick, A., \& Lynch, J. (2013). Place-responsive pedagogy: Learning from teachers' experiences of excursions in nature. Environmental Education Research, 19(6), 792-809.

Manzo, L. C. (2005). For better or worse: Exploring multiple dimensions of place meaning. Journal of Environmental Psychology, 25, 67-86. doi:10.1016/j.jenvp.2005.01.002

Mappin, M. J., \& Johnson, E. A. (2005). Changing perspectives of ecology and education in environmental education. In E. Johnson \& M. Mappin (Eds.), Environmental education and advocacy: Changing perspectives of ecology and education (pp. 1-27). Cambridge, UK: Cambridge University Press. 
Marcinkowski, T., Bucheit, J., Spero-Swingle, V., Lisenbardt, C., Engelhardt, J., Stadel, M., ... Guzmon, K. (2013). Selected trends in thirty years of doctoral research in environmental education in Dissertation Abstracts International from collections prepared in the United States of America. In R. B. Stevenson, M. Brody, J. Dillon, \& A. E. J. Wals (Eds.), International handbook of research on environmental education (pp. 45-62). New York and London: Routledge Taylor \& Francis Group.

McBride, B. B., Brewer, C. A., Berkowitz, A. R., \& Borrie, W. T. (2013). Environmental literacy, ecological literacy, ecoliteracy: What do we mean and how did we get here? Ecosphere, 4(5), 1-20. doi:http://dx.doi.org/10.1890/ES13-00075.1

McComas, W. F. (2002). The ideal environmental science curriculum: I. History, rationales, misconceptions \& standards. The American Biology Teacher, 64, 665-672.

McComas, W. F. (2003). The nature of the ideal environmental science curriculum: Advocates, textbooks, \& conclusions (Part II of II). The American Biology Teacher, 65, 171-178.

Membiela, P., DePalma, R., \& Suarez Pazos, M. (2011). A sense of place in the science classroom. Educational Studies, 37, 361-364.

Merriam, S. B. (2009). Qualitative research: A guide to design and implementation. San Francisco, California: Jossey-Bass.

Metz, D., McMillan, B., Maxwell, M., \& Tetrault, A. (2010). Securing the place of educating for sustainable development within existing curriculum frameworks: A reflective analysis. Canadian Journal of Environmental Education, 15, 150-169.

Miele, E. A., \& Powell, W. G. (2010). Science and the city: Community cultural and natural resources at the core of a place-based, science teacher preparation program. Journal of College Science Teaching, 40(2), 40-44. 
Millennium Ecosystem Assessment (2005). Ecosystems and human well-being: Synthesis. Washington, D.C.: Island Press. Retrieved from: http://www.millenniumassessment.org/documents/document.356.aspx.pdf

Morag, O., \& Tal, T. (2012). Assessing learning in the outdoors with the Field Trip in Natural Environments (FiNE) framework. International Journal of Science Education, 34(5), $745-777$.

Munson, B. H. (1994). Ecological misconceptions. Journal of Environmental Education, 25(4), $30-34$

National Research Council (2012). A framework for K-12 science education: Practices, crosscutting concepts, and core ideas. Washington, DC: The National Academies Press.

Nugent, G., Toland, M. D., Levy, R., Kunz, G., Harwood, D., Green, D., \& Kitts, K. (2012). The impact of an inquiry-based geoscience field course on pre-service teachers. Journal of Science Teacher Education, 23, 503-529.

Orr, D. W. (2005). Foreword. In M. K. Stone \& Z. Barlow (Eds.), Ecological literacy: Educating our children for a sustainable world (pp. ix-xi). San Francisco: Sierra Club Books.

Patrick, P., \& Tunnicliffe, S. D. (2011). What plants and animals do early childhood and primary students' [sic] name? Where do they see them? Journal of Science Education and Technology, 20, 630-642.

Penuel, W. R., Fishman, B. J., Yamaguchi, R., \& Gallagher, L. P. (2007). What makes professional development effective? Strategies that foster curriculum implementation. American Educational Research Journal, 44, 921-958. 
Powers, A. L. (2004). Teacher preparation for environmental education: Faculty perspectives on the infusion of environmental education into preservice methods courses. The Journal of Environmental Education, 35, 3-11.

Powers, J. S. (2010). Building a lasting foundation in ecological literacy in undergraduate, nonmajors courses. Nature Education Knowledge, 3(10).

Puk, T., \& Behm, D. (2003). The diluted curriculum: The role of government in developing ecological literacy as the first imperative in Ontario secondary schools. Canadian Journal of Environmental Education, 8, 217-232.

Puk, T., \& Stibbards, A. (2010). Ecological concept development of preservice teacher candidates: Opaque empty shells. International Journal of Environmental \& Science Education, 5(4), 461-476.

Putnam, R. T., \& Borko, H. (2000). What do new views of knowledge and thinking have to say about research on teacher learning? Educational Researcher, 29, 4-15.

Pyle, R. (2001). The rise and fall of natural history: How a science grew that eclipsed direct experience. Orion, 20(4), 16-23.

Resetarits, W. J., \& Bernardo, J. (1998). Experimental ecology: Issues and perspectives. New York, New York: Oxford University Press.

Resnick, L. B. (1987). The 1987 presidential address: Learning in school and out. Educational Researcher, 16, 13-20.

Rickinson, M. (2006). Researching and understanding environmental learning: Hopes for the next 10 years. Environmental Education Research, 12(3-4), 445-457. 
Rickinson, M., Dillon, J., Teamey, K., Morris, M., Choi, M. Y., Sanders, D., \& Benefield, P. (2004). A review of research on outdoor learning. Retrieved from https://www.fieldstudies-council.org/media/268859/2004_a_review_of_research_on_outdoor_learning.pdf

Risser, P. G. (1986). Address of the past president: Syracuse, New York; August 1986: Ecological literacy. Bulletin of the Ecological Society of America, 67(4), 264-270.

Roth, W.-M., \& Lee, S. (2004). Science education as/for participation in the community. Science Education, 88, 263-291. doi:10.1002/sce.10113

Russ, A., Peters, S. J., Krasny, M. E., \& Stedman, R. C. (2015). Development of ecological place meaning in New York City. The Journal of Environmental Education, 46(2), 73-93. doi:10.1080/00958964.2014.999743

Ryan, R. L. (2005). Exploring the effects of environmental experience on attachment to rural urban areas. Environment and Behavior, 37(1), 3-42. doi:10.1177/0013916504264147

Sadler, T. D., Burgin, S., McKinney, L., \& Ponjuan, L. (2010). Learning science through research apprenticeships: A critical review of the literature. Journal of Research in Science Teaching, 47(3), 235-256.

Sauve, L. (2005). Currents in environmental education: Mapping a complex and evolving pedagogical field. Canadian Journal of Environmental Education, 10, 11-37.

Sayers, K. L. (2004). Viewing themes of teaching and learning with a phenomenological lens. (Doctor of Education in Curriculum and Instruction), West Virginia University.

Schwartz, R. S., Lederman, N. G., \& Crawford, B. A. (2004). Developing views of nature of science in an authentic context: An explicit approach to bridging the gap between nature of science and scientific inquiry. Science Teacher Education, 88(4), 610-645. 
Scott, W. (2009). Environmental education research: 30 years on from Tbilisi. Environmental Education Research, 15(2), 155-164.

Semken, S., \& Butler Freeman, C. (2008). Sense of place in practice and assessment of placebased science teaching. Science Education, 92(6), 1042-1057. doi:10.1002/sce.20279

Skamp, K. (2009). Understanding teachers' "levels of use" of learnscapes. In (Vol. 15, pp. 93110). Environmental Education Research.

Slattery, D. (2000). Adult environmental education and ecology. Australian Journal of Environmental Education, 15/16, 85-93.

Smith, G. A. (2002). Place-based education: Learning to be where we are. April, 584-594.

Smith, G. A., \& Sobel, D. (2010). Place- and Community-based Education in Schools. New York, NY: Routledge.

Sobel, D. (1996). Beyond ecophobia: Reclaiming the heart in nature education. Great Barrington, MA: The Orion Society.

Sobel, D. (2004). Place-based education: Connecting classrooms \& communities. Barrington, Massachusetts: The Orion Society.

Stake, R. E. (1995). The art of case study research. Thousand Oaks, CA: Sage Publications.

Stebbins, R. C. (2012). Connecting with nature: A naturalist's perspective. United States of America: NSTApress.

Stedman, R. C. (2002). Toward a social psychology of place predicting behavior from placebased cognitions, attitude, and identity. Environment and Behavior, 34, 561-581.

Stevenson, R. B., \& Evans, N. S. (2011). The distinctive characteristics of environmental education research in Australia: An historical and comparative analysis. Australian Journal of Environmental Education, 27, 24-45. 
Strgar, J. (2007). Increasing the interest of students in plants. Journal of Biological Education, 42, 19-23.

Sukhontapatipak, C., \& Srikosamatara, S. (2012). The role of field exercises in ecological learning and values education: Action research on the use of campus wetlands. Journal of Biological Education, 46, 36-44.

Tal, T. (2008). Learning about agriculture within the framework of education for sustainability. Environmental Education Research, 14(3), 273-290.

Tal, T., \& Morag, O. (2009). Reflective practice as a means for preparing to teach outdoors in an ecological garden. Journal of Science Teacher Education, 20, 245-262.

Wandersee, J. H., \& Schussler, E. E. (2001). Toward a theory of plant blindness. Plant Science Bulletin, 47, 2-9.

Warkentin, T. (2011). Cultivating urban naturalists: Teaching experiential, place-based learning through nature journaling in Central Park. Journal of Geography, 110(6), 227-238. doi:10.1080/00221341.2011.566345

Weiland, I. S., \& Morrison, J. A. (2013). The integration of environmental education in two elementary preservice methods courses: A content-based and a method-based approach. Journal of Science Teacher Education, 24, 1023-1047.

Wenger, E. (1998). Communities of practice: Learning, meaning, and identity. Cambridge: Cambridge University Press.

Wenger, E. (2011). Communities of practice: A brief introduction. Retrieved from https://scholarsbank.uoregon.edu/xmlui/bitstream/handle/1794/11736/a\%20brief\%20intro duction $\% 20$ to $\% 20$ cop.pdf?sequence $=1$ 
Wilcove, D. S., \& Eisner, T. (2000). The impending extinction of natural history. Retrieved from http://chronicle.com/article/The-Impending-Extinction-of/4002/

Young, R. M., \& LaFollette, S. (2009). Assessing the status of environmental education in Illinois elementary schools. Environmental Health Insights, 3(95-103), 95.

Zak, K. M., \& Munson, B. H. (2008). An exploratory study of elementary preservice teachers' understanding of ecology using concept maps. The Journal of Environmental Education, $39,32-46$.

Zandvliet, D. B. (2014). PLACES and SPACES: Case studies in the evaluation of postsecondary, place-based learning environments. Studies in Educational Evaluation, 41, 18-28. 